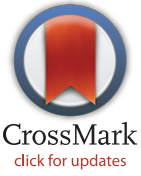

RESEARCH ARTICLE

\section{Racism as a Determinant of Health: A Systematic Review and Meta-Analysis}

\author{
Yin Paradies ${ }^{1 *}$, Jehonathan Ben ${ }^{1}$, Nida Denson ${ }^{2}$, Amanuel Elias ${ }^{1}$, Naomi Priest ${ }^{3}$, \\ Alex Pieterse $^{4}$, Arpana Gupta ${ }^{5}$, Margaret Kelaher ${ }^{6}$, Gilbert Gee ${ }^{7}$
}

1 Alfred Deakin Institute for Citizenship and Globalization, Faculty of Arts and Education, Deakin University, Melbourne, Victoria, Australia, 2 School of Social Sciences and Psychology, University of Western Sydney, Sydney, New South Wales, Australia, 3 Australian Centre for Applied Social Research Methods, Australian National University, Canberra, Australian Capital Territory, Australia, 4 Division of Counseling Psychology, University at Albany, State University of New York, New York, New York, United States of America, 5 Oppenheimer Center for Neurobiology of Stress, David Geffen School of Medicine, University of California, Los Angeles, Los Angeles, California, United States of America, 6 Centre for Health Policy Programs and Economics, Melbourne School of Population and Global Health, University of Melbourne, Melbourne, Victoria, Australia, 7 Department of Community Health Sciences, University of California, Los Angeles, Fielding School of Public Health, Los Angeles, California, United States of America

*yin.paradies@deakin.edu.au

\section{Abstract}

Despite a growing body of epidemiological evidence in recent years documenting the health impacts of racism, the cumulative evidence base has yet to be synthesized in a comprehensive meta-analysis focused specifically on racism as a determinant of health. This metaanalysis reviewed the literature focusing on the relationship between reported racism and mental and physical health outcomes. Data from 293 studies reported in 333 articles published between 1983 and 2013, and conducted predominately in the U.S., were analysed using random effects models and mean weighted effect sizes. Racism was associated with poorer mental health (negative mental health: $r=-.23,95 \% \mathrm{Cl}[-.24,-.21], k=227$; positive mental health: $r=-.13,95 \% \mathrm{Cl}[-.16,-.10], k=113$ ), including depression, anxiety, psychological stress and various other outcomes. Racism was also associated with poorer general health $(r=-.13(95 \% \mathrm{Cl}[-.18,-.09], k=30)$, and poorer physical health $(r=-.09,95 \% \mathrm{Cl}$ $[-.12,-.06], k=50)$. Moderation effects were found for some outcomes with regard to study and exposure characteristics. Effect sizes of racism on mental health were stronger in cross-sectional compared with longitudinal data and in non-representative samples compared with representative samples. Age, sex, birthplace and education level did not moderate the effects of racism on health. Ethnicity significantly moderated the effect of racism on negative mental health and physical health: the association between racism and negative mental health was significantly stronger for Asian American and Latino(a) American participants compared with African American participants, and the association between racism and physical health was significantly stronger for Latino(a) American participants compared with African American participants. Protocol PROSPERO registration number: CRD42013005464. 
Fellowship grant (http://www.arc.gov.au/ FF130101148).

Competing Interests: The authors have declared that no competing interests exist.

\section{Introduction}

Racism can be defined as organized systems within societies that cause avoidable and unfair inequalities in power, resources, capacities and opportunities across racial or ethnic groups. Racism can manifest through beliefs, stereotypes, prejudices or discrimination. This encompasses everything from open threats and insults to phenomena deeply embedded in social systems and structures [1]. Racism can occur at multiple levels, including: internalized (the incorporation of racist attitudes, beliefs or ideologies into one's worldview), interpersonal (interactions between individuals) and systemic (for example, the racist control of and access to labor, material and symbolic resources within a society) [1-3]. Racism persists as a cause of exclusion, conflict and disadvantage on a global scale [4], and existing data suggests racism is increasing in many national contexts (e.g., [5-9]).

Racism can impact health via several recognized pathways: (1) reduced access to employment, housing and education and/or increased exposure to risk factors (e.g., avoidable contact with police); (2) adverse cognitive/emotional processes and associated psychopathology; (3) allostatic load and concomitant patho-physiological processes; (4) diminished participation in healthy behaviors (e.g., sleep and exercise) and/or increased engagement in unhealthy behaviors (e.g., alcohol consumption) either directly as stress coping, or indirectly, via reduced selfregulation; and (5) physical injury as a result of racially-motivated violence [10-15].

The first reviews on discrimination and health were conducted in the mid 1990s and were concerned largely with conceptual and methodological advancements in studying the role of racism in health disparities in the United States [16, 17]. These reviews identified less than a dozen studies that were conducted since 1983 on racial discrimination and various health outcomes, including a range of mental and physical health outcomes. They provided early indication for the adverse impacts of racism on health and called for further research on the topic. Four additional reviews were conducted in the early 2000s that included studies from 1972 onwards, consisting of samples ranging from 13 to 53 studies [18-21]. These reviews further examined the poor mental and physical health outcomes of racial discrimination mainly in the U.S, among African-American adult populations. They found consistent evidence for associations between racism and mental health outcomes, and mixed evidence regarding associations with physical health outcomes (of which blood pressure and hypertension were the main outcomes).

Two larger systematic reviews were published in 2006 and 2009, covering a combined total of 253 empirical studies, published between 1984 and 2007 [10, 22]. International in scope, these reviews focused on racism and a plethora of health outcomes, and found the strongest and most robust associations between racism and poor mental health as well as health-related behaviors. More recently, two large-scale meta-analyses focused on the relationship between discrimination more generally, and mental health $[13,23]$ and physical health [13]. They examined 192 and 328 studies (with some overlap) published between 1986 and 2012, of which nearly two thirds of studies examined racial discrimination. These meta-analyses found significant negative impacts of discrimination on mental health $[13,23]$, and a somewhat weaker, but still significant, association with physical health [13]. Additional analyses focused specifically on racism found significant associations with mental health (operationalized as well-being), self-esteem and psychological distress, and similar results for life satisfaction, anxiety and depression (though metrics for the latter three were not published) [23]. Their results regarding the adverse mental health of racism and discrimination were confirmed also by a smaller metaanalysis and another review $[24,25]$.

Several reviews and meta-analyses have concentrated on specific populations, such as children and adolescents, and ethnic groups, including Asian Americans, African Americans, and 
Latino/a Americans, with negative mental health outcomes as the main health outcome of interest [14, 15, 26-31]. These reviews were published between 1985 and 2011 and included between 20 and 62 studies, with the exception of one review that included 121 studies [14]. They have found consistent, adverse associations with mental health, while for the few that also examined physical health findings were mixed [14, 15, 26, 27].

Several recent reviews and a meta-analysis have been conducted specifically on racism and physical health outcomes, particularly blood pressure and hypertension, and cardiovascular disease [32-35]. These works included study samples ranging from 15 to 44 studies, covering the period 1984-2013. They have found mixed, and often weak, associations between racism and hypertension and blood pressure, with the exception of ambulatory blood pressure, a potential measure of stress reactivity, which has shown consistent associations with racism [34, 35].

In summary, the reviews and meta-analyses thus far have noted that self-reported discrimination is consistently related to poor mental health, but less consistently related to poor physical health. A limitation of these prior reviews, however, is that cross-sectional studies were aggregated alongside longitudinal studies (with the exception of Schmitt et al. [23] analysis of longitudinal effects for discrimination more generally). Greater attention to longitudinal analyses is required as a way to assess causality, as well as to examine the possibility of a lag between exposure to discrimination and the development of physical health problems, which some studies have previously indicated [36-38].

\section{Moderators}

Moderators are variables that influence the nature (i.e., direction and/or strength) of the relationship between a predictor and an outcome variable [39]. Many scholars have noted the important role that moderators may play in understanding the differential health-related outcomes among individuals experiencing racism and associated stress [11, 40, 41]. Clark et al. [40] hypothesized that moderators may first influence perceiving the environmental stimulus as a type of racism, and, second, impact processes via which racism affects the individual. More recently, Williams and Mohammed [41] developed a causal model that highlights moderators such as age, socio-economic status, racial group, gender and relational status, as influencing the racism and health relationship.

Despite this theoretical interest, the empirical data regarding the influence of moderators on relationships between racism and health outcomes is currently mixed, with previous moderation analyses of participant subgroups largely inconclusive. Some studies have found no differences in the association between discrimination and health between men and women, while others have found stronger effects on the mental health of women, while still others have found the opposite [42]. In a recent meta-analysis, gender did not significantly moderate the association between discrimination and mental health, and between discrimination and physical health [13]. Similarly, ethnicity has been a significant moderator in some studies (e.g., [43]), whereas others have found no significant differences across ethnic groups (e.g., [44]). A metaanalysis, which conducted an analysis specifically on racism and mental health, found that effects were significantly smaller for studies of anti-White discrimination compared with studies of discrimination against other ethnic groups, but found no additional differences between other ethnic groups [23]. A meta-analysis comparing the associations between discrimination and mental and physical health in Asian, Black, Hispanic, Native American, and White participants showed no significant differences based on ethnicity [13]. Similarly, little is known about age as a possible moderator of this relationship. In a meta-analysis on discrimination and mental health, age was a significant moderator in multivariate (but not univariate) analysis [23], 
with larger effects found for children compared to adults but no significant differences between adolescents and adults.

Characteristics of racism exposure measurement, such as the instrument name, exposure type (i.e., direct/indirect), and exposure timeframe have yet to be examined in a meta-analysis while the location where studies were conducted, publication status (i.e., published/unpublished) and year, and study sampling procedures are under-explored as moderators.

\section{Study rationale}

This meta-analysis reviews the literature to-date focusing on the relationship between reported racism and mental and physical health outcomes. We examine key characteristics of this literature, including study methods, participant characteristics, racism exposure instruments, and health outcomes. We examine the overall magnitude of the relationship between racism and health for individual health outcomes (e.g., depression, anxiety), as well as for broader health outcome groups (e.g., negative mental health). Finally, we also examine possible study-level and participant-level moderators of the relationship between racism and health.

Despite a growing body of epidemiological evidence in recent years documenting the health impacts of racism, the cumulative evidence base has yet to be synthesized in a comprehensive meta-analysis that exclusively considers racism as a determinant of health. To our knowledge, associations between racism and some specific physical and mental health outcomes have yet to be examined in a meta-analysis focused specifically on racism (rather than on discrimination more generally) and on its associations with each of these outcomes, including general health, overweight and related conditions (e.g., obesity, diabetes), somatization, psychological stress and post-traumatic stress (PTS) and stress disorder (PTSD). Additionally, analyses focused on the association between racism and depression, anxiety and life satisfaction have been conducted [23], but the metrics of their results have yet to be published. We address these gaps in the current evidence base. Given the large number of studies examining the relationships between racism and each of these outcomes, moderation analyses per each outcome group are feasible.

Various moderators have yet to be explored in a meta-analysis of racism and health.

As well as racism resulting in ill-health, illness may also heighten the perception and reporting of racism [37]. Accordingly, it is critical to examine the longitudinal associations between racism and health, in order to better elucidate these causal pathways. A comparison of findings from longitudinal data and cross-sectional data has been conducted for general discrimination across mental health outcomes, where associations were significant for both data types. Crosssectional data demonstrated significantly stronger effects while longitudinal effects decreased over time [23]. For the first time, this review compares these data types in the specific context of racism.

\section{Methods}

This meta-analysis follows the reporting guidelines and criteria set in Preferred Reporting Items for Systematic Reviews (PRISMA) [45]. A protocol for this meta-analysis has been previously published [46].

\section{Search strategy}

The literature search for this study was conducted in English, and included published and unpublished papers from the earliest time available in specified databases to the end of September 2013. Papers in languages other than English were excluded. Journal articles, theses and dissertations, books and book chapters and evaluation reports were all considered for inclusion. 
Other materials, including conference papers and presentations, were excluded. The majority of articles were identified through an online search. The search covered the following databases and electronic collections: Medline, PsycInfo, Sociological Abstracts, Social Work Abstracts, ERIC, CINAHL, Academic Search Premier, Web of Science and ProQuest (for dissertations/ theses). For a list of search terms used, please see S1 Appendix. In addition, the authors' personal databases were searched for additional references. We also identified 25 major literature reviews, meta-analyses and other relevant works for which reference lists were manually searched for additional articles.

\section{Inclusion criteria}

Articles were considered for review if they consisted of empirical studies reporting quantitative data on the association between racism and a health outcome/s. The titles and abstracts of articles were first screened, and then their full texts were screened in an additional stage. We use 'articles' throughout this paper to refer to both published and unpublished material, while we use 'study' to relate to unique research; therefore one study can be reported in multiple articles, and an article may report several studies.

Exposure. Reported racism is the exposure examined in this study, and includes: selfreported racism experienced directly in interpersonal contact; racism directed towards a group (e.g., based on ethnicity/race/nationality) of which the person is a member; vicarious experiences of racism (e.g., witnessing racism experienced by family members or friends); proxy reports of racism (e.g., a child's experiences of racism as reported by their parent); and internalized racism (i.e., the incorporation of racist attitudes and/or beliefs within an individual's worldview). Exposure measures include discrimination, maltreatment, prejudice, stereotypes, aggression and related terms (see S1 Appendix), where the reason/s for these include race, skin color, ethnicity, culture, ancestry, origin, birth country, nationality, migration status, religion, language and/or accent.

More general measures of discrimination, wherein the specific effect of racism cannot be isolated, were excluded. For example, papers that used the Everyday Discrimination Scale as a measure in its original (general discrimination) format, were excluded, unless the scale was modified to explicitly specify race, skin color, ethnicity, etc. as the reason for discrimination. In cases where the majority of items assessed racism specifically and all remaining items were about discrimination broadly defined (where the reason for discrimination was not specified), the measure was included.

Exposures that focused solely on discrimination due to other reasons (e.g., gender, socioeconomic status) were excluded. Several instruments combine racism and possible health outcomes in the same measure. These were excluded since this review is focused on studies in which exposure and outcome were clearly delineated as separate constructs, to allow an examination of their association without possible confounding. Exposures to race-related stress or discrimination-distress (e.g., the extent to which racial discrimination was stressful/upsetting, as measured for example by the Index of Race-Related Stress-Brief Version (IRRS-B); [47] or by the Racism Experiences Stress Scale (EXP-STR); [48]), and other exposures relating racism to health within the same instrument, or combining racism with responses to racism (e.g., how much respondents are bothered by racism) were therefore excluded. For example, versions of the Perceived Racism Scale (PRS; [49]) that included measurement of emotions, coping behaviors, and cognitive appraisals related to racist encounters, were excluded (e.g., [50]). Ecological exposure measures of racism (e.g., racial segregation), experimental exposures (e.g., videos, vignettes, tasks) (e.g., [51, 52]) and other exposures where racism was assessed by the researcher, were also excluded due to our focus on observational studies examining racism perceived by research participants. 
Outcomes. The following health outcomes were included: (1) negative mental health (depression, anxiety, distress, psychological stress, negative affect, post-traumatic stress (PTS) and posttraumatic stress disorder (PTSD), somatization, internalizing, suicidal ideation/planning/attempts, other mental health symptoms such as paranoia and psychoticism, and general mental health); (2) positive mental health (self-esteem, life satisfaction, control and mastery, wellbeing, positive affect); (3) physical health (blood pressure and hypertension, overweight-related measures, heart conditions and illnesses, diabetes, high cholesterol, and miscellaneous/mixed measures of physical health); and (4) general health (including both physical and mental health, or unspecified as physical and/or mental health; e.g., feeling unhealthy).

Several articles used relevant exposure and outcome measures but did not examine and/or did not report their association, and were therefore excluded. Studies that measured racism as an outcome (rather than as an exposure) were also excluded.

\section{Screening}

Approximately 20,672 articles were screened for titles and abstracts. Online database searches yielded 19,292 articles, searches of the authors' personal databases yielded 896 articles, and another 484 articles were found in the reference lists of 25 meta-analyses and literature reviews. Search results were imported into Endnote X5 [53], duplicates deleted, and two reviewers independently screened all titles and abstracts to assess eligibility for inclusion. All authors of the study protocol [46] were involved in the screening. Articles were further considered for inclusion if their title and abstract indicated that they may contain empirical research, and that they report quantitative data on the relationship between racism and health. Articles examining discrimination more generally were retained at this stage, and their full-texts further examined in the next stage. Articles not focused primarily on the association between racism and relevant health outcomes but nonetheless reporting association/s between them were included (e.g., associations between racism and health reported as part of a large correlation matrix in a study primarily focused on other variable/s). Disagreements were resolved by consensus or by a third reviewer. After completing the first screening stage of titles and abstracts, a total of 1,110 articles were retained.

Full texts of potentially eligible articles were obtained, with each full text then independently screened by two reviewers. Disagreements were resolved by consensus or by a third reviewer. The main reasons for exclusion were the reporting of irrelevant exposure and/or irrelevant outcome measures, especially articles only reporting general experiences of discrimination. Associations with outcome groups such as health behaviors/risk behaviors, pregnancy and birth outcomes and health care utilization, were excluded as beyond the scope of this meta-analysis. Where the exact same journal article was published multiple times, only the most recent version was retained and duplicates excluded. Duplicate articles by the same authors that report identical association data were excluded. Multiple articles reporting identical association data but written by different authors were retained and their associations were averaged using Comprehensive Meta-Analysis software version 2.0 (CMA, see below) [54]. After completing the second stage of screening, 534 articles remained.

In the third and final screening stage, one reviewer examined whether articles reported appropriate and sufficient association data to allow the calculation of correlation coefficients. Decisions regarding exclusion were discussed with a second reviewer. Articles reporting only adjusted associations between racism and health were recorded but excluded from the metaanalysis. While it is appropriate to adjust for covariates in individual studies, since articles on racism and health often adjust for different sets of covariates, the effects of each covariate or sets of covariates cannot be determined. Articles adjusting for different covariates and 
reporting effect size data that need to be converted pose an additional limitation since such consistent conversions are not possible [13]. Given that few articles adjust for the same sets of covariates (e.g., [13]) we opted to focus solely on unadjusted effect size data.

The correlation coefficient was the most commonly reported measure of association between racism and health (particularly mental health), and was used as the measure of effect size. Beside correlations and sample sizes, standardized beta coefficients in unadjusted (univariate) regression models, which are equal to correlation coefficients, were used as correlations. All other metrics were converted to correlation coefficients. The following data formats were converted using CMA: 1) Odds Ratios (OR) and confidence intervals (CIs); 2) Means, standard deviations and sample sizes of two groups (racism and no racism); 3) Cross-tabulations (2x2) of events and non-events (racism/no racism and poor/good health); 4) Means and samples sizes for two groups, and an independent group t-value; 5) Means and samples sizes for two groups, and an independent group p-value; 6) Standardized mean differences (Cohen's d) and sample sizes for two groups; and 7) $p$-value and sample size for correlation coefficient. In few cases (less than $2 \%$ of associations) only the sample size and $p$-level were reported, as well as whether the association was significant or not. Where the $p$-value was not significant and its exact value not reported, the correlation coefficient was conservatively recorded as zero (see [34] for a similar approach). Where the $p$-value was significant and its exact value not reported, the $p$-value was conservatively recorded just below the $p$-level (e.g., a significant $p$-value at 0.05 was recorded as $p=0.049999)$. Unstandardized regression coefficients were first converted into standardized betas and then converted into Cohen's $d$ using the Campbell Collaboration webbased effect size calculator [55, 56], before their conversion into correlations. Covariances were converted into correlations using corresponding standard deviations [57]. When the sample size was described as a range, the range's minimum sample size was used.

After exclusion of articles that did not report appropriate and sufficient association data to allow the calculation of correlation coefficients (including articles reporting adjusted effect size data only), 333 articles were left that comprised the final sample for analysis. Fig 1 summarizes the numbers of articles included at each stage of screening.

\section{Data extraction and coding}

Articles were reviewed and data were extracted and coded by six reviewers, including two of the authors and four postgraduate students (three doctoral students and one master's student, all with experience in research on racism and health). An Excel spreadsheet and a corresponding manual were developed for data extraction purposes (both available from the authors upon request). Reviewers extracted five types of data from each article, including data at the level of the study, participants, exposure measures, outcome measures, and effect size data. Before extraction began, reviewers read the study protocol [46], and previous meta-analyses on the topic. They were instructed on using the data extraction manual and spreadsheet, practiced extracting data from several articles, and discussed unclear issues with the first and second authors. Two reviewers each independently extracted data from a random sample of approximately $10 \%$ of articles, for which agreement was $85 \%$. Data from all other articles were extracted by one of the six reviewers, with another reviewer double-checking coding. Disagreements were resolved by a third reviewer.

\section{Data integration}

Using CMA, effect size data were coded so that a negative correlation indicates association between high levels of racism and low (i.e. poor) levels of health, that is, when racism increases, decreased health was coded as a negative association (or OR values lower than 1). Where OR 


\section{Stage 1: 20,672 articles screened for titles and} abstracts

From: 1) online databases $(\mathrm{k}=19,292) ; 2)$

personal databases $(\mathrm{k}=896) ; 3)$ reference lists of

Removed if title and abstract indicated:

25 meta-analyses and literature reviews $(\mathrm{k}=484)$

1) Not empirical

2) Does not report quantitative data

3) Does not report on the association between racism and a health outcome/s

\section{Removed if according to full-text:}

1) Not empirical

2) Does not report quantitative data

3) Does not report on the association between racism and a health outcome/s

4) Does not contain relevant exposure/s and/or outcome/s

\section{Stage 2: 1,110 articles screened for full-texts} (Remained after review of titles and abstracts)

\section{Removed if according to full-text:}

1) Reports only adjusted association/s

2) Does not report statistics that allow calculation of effect size

Stage 3: 534 articles screened for data type (Remained after review of full-texts)

Fig 1. PRISMA screening process flowchart.

doi:10.1371/journal.pone.0138511.g001

293 studies reported in 333 articles

Included in the analysis values higher than 1 originally indicated association between high levels of racism and poorer health, and values lower than 1 originally indicated association between high levels of racism and better health, these values were reverse-coded using 1/OR.

Weighted effect sizes were calculated to account for variation in sample sizes, giving more weight to effects from larger samples. When a study comprises multiple associations between racism and health for the same participant group/s, these associations are not independent. To ensure that data are independent, each study should contribute exactly one association per analysis. A single association can be selected or calculated through averaging. We chose 
averaging as it allows retaining as much data as possible. We extracted all relevant associations and used a shifting unit of analysis approach (e.g., [58]) to conduct analyses both at the level of individual outcomes (e.g., for depression only), and at the level of broader outcome groups (e.g., negative mental health), in which case we averaged associations for different negative mental health outcomes such as depression, anxiety and distress. Where multiple articles reported associations from the same study or data source, these associations were averaged. There were 25 such studies, reported in 70 articles. Studies utilized in multiple papers included the following: Family and Community Health Study (FACHS; $\mathrm{k}=11$ ), Coronary Artery Risk Development in Young Adults Study (CARDIA; $\mathrm{k}=4$ ), United for Health Study $(\mathrm{k}=4)$, Aboriginal Birth Cohort Study (ABC; k = 3), California Health Interview Survey (CHIS; k =3), Diabetes Study of Northern California (DISTANCE, $\mathrm{k}=3$ ), International Comparative Study of Ethnocultural Youth (ICSEY; K = 3), Latino Acculturation and Health Project $(\mathrm{k}=3)$, National Survey of American Life (NSAL; $k=3$ ), Black Women's Health Study (BWHS; k =2), Detroit Arab American Study (DAAS; k = 2), Maryland Adolescent Development in Context Study (MADICS; $\mathrm{k}=2$ ), National Latino and Asian American Study (NLAAS; $\mathrm{k}=2$ ), National Survey of Black Americans (NSBA; $k=2$ ), Oslo Health Study $(k=2)$, and Sinai Improving Community Health Survey $(k=2)$. We also examined associations from papers by the same first author where the names of data sources were not mentioned but where the methodology and samples characteristics were identical or nearly identical, suggesting the same data may have been used in multiple papers. Nine such potential data sources, each reported in multiple papers, were identified in discussion between two reviewers. Associations were averaged for each data source using CMA.

We used the random effects model in aggregating effect sizes in all analyses. This model has been used in previous meta-analyses on the topic, as it is more appropriate than a fixed-effects model given various differences in methods, instrumentation and sample characteristics across studies (e.g., [13]) and considering that our aim is to generalize findings to the population of studies on racism and health outcomes (see also [31,59]). Mixed effect models were used in all moderator analyses, as a more conservative approach that enables testing of differences between different moderator levels (e.g., [31]).

\section{Moderation analyses}

Moderation analyses were conducted separately for each individual outcome, as well as for the broader outcome groups of negative mental health, positive mental health, physical health, and general health. Moderation analyses were conducted only when at least two levels of the moderator included five or more studies. This threshold was used in prior meta-analyses, and based on minimum thresholds established in the literature [60, 61]. Study was the unit of analysis utilized in moderation for the following variables: publication status (published/unpublished), sampling procedure (representative/non-representative), country (U.S./Other than U.S.), publication year (2005 or earlier/2006 or later), and data types (cross-sectional/longitudinal). Missing values were less than $5 \%$ and excluded from all analyses.

We also conducted study-level analyses for exposure measure characteristics: exposure instrument name (comparing the 8 most frequently reported instruments, e.g., Schedule of Racist Events (SRE), Experience of Discrimination (EOD)), exposure instrument type (direct/ indirect exposure to racism), exposure instrument number of items ( 8 or less $/ 9$ or more), exposure instrument reliability coefficient (Cronbach's alpha) value (lower than $0.8 / 0.8$ or higher) [62], exposure timeframe (less than 3 years/3 years or more/not specified). Categorizations were based on commonly used cutoff points (see for example $[32,63]$ ), with the aim of retaining as much data as possible given low study numbers reporting each moderator level in several 
analyses. Where a study reported multiple levels of the same moderator (e.g., a study reporting two exposure instruments, each using a different timeframe), such studies were excluded from the moderation analysis to avoid violating the assumption of independence.

Additional moderation analyses were conducted for participant subgroups. We included in the analysis studies entirely focused on a single participant subgroup (e.g., females only) as well as studies that reported separate, independent associations for multiple different subgroups (e.g., associations for females and males). Participant groups analyzed included: sex (male/ female), age (under 18/18 or over), U.S. ethnic group (African American/Asian American/ European American/Latino/a American/Native American), birth country (local-born/foreignborn), and, among student samples, current education level (primary/secondary/tertiary).

\section{Quality appraisal}

Several moderators were also examined as indicators of study quality, namely: 1) publication status; 2) sampling procedure; 3 ) data type (i.e., longitudinal versus cross-sectional); 4) exposure instrument number of items; and 5) Exposure instrument reliability coefficient (Cronbach's alpha) value. Published studies, representative sampling, longitudinal data, 9 or more items and alpha coefficient values of 0.8 or higher for exposure measures, were considered as indicators of higher study quality.

\section{Publication bias analyses}

Three methods were used to assess publication bias among the sample of studies. First, we produced funnel plots and examined their symmetry to assess whether there was evidence of bias. Second, we used Egger's weighted regression method [64], where the intercept's significance was examined for statistical evidence of bias. Third, we calculated a fail-safe $\mathrm{N}$ to estimate the number of un-located studies with an average zero effect size required to change the results substantively [65]. The fail-safe $\mathrm{N}$ allows us to assess whether the effect is an artifact of bias. Where we detected publication bias, we used the trim and fill method to estimate and adjust for missing (un-reported) studies to estimate what the effect size would have been in the absence of bias $[66,67]$. All tests of publication bias, as well as the trim and fill point estimates, were calculated using the CMA program.

\section{Results}

Descriptive statistics are provided in Tables 1 and 2. The screening resulted in 333 articles that met all inclusion criteria and comprised the final sample analyzed in this study [43-44, 68-398]. The 333 articles contained unadjusted association data from 293 unique studies, after accounting for multiple articles that report the same study and for several articles $(\mathrm{N}=5)$ that report two studies each. As in previous reviews and meta-analyses, this descriptive section reports on data per article rather than per study. Since multiple articles reporting the same study often examine different subsets of the data, reporting descriptive data at the level of the study was not feasible. This approach potentially double counts participants from 25 studies, each reported in multiple articles (altogether $\mathrm{N}=70$ articles), which we recognize as a potentially minor bias. Study, exposure, and outcome characteristics are presented in Table 1. All articles were published between 1983 and 2013, with their number increasing over time: 11.4\% were published between 19832000, 21.3\% between 2001-2005, 38.4\% between 2006-2010, and 28.8\% between 2011 and September 2013. A majority of the articles were published in academic journals (78.4\%), and theses/ dissertations (20.7\%). Most of the research they report was conducted in the U.S. (81.4\%), followed by the U.K. (2.7\%), Australia (2.7\%), Canada (2.1\%), The Netherlands (1.8\%), Finland (1.5\%), Israel (1.2\%), Norway (1.2\%), Spain (0.9\%), Portugal (0.9\%), New Zealand (0.6\%) and 
Table 1. Study, exposure, and outcome characteristics ( $N=333$ articles).

\begin{tabular}{|c|c|c|c|}
\hline Variable & Groups & $\begin{array}{l}\text { No. of articles } \\
\text { reporting }\end{array}$ & $\begin{array}{l}\% \text { of articles } \\
\text { reporting }\end{array}$ \\
\hline Total number of articles & & 333 & $100.0 \%$ \\
\hline \multirow{5}{*}{$\begin{array}{l}\text { Sample size range ( } \mathrm{N} \\
\text { participants) }\end{array}$} & $39-100$ & 36 & $10.8 \%$ \\
\hline & $101-200$ & 84 & $25.2 \%$ \\
\hline & $201-300$ & 63 & $18.9 \%$ \\
\hline & $301-1,000$ & 92 & $27.6 \%$ \\
\hline & $1,001-48,924$ & 58 & $17.4 \%$ \\
\hline \multirow[t]{4}{*}{ Year of publication } & $1983-2000$ & 38 & $11.4 \%$ \\
\hline & 2001-2005 & 71 & $21.3 \%$ \\
\hline & 2006-2010 & 128 & $38.4 \%$ \\
\hline & 2011-September 2013 & 96 & $28.8 \%$ \\
\hline \multirow[t]{3}{*}{ Type of publication } & Academic journal & 261 & $78.4 \%$ \\
\hline & Dissertation/Thesis/Evaluation report & 70 & $21.0 \%$ \\
\hline & Book chapter & 2 & $0.6 \%$ \\
\hline \multirow[t]{13}{*}{ Country } & United States & 271 & $81.4 \%$ \\
\hline & United Kingdom & 9 & $2.7 \%$ \\
\hline & Australia & 9 & $2.7 \%$ \\
\hline & Canada & 7 & $2.1 \%$ \\
\hline & The Netherlands & 6 & $1.8 \%$ \\
\hline & Finland & 5 & $1.5 \%$ \\
\hline & Israel & 4 & $1.2 \%$ \\
\hline & Norway & 4 & $1.2 \%$ \\
\hline & Spain & 3 & $0.9 \%$ \\
\hline & Portugal & 3 & $0.9 \%$ \\
\hline & New Zealand & 2 & $0.6 \%$ \\
\hline & Barbados & 2 & $0.6 \%$ \\
\hline & Other ( 1 article per country/ region) & 8 & $2.4 \%$ \\
\hline \multirow[t]{3}{*}{ Sampling procedure } & Non-representative & 222 & $66.7 \%$ \\
\hline & Representative & 102 & $30.6 \%$ \\
\hline & Other/Not reported & 9 & $2.7 \%$ \\
\hline \multirow[t]{3}{*}{ Data type } & Cross-sectional & 299 & $89.8 \%$ \\
\hline & Longitudinal & 30 & $9.0 \%$ \\
\hline & Other & 4 & $1.2 \%$ \\
\hline \multirow[t]{8}{*}{ Exposure instrument name* } & Schedule of Racist Events (SRE) & 34 & $10.2 \%$ \\
\hline & Racism and Life Experience Scales (RaLES) & 20 & $6.0 \%$ \\
\hline & Experiences of Discrimination (EOD) & 19 & $5.7 \%$ \\
\hline & Perceived Racism Scale (PRS) & 19 & $5.7 \%$ \\
\hline & Everyday Discrimination Scale (EDS)** & 14 & $4.2 \%$ \\
\hline & Perceived Ethnic Discrimination Questionnaire (PEDQ) & 10 & $3.0 \%$ \\
\hline & $\begin{array}{l}\text { Multidimensional Inventory of Black Identity (MIBI): public regard } \\
\text { subscale }\end{array}$ & 10 & $3.0 \%$ \\
\hline & Nadanolitization scale & 5 & $1.5 \%$ \\
\hline \multirow[t]{4}{*}{ Exposure number of items* } & Single item/s & 56 & $16.8 \%$ \\
\hline & $2-8$ items & 117 & $35.1 \%$ \\
\hline & 9 or more & 162 & $48.6 \%$ \\
\hline & Not reported & 19 & $5.7 \%$ \\
\hline Exposure Cronbach Alpha* & 0.79 or lower & 47 & $14.1 \%$ \\
\hline
\end{tabular}


Table 1. (Continued)

\begin{tabular}{|c|c|c|c|}
\hline Variable & Groups & $\begin{array}{l}\text { No. of articles } \\
\text { reporting }\end{array}$ & $\begin{array}{l}\% \text { of articles } \\
\text { reporting }\end{array}$ \\
\hline & 0.80 or higher & 162 & $48.6 \%$ \\
\hline & Not reported & 77 & $23.1 \%$ \\
\hline & Mixed (instruments including subscales from both levels) & 10 & $3.0 \%$ \\
\hline & Not applicable (single items) & 56 & $16.8 \%$ \\
\hline \multirow[t]{5}{*}{ Exposure type* } & Direct & 266 & $79.9 \%$ \\
\hline & Indirect (e.g., group, vicarious, proxy) & 60 & $18.0 \%$ \\
\hline & Internalized & 10 & $3.0 \%$ \\
\hline & Mixed (instruments including subscales from both levels) & 12 & $3.6 \%$ \\
\hline & Not Reported & 4 & $1.2 \%$ \\
\hline \multirow{6}{*}{$\begin{array}{l}\text { Timeframe of Racism } \\
\text { Exposure* }\end{array}$} & Last month & 12 & $3.6 \%$ \\
\hline & Last 12 months (includes last 6) & 55 & $16.5 \%$ \\
\hline & Last $>12$ months and $<3$ years & 10 & $3.0 \%$ \\
\hline & Last 3 years-lifetime & 47 & $14.1 \%$ \\
\hline & Not specified & 210 & $63.1 \%$ \\
\hline & Mixed (instruments including subscales from both levels) & 15 & $4.5 \%$ \\
\hline \multirow{11}{*}{$\begin{array}{l}\text { Outcomes-negative mental } \\
\text { health* }\end{array}$} & Depression & 124 & $37.2 \%$ \\
\hline & Psychological stress & 71 & $21.3 \%$ \\
\hline & Distress & 61 & $18.3 \%$ \\
\hline & Anxiety & 48 & $14.4 \%$ \\
\hline & Negative affect & 25 & $7.5 \%$ \\
\hline & PTSD and PTS & 16 & $4.8 \%$ \\
\hline & Somatization & 13 & $3.9 \%$ \\
\hline & Internalizing & 12 & $3.6 \%$ \\
\hline & Suicidal ideation, planning, attempts & 12 & $3.6 \%$ \\
\hline & General mental health & 12 & $3.6 \%$ \\
\hline & Other mental health symptoms (e.g., paranoia, psychoticism) & 12 & $3.6 \%$ \\
\hline \multirow{5}{*}{$\begin{array}{l}\text { Outcomes-positive mental } \\
\text { health* }\end{array}$} & Self esteem & 81 & $24.3 \%$ \\
\hline & Life satisfaction & 28 & $8.4 \%$ \\
\hline & Control/Mastery & 19 & $5.7 \%$ \\
\hline & Wellbeing & 10 & $3.0 \%$ \\
\hline & Positive affect & 4 & $1.2 \%$ \\
\hline \multirow[t]{6}{*}{ Outcomes-physical health* } & Blood pressure \& Hypertension & 24 & $7.2 \%$ \\
\hline & Overweight (BMI, WC, WHR, overweight, obesity) & 17 & $5.1 \%$ \\
\hline & Heart conditions/illnesses & 8 & $2.4 \%$ \\
\hline & Diabetes & 7 & $2.1 \%$ \\
\hline & Cholesterol & 4 & $1.2 \%$ \\
\hline & Miscellaneous physical health & 20 & $6.0 \%$ \\
\hline Outcomes-general health* & General health (unspecified/ physical \& mental) & 30 & $9.0 \%$ \\
\hline
\end{tabular}

* Note that numbers do not add to $100 \%$ due to articles reporting multiple exposure instrument and multiple outcomes

* Includes Major Discrimination, and instruments from the Detroit Area Study.

doi:10.1371/journal.pone.0138511.t001

Barbados (0.6\%). Research from eight other countries/regions was reported in one article each (2.4\% altogether). Most articles (89.8\%) reported cross-sectional data, with only $9.0 \%$ reporting 
Table 2. Participant characteristic ( $\mathrm{N}=333$ articles).

\begin{tabular}{|c|c|c|c|}
\hline & No. of articles reporting & & $\%$ of participants \\
\hline \multirow[t]{2}{*}{ Age } & 264 & Children and adolescents (under 18 only) & $15.6 \%$ \\
\hline & & Adults (18 and older only) & $84.4 \%$ \\
\hline \multirow[t]{2}{*}{ Sex } & 322 & Male & $40.0 \%$ \\
\hline & & Female & $60.0 \%$ \\
\hline \multirow[t]{8}{*}{ US Racial/ethnic groups } & 271 & African American & $37.1 \%$ \\
\hline & & European American & $29.6 \%$ \\
\hline & & Hispanic/Latin/o American & $18.6 \%$ \\
\hline & & Asian American & $9.4 \%$ \\
\hline & & Native American & $0.7 \%$ \\
\hline & & Arab American & $0.7 \%$ \\
\hline & & International students & $0.4 \%$ \\
\hline & & Other (definitions differ across studies) & $3.6 \%$ \\
\hline \multirow[t]{2}{*}{ Birth country } & 147 & Locally-born & $66.9 \%$ \\
\hline & & Foreign-born & $33.1 \%$ \\
\hline \multirow[t]{4}{*}{ Current education, student samples } & 137 & Primary & $13.9 \%$ \\
\hline & & Secondary & $54.7 \%$ \\
\hline & & Mixed primary and secondary & $3.0 \%$ \\
\hline & & Tertiary & $28.5 \%$ \\
\hline \multirow[t]{3}{*}{ Education completed, non-student samples } & 68 & Less than high school/GED & $18.0 \%$ \\
\hline & & High school & $27.2 \%$ \\
\hline & & More than high school & $54.8 \%$ \\
\hline
\end{tabular}

doi:10.1371/journal.pone.0138511.t002

longitudinal data. The rest (1.2\%) were mostly quasi-experimental. Two-thirds of articles (66.7\%) reported using non-representative sampling procedures, and $30.6 \%$ of articles reported using representative sampling procedures.

The total sample across all studies consisted of 309,687 participants $(M=1,057$ per study, Range: $39-48,924)$. The sample size per article varied greatly: $10.8 \%$ of the 333 articles reported a sample of 39-100 participants, $25.2 \%$ a sample of $101-200$ participants, $18.9 \% \%$ a sample of 201-300 participants, $27.6 \%$ a sample of $301-1,000$ participants, and $17.4 \%$ a sample of $1,001-$ 48,924 participants.

Articles used a variety of instruments for assessing exposure to racism, with several articles using more than one exposure instrument. The most commonly used instruments of exposure to racism were the Schedule of Racist Events (SRE) (used in 10.2\% of articles), Racism and Life Experience Scales (RaLES) (6.0\%), Experiences of Discrimination (EOD) (5.7\%), Perceived Racism Scale (PRS) (5.7\%), Everyday Discrimination Scale (EDS) (4.2\%), Perceived Ethnic Discrimination Questionnaire (PEDQ) (3.0\%), Multidimensional Inventory of Black Identity (MIBI)-public regard subscale (3.0\%), and the Nadanolitization scale (NAD) (1.5\%). Most articles (79.9\%) used measures of direct exposure to racism, and $18.0 \%$ of articles used indirect measures (e.g., group, vicarious, proxy-reports). Most articles used instruments that did not specify the exposure timeframe (63.1\%), while a 12-month exposure timeframe was used in $16.5 \%$ of articles, and more than 3 years (including lifetime exposure) in $14.1 \%$ of articles. With regard to internal reliability of exposure instruments, almost half of the articles (48.6\%) reported instruments with Cronbach's alpha coefficients of 0.80 or higher, and $14.1 \%$ of articles reported coefficients of 0.79 or lower. Nearly half of the articles $(48.6 \%)$ used instruments with 9 or more items, over a third (35.1\%) used instruments with $2-8$ items, and single items were reported in $16.8 \%$ of articles. 
The most frequently reported mental health outcome was depression (reported in $37.2 \%$ of articles), followed by self-esteem (24.3\%), psychological stress (21.3\%), distress (18.3\%), anxiety $(14.4 \%)$. Life satisfaction was reported in $8.4 \%$ of articles, followed by negative affect (7.5\%), control and/or mastery (5.7\%), posttraumatic stress and posttraumatic stress disorder (4.8\%), somatization (3.9\%), internalizing (3.6\%), suicidal ideation, planning and/or attempts (3.6\%), general mental health (3.6\%), wellbeing (3.0\%), and positive affect (1.2\%). Other mental health symptoms such as paranoia and psychoticism, were reported in $3.6 \%$ of articles. Among physical health outcomes, blood pressure and hypertension were reported in $7.2 \%$ of articles, followed by overweight-related outcomes (Body Mass Index (BMI), overweight, obesity, Waist Circumference (WC), Waist-Hip Ratio (WHR)) (5.1\%), heart conditions and illnesses (2.4\%), diabetes (2.1\%), cholesterol (1.2\%). Miscellaneous physical health outcomes were reported in $6.0 \%$ of articles. Miscellaneous physical health outcomes included: 1) measures that combine some of the physical health outcomes listed above (e.g., a measure combining blood pressure and diabetes); and 2) measures of other health outcomes listed below, either on their own, combined with each other, or combined with outcomes listed above. These included: angina back problems, arthritis, asthma, bodily pain, brittle bones, cancer, constipation, diarrhea, ear infection, exhaustion, fever, headache, gastrointestinal infection and disease, general/overall physical health, kidney and liver/gallbladder problems, major paralysis, muscular problems, nausea, neurological conditions, number of childhood illnesses, osteoporosis, Parkinson's disease, physical disability, physical functioning and role-physical, physical healthrelated quality of life, respiratory infection, rheumatism, scabies, sickle cell disease, sickle cell trait, skin infection, sleeping problems, sore throat, stomachache, stroke, and trouble breathing. General health outcomes, either unspecified as physical or mental health, or combining physical and mental health, were reported in $9.0 \%$ of articles.

Table 2 reports the characteristics of the participants across articles. Most articles reported age, sex and, for U.S. articles, ethnic groups (Table 2). Age was reported in 264 articles, where $84.4 \%$ of participants were aged 18 years or above. Sex was reported in 322 articles, with females accounting for $60 \%$ of the total sample. Ethnic groups in the U.S. were reported in 271 articles. The largest participant subgroup was African Americans (37.1\%), followed by European Americans (29.6\%), Hispanic/Latino/a Americans (18.6\%), and Asian Americans (9.4\%). Birth country was reported in 147 articles, where $66.9 \%$ of participants were native-born, and $33.1 \%$ foreign-born. Level of education was captured in two ways. In 137 articles reporting student samples, $13.9 \%$ of participants were elementary, $54.7 \%$ were secondary, and $28.5 \%$ were tertiary school students. Additionally, in 68 articles that reported the highest level of education completed, $18.0 \%$ of participants completed less than high school/ General Education Development (GED), 27.2\% completed high school, and 54.8\% completed more than high school.

Additional papers reported different groupings of highest levels of education that are not presented here.

\section{Effect sizes ( $r$ ) by outcome groups}

Table 3 presents the mean weighted effect sizes for the associations between racism and negative mental health, positive mental health, physical health, and general health using a randomeffects model. Study-level results and forest plots are presented for the four main outcome groups (see Figs 2-5). Of these four health outcome groups, the largest mean weighted effect size was for negative mental health $(r=-.23,95 \%$ CI $[-.24,-.21], k=227)$ and the smallest mean weighted effect size was for negative physical health $(r=-.09,95 \% \mathrm{CI}[-.12,-.06], k=50)$. The mean weighted effect size for positive mental health was $r=-.13(95 \%$ CI $[-.16,-.10], k=113)$, and for general health $r=-.13$ (95\% CI [-.18,-.09], $k=30$ ). Based on the criteria of non- 
Table 3. Effect sizes for associations between racism and health outcomes.

\begin{tabular}{|c|c|c|c|c|c|c|c|c|c|}
\hline Outcome group & Outcome & $\mathbf{r}$ & Lower $\mathrm{Cl}$ & Upper Cl & $\mathbf{z}$ & p-value & $\mathbf{k}$ & Q-value & p-value $\mathbf{Q}$ \\
\hline \multirow[t]{12}{*}{ Negative mental health (NM) } & DEP & -0.21 & -0.23 & -0.19 & -18.40 & $<0.001$ & 109 & 976.78 & $<0.001$ \\
\hline & DIS & -0.22 & -0.25 & -0.19 & -14.11 & $<0.001$ & 55 & 447.87 & $<0.001$ \\
\hline & STR & -0.27 & -0.30 & -0.23 & -12.82 & $<0.001$ & 66 & 891.69 & $<0.001$ \\
\hline & ANX & -0.24 & -0.29 & -0.19 & -9.50 & $<0.001$ & 40 & 249.34 & $<0.001$ \\
\hline & INT & -0.26 & -0.34 & -0.17 & -5.65 & $<0.001$ & 9 & 39.11 & $<0.001$ \\
\hline & NA & -0.20 & -0.24 & -0.16 & -10.00 & $<0.001$ & 23 & 69.73 & $<0.001$ \\
\hline & PTS/PTSD & -0.34 & -0.40 & -0.27 & -8.96 & $<0.001$ & 16 & 68.48 & $<0.001$ \\
\hline & SOM & -0.23 & -0.29 & -0.17 & -7.61 & $<0.001$ & 13 & 40.07 & $<0.001$ \\
\hline & SUI & -0.16 & -0.19 & -0.12 & -8.57 & $<0.001$ & 10 & 3.76 & 0.927 \\
\hline & MHS & -0.21 & -0.29 & -0.12 & -4.72 & $<0.001$ & 11 & 136.39 & $<0.001$ \\
\hline & $\mathrm{GMH}$ & -0.18 & -0.24 & -0.12 & -5.55 & $<0.001$ & 12 & 48.84 & $<0.001$ \\
\hline & Overall NM & -0.23 & -0.24 & -0.21 & -27.28 & $<0.001$ & 227 & 2278.70 & $<0.001$ \\
\hline \multirow[t]{6}{*}{ Positive mental health (PM) } & SE & -0.12 & -0.15 & -0.10 & -9.28 & $<0.001$ & 78 & 284.86 & $<0.001$ \\
\hline & CON & -0.11 & -0.14 & -0.07 & -5.92 & $<0.001$ & 18 & 40.56 & 0.001 \\
\hline & LS & -0.16 & -0.22 & -0.10 & -5.35 & $<0.001$ & 29 & 295.24 & $<0.001$ \\
\hline & PA & 0.00 & -0.06 & 0.07 & 0.09 & 0.926 & 4 & 1.02 & 0.796 \\
\hline & WB & -0.19 & -0.26 & -0.12 & -5.10 & $<0.001$ & 10 & 33.89 & $<0.001$ \\
\hline & Overall PM & -0.13 & -0.16 & -0.10 & -9.36 & $<0.001$ & 113 & 945.00 & $<0.001$ \\
\hline \multirow[t]{7}{*}{ Physical health $(\mathrm{PH})$} & BP \& HTN & 0.00 & -0.02 & 0.01 & -0.24 & 0.814 & 24 & 25.78 & 0.312 \\
\hline & $\mathrm{CHO}$ & 0.00 & -0.02 & 0.02 & -0.10 & 0.919 & 4 & 1.84 & 0.606 \\
\hline & DIA & -0.02 & -0.09 & 0.04 & -0.70 & 0.482 & 7 & 14.98 & 0.020 \\
\hline & HRT & 0.00 & -0.05 & 0.06 & 0.15 & 0.880 & 8 & 9.79 & 0.201 \\
\hline & OW & -0.08 & -0.11 & -0.05 & -5.31 & $<0.001$ & 15 & 22.16 & 0.075 \\
\hline & Misc & -0.13 & -0.18 & -0.08 & -5.15 & $<0.001$ & 20 & 251.00 & $<0.001$ \\
\hline & Overall PH & -0.09 & -0.12 & -0.06 & -5.384 & $<0.001$ & 50 & 445.520 & $<0.001$ \\
\hline General health $(\mathrm{GH})$ & $\mathrm{GH}$ & -0.13 & -0.18 & -0.09 & -5.61 & $<0.001$ & 30 & 615.85 & $<0.001$ \\
\hline
\end{tabular}

DEP-Depression; DIS-Distress; STR-Stress; ANX-Anxiety; INT-Internalizing; NA-Negative affect; PTS/PTSD-Post-traumatic stress and post-traumatic stress disorder; SOM-Somatization; SUI-Suicidal ideation, planning, and attempts; MHS-Other mental health symptoms (e.g., paranoia, psychoticism); GMH-General mental health; Overall NM-Overall negative mental health; SE-Self-esteem; CON-Control/Mastery; LS-Life satisfaction; PA-Positive affect; WB-Wellbeing; Overall PM-Overall positive mental health; BP \& HTN-Blood pressure and hypertension; CHO-cholesterol; DIA-Diabetes; HRTHeart conditions/illnesses; OW—Overweight (BMI, WC, WHR, overweight, obesity); MISC—Miscellaneous physical health; Overall PH-Overall physical health; GH—General health (unspecified/ physical \& mental)

doi:10.1371/journal.pone.0138511.t003

overlapping Confidence Intervals (CIs), these data suggest stronger effects of racism on negative mental health compared with physical health, general health, and positive mental health.

Examination of the funnel plots showed fairly symmetric plots for all four outcome groups (available upon request from the authors). Using Rosenthal's (1979) fail-safe $N$ criterion that the value should be over five times greater than the number of studies included in the metaanalysis, the fail-safe $N$ for all outcome groups were at least eight times larger than the criterion value, suggesting that the effect sizes are unlikely to be an artifact of bias. Finally, Egger's regression intercept was statistically significant for negative mental health, physical health, and general health, suggesting potential publication bias. It was not statistically significant for positive mental health. For negative mental health, physical health, and general health, Duval and Tweedie's trim-and-fill procedures were utilized. The number of imputed missing studies ranged from two studies (for general health) to 47 studies (for negative mental health). Imputing resulted only in minor reductions in effect sizes, which remained significant, indicating that 
Sudy name



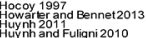

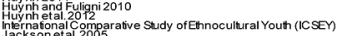

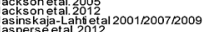

Jasperse
Juntiner 2009
Jones 2008
Jones etal. 20

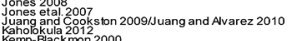

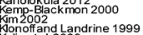

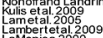

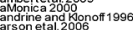

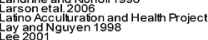

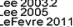

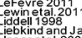

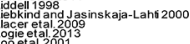

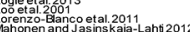

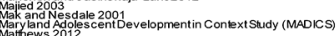

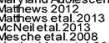

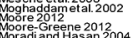



Wulia and Zemore 2012 12 American Shudy (NLAAS

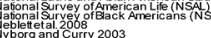

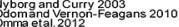



ter

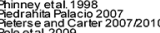

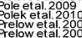

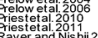



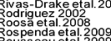

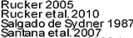



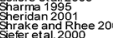

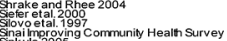

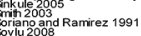

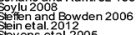

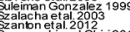

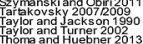

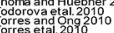

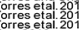

fran 2010 -

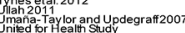

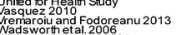

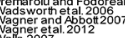



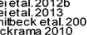

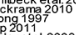

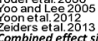



Correlarion and $95 \% \mathrm{CI}$

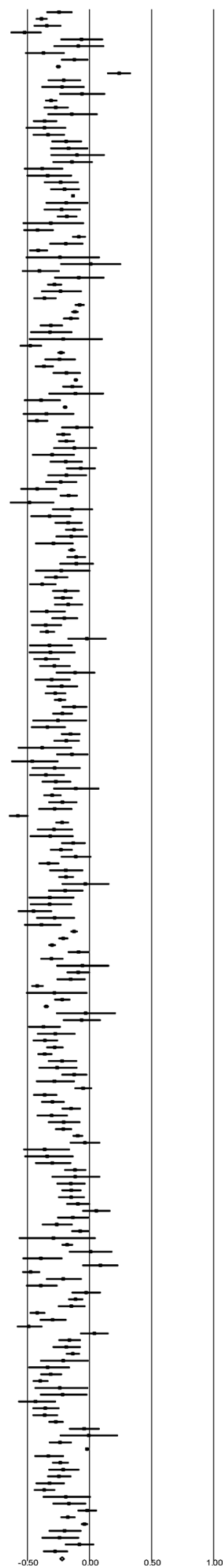


Fig 2. Forest plot of the effect sizes for individual studies included in the meta-analysis: Negative Mental Health $(k=227)$.

doi:10.1371/journal.pone.0138511.g002

the impact of bias is likely to be trivial. The largest adjustment was for negative mental health, adjusted from $r=-.23$ to $r=-.18,95 \%$ CI $[-.20,-.17]$.

\section{Effect sizes ( $r$ ) by individual outcomes}

Table 3 also presents the mean weighted effect sizes for the associations between racism and individual health outcomes using a random-effects model. Due to space limitations, forest plots are not presented for individual outcomes, but are available from the authors upon request. The majority of studies examined negative mental health outcomes, with the mean weighted effect sizes ranging from $r=-.34$ for post-traumatic stress and post-traumatic stress disorders (95\% CI [-.40,-.27], $k=16$ ) to $r=-.16$ for suicidal ideation (95\% CI [-.19,-..12], $k=10$ ). All effect sizes for the negative mental health outcomes were significantly negative, indicating that racism is related to poorer mental health.

The effect sizes for positive mental health outcomes ranged from $r=.00$ (positive affect) to $r=-.19$ (wellbeing). With the exception of positive affect $(k=4)$, which did not reach significance, racism had a significant negative association with all positive mental health outcomes.

The effect sizes for physical health outcomes ranged from $r=.00$ for each of the following: blood pressure and hypertension (95\% CI [-.02, .01], $k=24)$, cholesterol (95\% CI $[-.02, .02]$, $k=4)$ and heart conditions and illnesses (95\% CI $[-.05, .06], k=8)$ to $r=-.13$ for miscellaneous physical health $(95 \% \mathrm{CI}[-.18,-.08], k=20)$. Except for weight-related outcomes $\mathrm{r}=-.08(95 \%$ CI $[-.11,-.05], k=15)$ and miscellaneous physical health outcomes, there was no statistically significant association between racism and physical health outcomes.

Examination of the funnel plots showed fairly symmetric distributions (available upon request from the authors) and the fail-safe Ns were all well above the criterion values for all individual health outcomes. Of the 23 individual outcomes, Egger's regression intercept was statistically significant for seven: depression, distress, stress, self-esteem, life satisfaction, overweight, and general health. Imputing possible missing studies for these seven outcomes resulted in either no, or very little, reduction in effect sizes, suggesting that the impact of bias is likely to be trivial. Depression $(k=109)$ had the highest number of imputed studies (i.e., 23 studies) and largest adjustment to its random-effects point estimate from $r=-.21$ to $r=-.18$, $95 \%$ CI $[-.19,-.15]$.

\section{Study-level moderators}

Using moderation analyses, we examined whether associations between racism and health were moderated by study-level variables. Results are shown in Table 4. Significant moderation effects were found for all moderators except the internal reliability of exposure instruments.

Publication status: publication status significantly moderated the association between racism and self-esteem $(Q(1)=7.38, p=.007)$, and between racism and positive mental health more broadly $(Q(1)=5.89, p=.015)$. Published studies had larger effect sizes as compared to unpublished studies.

Publication year: publication year was a significant moderator for the association between racism and depression $(Q(1)=6.04, p=.014)$, and between racism and anxiety $(Q(1)=7.00$, $p=.008$ ). Studies published from 2006 onwards had stronger effect sizes compared to studies published before 2006. 
Study name

Abbassi-Zoabi 2012

Asmenta and 1983

Ashburn-Nardo etal. 2007

Bailey 2008

Barnes and Lightsey 2005

Barry and Grilo 2003

Basurto 1996

Behnke etal. 2011

Best 2005

Bodkin-Andrews etal. 2010

Brascombe etal. 199

Brown 1991

Buchanan 2002/2008

Cassidy 2004/Cassidy etal 2005

Contrada 200

Copeland-Linder etal. 2010

Coronary Artery Risk Developmentin Young Adults (CARDIA) Study Cronin etal. 2011

Dang 2012

Diabetes Study of Northern California (DISTANCE)

Douglas Low 2007

DuBois etal. 2002

Family and Community Health Study (FACHS)

Fischer and Shaw 1999

Ford 2013
Giamo etal. 2012

Green 1991

Greene etal. 2006

Harris-Brittetal. 2007

Huynh and Fuligni 2010

Hern

Jackson etal. 2012

Jasinskaja-Lahti etal 2001/2007/2009



Kaduvettoor-Davids on and Inman 2012

Lambertetal. 2009

LaMonica 2000

atino Acculturation and Health Project

Lee 2001

Lee 20032

Lee 2005

Liebkind and J as ins k aja-Lahti 2000

Major etal. 2007

Maryland Adoles cent Developmentin Context Study (MADICS)

Matthews 2012

Medley-Proctor 2005

Moradiand Hasan 2004

Moradi and Risco 2006

National Survey of Black Americans (NSBA)

Neblettetal. 2008

Nyborg and Curry 2003

Phinney etal. 1998

Pieterse and Carter 2007/2010

Polek et al. 2010

Postmes and Branscombe 2002

Postmes and Branscombe 2002.

Prelow etal. 2006
Priestetal. 2010

Raver and Nis hii 2010
Rivas-Drake etal. 2008

Rosas 1999

Schaatsma 2011

Schneider etal. 2000.

Sellers etal. 200

Sharma 1995

Shorey etal. 2002
Soriano and Ramirez 1991
Stevens-Watkins etal. 2012

Suleiman Gonzalez 1999
Tartakovsky 20072009

Tawa etal. 201

Terrell 2003

Trevino and Ernst2012

Tynos etal. 2012

Umaña-Taylor and Updegraff2007

Vasquez 2010

Verkuyten 1998

Verkuyten and Nekuee 2001

Walls 2007

Weietal.2008
Wei otal.2012a

Weietal. 2013

Wickrama 201

Wong 1997
Yap 2011

Yap etal. 2011

Yoon et al. 2012

Combined effect size

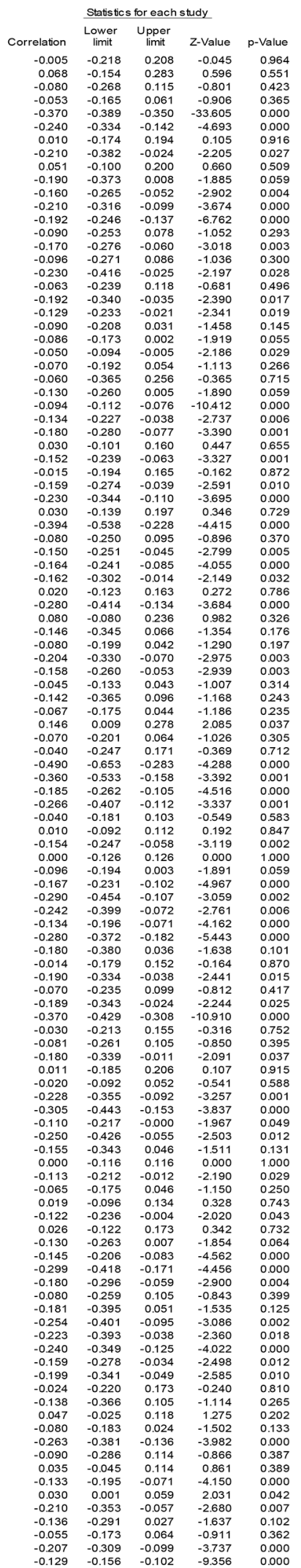

Correlation and $95 \% \mathrm{Cl}$

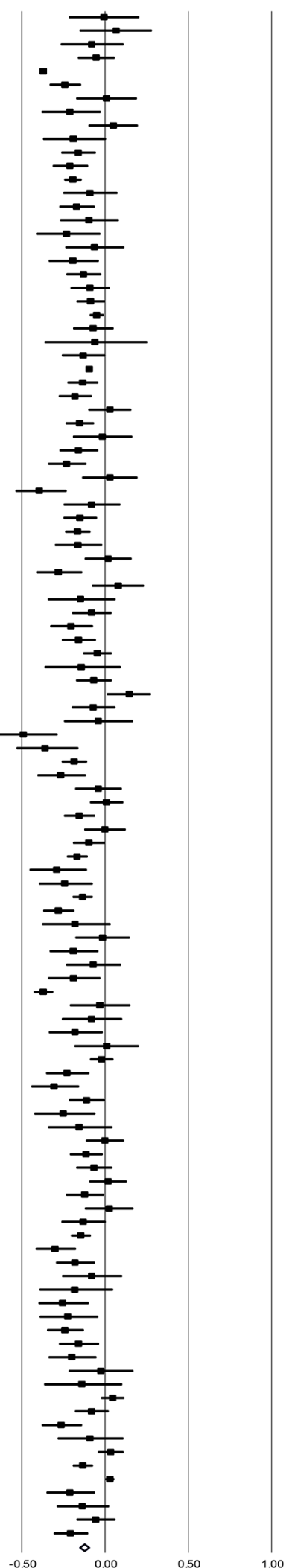

Fig 3. Forest plot of the effect sizes for individual studies included in the meta-analysis: Positive Mental Health $(k=113)$.

doi:10.1371/journal.pone.0138511.g003 
Study name

Agudelo Suarez e al.2011

Barksdale etal. 2009

Black Women's Health Study (BWHS)

Burgess etal. 2009

California Health Interview Survey (CHIS)

Cardarelli etal. 2010

Chambers etal. 2004

Clark 2000

Clark 2003

Clark and Gochet2006

Cooper etal. 2009

Coronary Artery Risk Developmentin Young Adults (CARDIA) Study

de Castro 2008

Diabetes Study of Northern California (DISTANCE)

Dixon etal. 2012

Douglas Low 2007

Epeletal. 2010

Finch and Vega 2003

Flores etal. 2008

Gonzales 2010

Hammond 2010

Heimetal. 2011

Hill etal. 2007

Howarter and Bennet2013

Huynh and Fuligni 2010

Jagusztyn 2007

Kaholokula 2012

Krieger etal. 2010

Moghaddametal. 2002

Moore-Greene 2012

National Latino and Asian American Study (NLAAS)

National Survey of American Life (NSAL)

Neblettand Carter 2012

Peters 2004/2006

Pointer etal. 2008

Poston etal. 2001

Priestetal. 2010

Raver and Nishii 2010

Roberts 2008

Schneider etal. 2000.2

Sellers etal. 2009

Steffen etal. 2003

Taylor and Jackson 1990

Thompson 1999

Todorova etal. 2010

Tull and Chambers 2001

Tull etal. 1999

Tull etal. 2007

United for Health Study

Walters 2004

Combined effect size
Statistics for each study

Correlation $\begin{gathered}\text { Lower } \\ \text { limit }\end{gathered} \begin{gathered}\text { Upper } \\ \text { limit }\end{gathered}$ Z-Value $\quad$-Value

0.000

$\begin{array}{rrrrr}-0.005 & -0.043 & 0.034 & -0.244 & 0.807\end{array}$

$\begin{array}{lllll}-0.188 & -0.287 & -0.086 & -3.571 & 0.000\end{array}$

$\begin{array}{lllll}-0.068 & -0.095 & -0.041 & -4.969 & 0.000\end{array}$

$\begin{array}{lllll}0.034 & -0.065 & 0.132 & 0.672 & 0.502\end{array}$

$\begin{array}{lllll}-0.098 & -0.245 & 0.054 & -1.264 & 0.206\end{array}$

$\begin{array}{lllll}0.110 & -0.213 & 0.411 & 0.663 & 0.508\end{array}$

$\begin{array}{lllll}0.010 & -0.236 & 0.255 & 0.079 & 0.937\end{array}$

$\begin{array}{lllll}-0.093 & -0.223 & 0.041 & -1.357 & 0.175\end{array}$

$\begin{array}{lllll}-0.180 & -0.353 & 0.005 & -1.907 & 0.057\end{array}$

$\begin{array}{lllll}-0.014 & -0.055 & 0.027 & -0.657 & 0.511\end{array}$

$\begin{array}{lllll}-0.130 & -0.177 & -0.082 & -5.309 & 0.000\end{array}$

$\begin{array}{lllll}-0.054 & -0.126 & 0.020 & -1.436 & 0.151\end{array}$

$\begin{array}{lllll}-0.159 & -0.258 & -0.057 & -3.053 & 0.002\end{array}$

$\begin{array}{lllll}-0.148 & -0.241 & -0.053 & -3.041 & 0.002\end{array}$

$\begin{array}{lllll}-0.140 & -0.200 & -0.079 & -4.459 & 0.000\end{array}$

$\begin{array}{lllll}-0.080 & -0.115 & -0.044 & -4.398 & 0.000\end{array}$

$\begin{array}{lllll}-0.250 & -0.381 & -0.110 & -3.446 & 0.001\end{array}$

$\begin{array}{lllll}0.019 & -0.119 & 0.156 & 0.264 & 0.792\end{array}$

$\begin{array}{lllll}-0.065 & -0.197 & 0.069 & -0.950 & 0.342\end{array}$

$\begin{array}{lllll}-0.070 & -0.149 & 0.009 & -1.727 & 0.084\end{array}$

$\begin{array}{lllll}-0.104 & -0.403 & 0.214 & -0.636 & 0.525\end{array}$

$\begin{array}{lllll}-0.180 & -0.301 & -0.054 & -2.778 & 0.005\end{array}$

$\begin{array}{lllll}-0.177 & -0.254 & -0.099 & -4.382 & 0.000\end{array}$

$\begin{array}{lllll}-0.004 & -0.192 & 0.185 & -0.038 & 0.970\end{array}$

$\begin{array}{lllll}-0.079 & -0.238 & 0.085 & -0.946 & 0.344\end{array}$

$\begin{array}{lllll}0.173 & -0.237 & 0.530 & 0.821 & 0.411\end{array}$

$\begin{array}{lllll}-0.032 & -0.223 & 0.162 & -0.317 & 0.751\end{array}$

$\begin{array}{lllll}-0.095 & -0.296 & 0.114 & -0.889 & 0.374\end{array}$

$\begin{array}{lllll}-0.142 & -0.258 & -0.022 & -2.320 & 0.020\end{array}$

$\begin{array}{lllll}-0.049 & -0.130 & 0.032 & -1.180 & 0.238\end{array}$

$\begin{array}{lllll}-0.017 & -0.152 & 0.119 & -0.240 & 0.810\end{array}$

$\begin{array}{lllll}-0.030 & -0.183 & 0.125 & -0.379 & 0.705\end{array}$

$\begin{array}{lllll}0.083 & -0.068 & 0.229 & 1.078 & 0.281\end{array}$

$\begin{array}{lllll}0.004 & -0.009 & 0.017 & 0.617 & 0.537\end{array}$

$\begin{array}{llll}-0.099 & -0.206 & 0.011 & -1.770\end{array}$

$\begin{array}{lllll}-0.170 & -0.239 & -0.099 & -4.645 & 0.000\end{array}$

$\begin{array}{lllll}-0.077 & -0.168 & 0.015 & -1.639 & 0.101\end{array}$

$\begin{array}{llll}-0.090 & -0.204 & 0.026 & -1.520\end{array}$

$\begin{array}{lllll}-0.008 & -0.106 & 0.090 & -0.159 & 0.874\end{array}$

$\begin{array}{lllll}-0.195 & -0.413 & 0.044 & -1.604 & 0.109\end{array}$

$\begin{array}{lllll}-0.105 & -0.218 & 0.011 & -1.776 & 0.076\end{array}$

$\begin{array}{lllll}0.006 & -0.193 & 0.204 & 0.054 & 0.957\end{array}$

$\begin{array}{lllll}-0.017 & -0.076 & 0.041 & -0.581 & 0.561\end{array}$

$\begin{array}{lllll}-0.250 & -0.468 & -0.002 & -1.974 & 0.048\end{array}$

$\begin{array}{lllll}-0.224 & -0.401 & -0.031 & -2.272 & 0.023\end{array}$

$\begin{array}{lllll}-0.128 & -0.244 & -0.009 & -2.111 & 0.035\end{array}$

$\begin{array}{lllll}-0.025 & -0.093 & 0.044 & -0.706 & 0.480\end{array}$

$\begin{array}{lllll}-0.170 & -0.295 & -0.040 & -2.546 & 0.011\end{array}$

$\begin{array}{lllll}-0.090 & -0.122 & -0.057 & -5.384 & 0.000\end{array}$
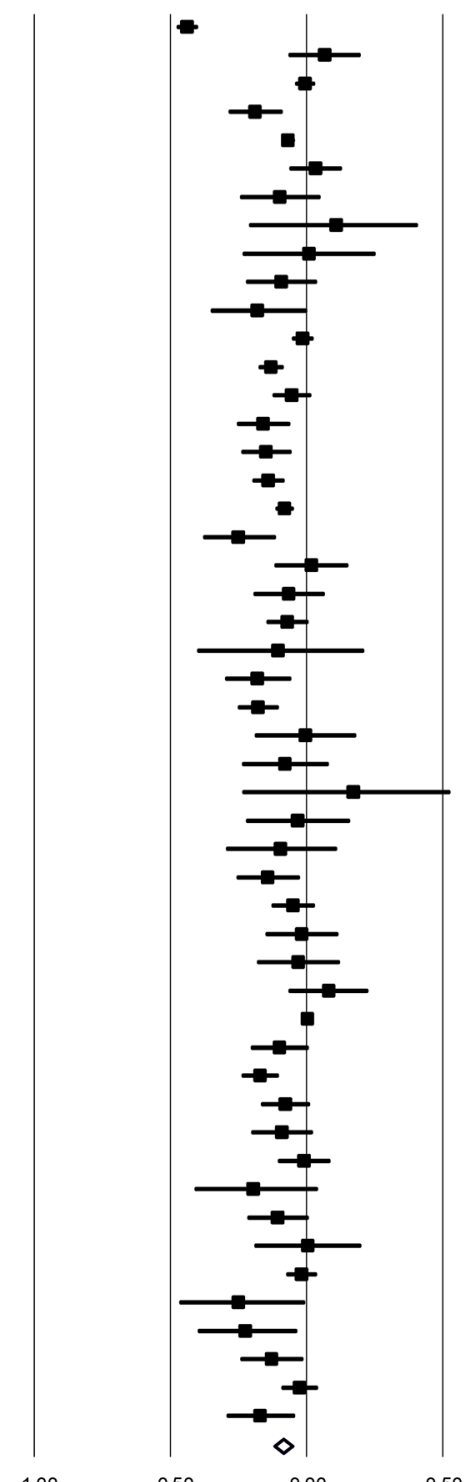



1.00

Fig 4. Forest plot of the effect sizes for individual studies included in the meta-analysis: Physical Health $(k=50)$.

doi:10.1371/journal.pone.0138511.g004

Country: the country where the study was conducted significantly moderated the association between racism and negative affect $(Q(1)=4.33, p=.037)$, and between racism and selfesteem $(Q(1)=5.02, p=.025)$. Specifically, the effect sizes for studies conducted outside the U.S. were larger than effect sizes for studies conducted in the U.S.

Sampling: the sampling design was a significant moderator of the association between racism and the following three outcomes: stress $(Q(1)=3.98, p=.046)$, anxiety $(Q(1)=4.34$, $p=.037)$, and negative mental health more broadly $(Q(1)=5.13, p=.023)$. The effect sizes for studies using non-representative sampling were larger than the effect sizes for studies using representative sampling. 
Study name

Agudelo Suarez e al. 2011

Becares etal. 2009

Bird etal. 2004

Blankenau and Boye-Beaman 2000

Brondolo etal. 2011

Buchanan 2002/2008

California Health Interview Survey (CHIS)

Coronary Artery Risk Developmentin Young Adults (CARD IA) Study

Crengle etal. 2012

De Maio 2010

DetroitArab Americ an Study (DAAS)

Douglas Low 2007

Flores etal. 2008

Galvan 2010

Gonzales 2010

Gutierres etal. 1994

Hausmann etal. 2009

Jasinskaja-Lahti etal 2001/2007/2009

Mansouri etal. 2009

National Survey of Black Americans (NSBA)

Pieterse and Carter 2007/2010

Priestetal. 2010

Priestetal. 2011

Sharif 2007

Sinai Improving Community Health Survey

Soylu 2008

Swami 2010

Todorova etal. 2010

United for Health Study

Williams 1999

Combined effect size
Statistics for each study

\begin{tabular}{|c|c|c|c|c|}
\hline rrelation & $\begin{array}{c}\text { Lower } \\
\text { limit }\end{array}$ & $\begin{array}{l}\text { Upper } \\
\text { limit }\end{array}$ & Z-Value & $p$-Value \\
\hline-0.121 & -0.181 & -0.060 & -3.854 & 0.000 \\
\hline-0.059 & -0.117 & -0.001 & -2.001 & 0.045 \\
\hline-0.260 & -0.426 & -0.076 & -2.753 & 0.006 \\
\hline-0.467 & -0.630 & -0263 & -4.202 & 0.000 \\
\hline-0.284 & -0.350 & -0216 & -7.869 & 0.000 \\
\hline-0.098 & -0.298 & 0.110 & -0.922 & 0.356 \\
\hline 0.005 & -0.003 & 0.013 & 1.236 & 0.216 \\
\hline 0.044 & -0.032 & 0.119 & 1.132 & 0.257 \\
\hline-0.103 & -0.138 & -0.069 & -5.879 & 0.000 \\
\hline-0.048 & -0.078 & -0.018 & -3.137 & 0.002 \\
\hline 0.065 & 0.001 & 0.129 & 1.993 & 0.046 \\
\hline-0.139 & -0.232 & -0.044 & -2.848 & 0.004 \\
\hline-0.240 & -0.363 & -0.109 & -3.547 & 0.000 \\
\hline-0.120 & -0.294 & 0.061 & -1.299 & 0.194 \\
\hline-0.250 & -0.335 & -0.162 & -5.443 & 0.000 \\
\hline 0.000 & -0.076 & 0.076 & 0.000 & 1.000 \\
\hline-0.282 & -0.322 & -0240 & -12.639 & 0.000 \\
\hline-0.120 & -0.166 & -0.074 & -5.087 & 0.000 \\
\hline-0.118 & -0.203 & -0.032 & -2.675 & 0.007 \\
\hline 0.060 & -0.019 & 0.138 & 1.492 & 0.136 \\
\hline-0.260 & -0.443 & -0.056 & -2.482 & 0.013 \\
\hline-0.132 & -0.283 & 0.024 & -1.661 & 0.097 \\
\hline-0.248 & -0.416 & -0.063 & -2.613 & 0.009 \\
\hline-0.144 & -0.274 & -0.009 & -2.096 & 0.036 \\
\hline-0.077 & -0.124 & -0.029 & -3.167 & 0.002 \\
\hline-0.325 & -0.407 & -0238 & -7.009 & 0.000 \\
\hline-0.140 & -0.256 & -0.020 & -2.285 & 0.022 \\
\hline 0.040 & -0.018 & 0.099 & 1.358 & 0.175 \\
\hline 0.004 & -0.205 & 0.213 & 0.041 & 0.967 \\
\hline-0.400 & -0.449 & -0.349 & -13.968 & 0.000 \\
\hline-0.134 & -0.181 & -0.088 & -5.607 & 0.00 \\
\hline
\end{tabular}

Correlation and $95 \% \mathrm{Cl}$

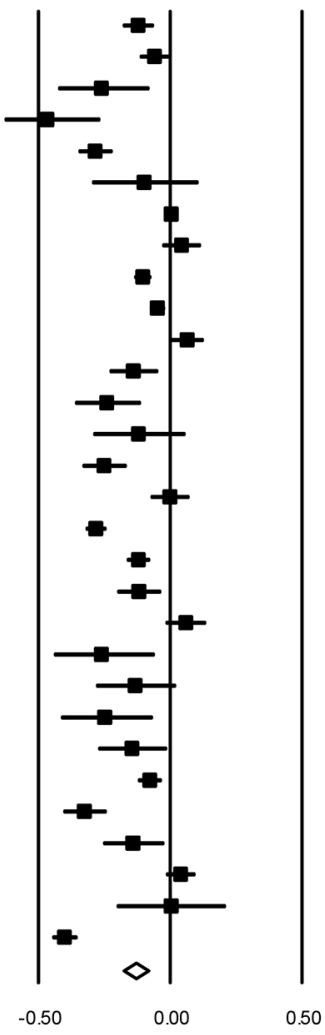



Fig 5. Forest plot of the effect sizes for individual studies included in the meta-analysis: General Health $(\mathbf{k}=30)$.

doi:10.1371/journal.pone.0138511.g005

Longitudinal versus cross-sectional data: there were sufficient numbers of studies reporting longitudinal data to allow the comparison of effect sizes from cross-sectional data versus longitudinal data for two outcome groups, positive mental health and negative mental health as well as two individual health outcomes, self-esteem and depression. Type of data collected (i.e., longitudinal versus cross-sectional data) significantly moderated the association between racism and negative mental health $(Q(1)=5.58, p=.018)$, but did not moderate the associations for self-esteem $(Q(1)=2.63, p=.105)$, positive mental health $(Q(1)=3.00, p=.083)$, and depres$\operatorname{sion}(Q(1)=2.37, p=.124)$. There was insufficient data to examine data type features for physical health and other outcomes.

For negative mental health, a moderation analysis of cross-sectional and longitudinal studies (regardless of time between exposure and outcome), showed that the effect size for crosssectional data $(r=-.22, z=-25.55, p<.001, k=197)$ was larger than the effect size for longitudinal data $(r=-.16, z=5.84, p<.001, k=14, Q(1)=5.58, p=.018)$. Sufficient longitudinal data were reported in studies on racism and negative mental health to allow separate analyses for short-term longitudinal data (up to 1 year between exposure and outcome) and long-term longitudinal data (more than 1 year between exposure and outcome) (not reported in the table). This moderator was significant once again $(Q(2)=13.08, p=.001)$. The effect size for cross-sectional data $(r=-.22, z=-25.55, p<.001, k=197)$ was similar to the effect for shortterm longitudinal data $(r=-.21, z=-4.38, p=<.001, k=5, \mathrm{Q}(1)=0.049, \mathrm{p}=.826)$, and significantly larger than the effect for long-term longitudinal data $(r=-.11, z=-3.79, p<.001, k=7$, $(\mathrm{Q}(1)=13.082, \mathrm{p}<.001)$, which was significant nonetheless. For the longitudinal studies 
4 政



동

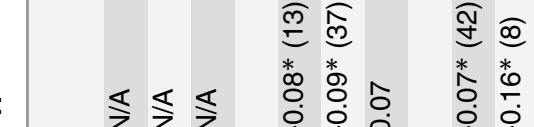

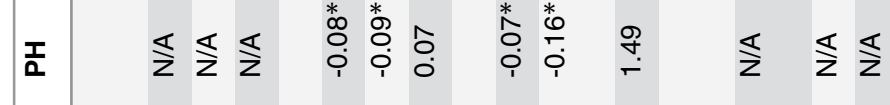
E

$\stackrel{0}{\infty}$

\section{$\sum$}

9

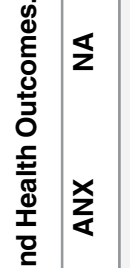

山

$\sum$

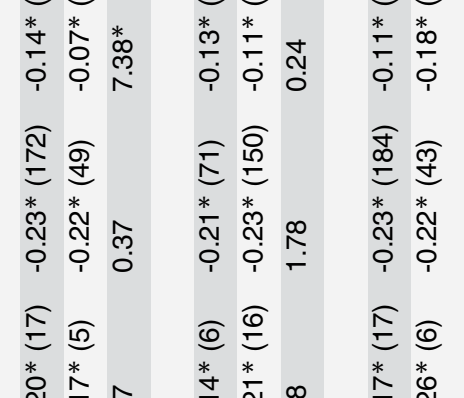

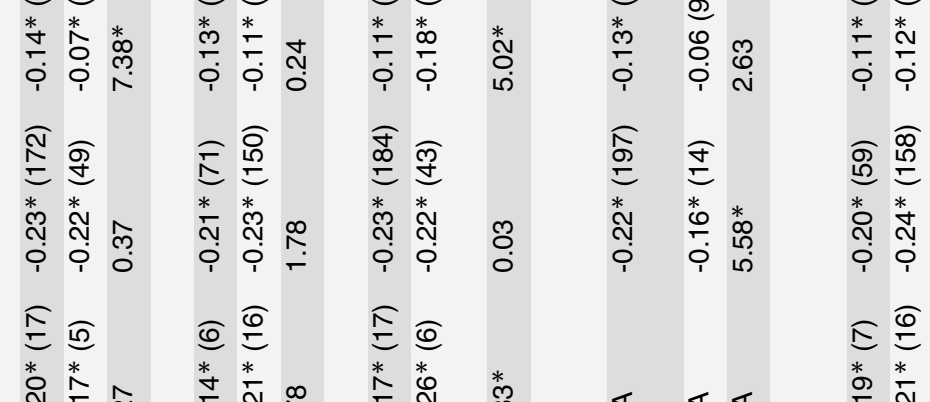

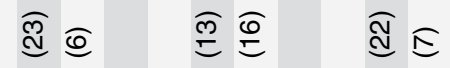

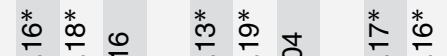

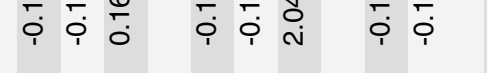

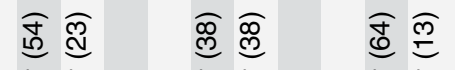

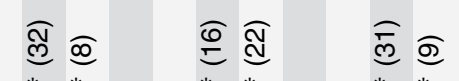

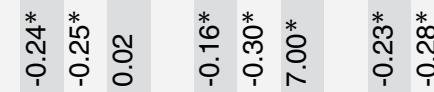



$\frac{\mathfrak{c}}{\mathfrak{c}}$

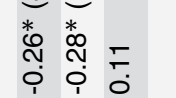



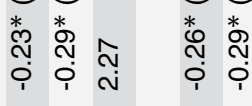

$\frac{2}{D}$

$\stackrel{\frac{\pi}{2}}{\frac{\pi}{2}}$

흔 㞻

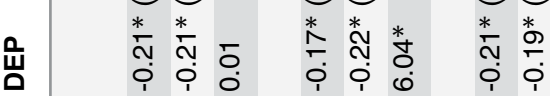

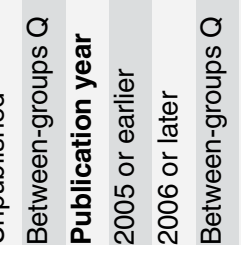

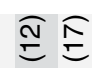

సิ

हิ $\stackrel{\infty}{=}$

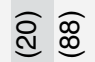

ס $\quad \ll \quad \ll$

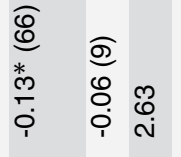

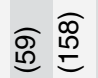

E

ô

$\stackrel{10}{=} \stackrel{0}{=}$

离

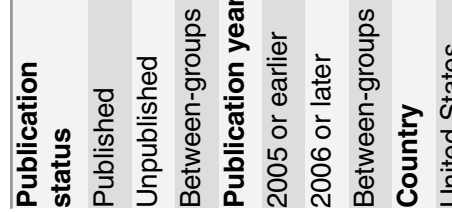

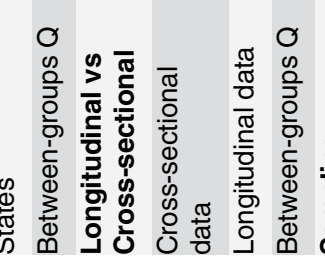

ing

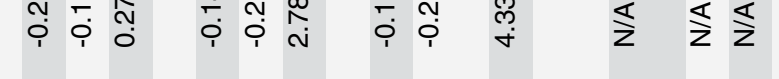

i

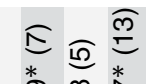

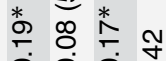

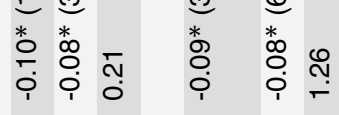

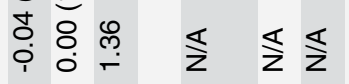

E

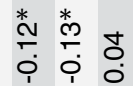

$\stackrel{*}{m}$

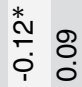

बิ

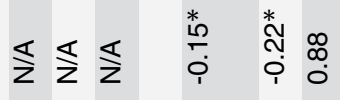

Еत्ष 迎

ㄴ.

范

厄ิ बิ

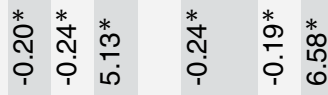

क.

हิ ले

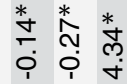



กָ

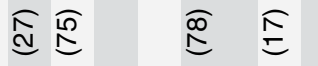

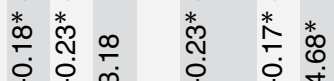

응 $\widehat{\bar{N}}$

*

i i i

$\widehat{\underline{0}}$

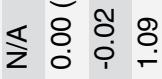

ลิ

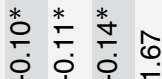

ळ $\stackrel{0}{=}$

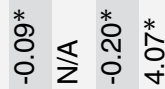

ิㅡㄹ



过恣

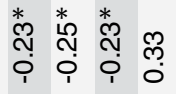

芹E

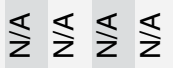

오

ํ.

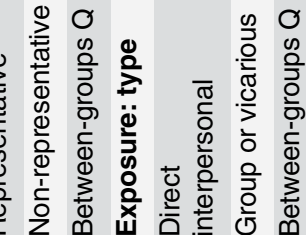

* * * *

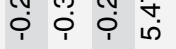

Ð $\stackrel{\sigma}{=}$

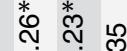
ํํํ

लै

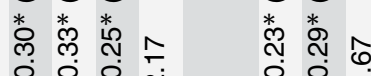

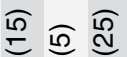

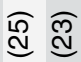

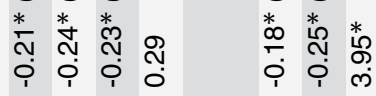

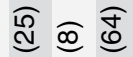

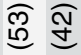

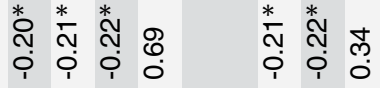




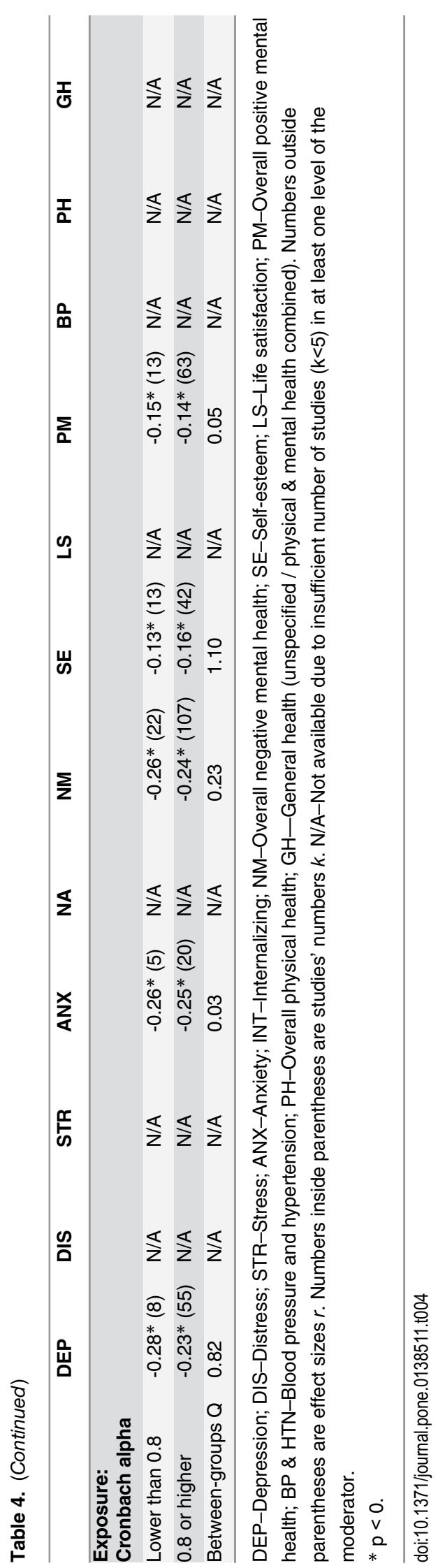


reporting negative mental health outcomes, we also tested the months between exposure and outcome as a potential moderator. The number of months between exposure and outcome was not a significant predictor of effect sizes $(B=.0057, z=1.57, p=.115, k=12)$. Two studies reported both short-term and long-term longitudinal effects and were excluded from this supplementary analysis.

Exposure instrument type: exposure instrument type was a significant moderator for the association between racism and depression $(Q(1)=4.68, p=.031)$, and between racism and negative mental health more broadly $(Q(1)=6.58, p=.010)$. Studies using exposure instruments that measure direct exposure to racism had larger effect sizes as compared to studies using exposure instruments that measure indirect (i.e., group or vicarious) exposure to racism.

Exposure instrument timeframe: the exposure instrument timeframe significantly moderated the association between racism and life satisfaction $(Q(1)=4.07, p=.044)$. Studies that ask about exposure to racism in the last 3 years or less had a smaller effect size as compared to studies using exposure instruments with unspecified timeframes.

Number of exposure instrument items: the number of items in the exposure instruments significantly moderated the association between racism and distress $(Q(1)=3.95, p=.047)$. The effect size for studies using exposure instruments with 9 items or more was larger than the effect size for studies using exposure instruments with 8 items or less.

Internal reliability of exposure instruments: only five outcome groups (depression, anxiety, self-esteem, negative mental health and positive mental health) had sufficient studies to allow moderation analysis using internal reliability of the exposure instrument as a moderator. In these analyses, exposure instrument reliability did not significantly moderate the associations between racism and any of the five health outcomes $(Q(1)=0.82, p=.364 ; Q(1)=0.03$, $p=.854 ; Q(1)=1.10, p=.295 ; Q(1)=0.23, p=.628 ; Q(1)=0.05, p=.827$, respectively).

Exposure instrument name (not shown in table): additional moderation analyses examining exposure instrument utilized as a possible moderator were run for depression, negative mental health, positive mental health and physical health (with insufficient studies for all other outcomes). For depression and positive mental health, exposure instrument name was not significant as a moderator $(Q(1)=1.01, p=.605 ; Q(1)=0.21, p=.650$, respectively). For negative mental health, the effects for PRS $(r=-.32, z=-10.39, p<.001, k=14)$, and PEDQ $(r=-.33$, $z=-8.84, p<.001, k=9)$ were significantly larger than the effect for RaLES $(r=-.20, z=-4.18$, $p<.001, k=7)(Q(1)=4.44, p=.035 ; Q(1)=4.40, p=.036$, respectively). For physical health, the effects for NAD $(r=-.11, z=-3.42, p=.001, k=5)$, EDS $(r=-.07, z=-2.61, p=.009, k=6)$ and EOD $(r=-.09, z=-2.17, p=.030, k=6)$ were significantly larger than the effect for PRS $(r=.00, z=0.62, p=.534, k=6)(Q(1)=12.05, p=.001 ; Q(1)=7.19, p=.007 ; Q(1)=5.02$, $p=.025$, respectively).

\section{Participant-level moderators}

We conducted moderation analyses for participant subgroups, examining age, sex, ethnicity (for studies conducted in the U.S.), level of education and birthplace as potential moderators of the association between racism and health outcomes. Age ( $\geq 18$ years vs. $<18$ years), sex (male vs. female), current education level (primary vs. secondary vs. tertiary) and birthplace (local vs. foreign born) did not significantly moderate the association between racism and any of the health outcomes examined, where at least two levels of the moderator consisted of five or more studies. However, the associations between racism and depression, negative mental health, and physical health were significantly different across U.S. ethnic groups.

For depression $(Q(2)=6.29, p=.043)$, the associations for Asian Americans produced the largest effect size $(r=-.28, z=-6.21, p<.001, k=11)$, followed by associations for Latino/a 
Americans $(r=-.24, z=-12.49, p<.001, k=29)$. While these two groups did not have significantly different effect sizes from each other, they both had significantly larger effects when compared with African Americans $(r=-.18, z=-8.06, p<.001, k=38)$. Effect sizes for the other ethnic groups (European Americans, Native Americans) were few in number and were therefore not included in the analysis.

For negative mental health, which consists of depression as well as other mental health outcomes, the overall moderation analysis including 5 ethnic groups was not significant $(Q(4)=7.64, p=.106)$. However, ethnicity was significant as a moderator in pairwise analyses comparing effects for African Americans with effects for Latino/a Americans and for Asian Americans. Accordingly, the associations for Asian Americans produced the largest effect size $(r=-.28, z=-8.30, p<.001, k=20)$, followed by Latino/a Americans $(r=-.25, z=-14.32$, $p<.001, k=49)$. While these two groups did not have significantly different effect sizes from each other, both had significantly larger effect sizes when compared with African Americans $(r=-.20, z=-10.79, p<.001, k=68)$. The effect sizes for European Americans $(r=-.21$, $z=-5.28, p<.001, k=6)$, and for Native Americans $(r=-.21, z=-8.25, p<.001, k=6)$, were not significantly different from the effect sizes for the 3 other ethnic groups.

For physical health, African Americans and Latino/a Americans were the only groups for which sufficient numbers of associations were reported to allow moderation analysis. Ethnicity significantly moderated the association between racism and physical health $(Q(1)=5.22, p=.022)$. Specifically, the effect size for Latino/a Americans $(r=-.12, z=-3.26, p=.001, k=5)$ was significantly larger than the effect size for African Americans $(r=-.03, z=-2.33, p=.020, k=24)$.

\section{Discussion}

This meta-analysis is the first to focus specifically on racism and health across a range of populations, national contexts and health outcomes. Using a comprehensive and rigorous search protocol, a total of 293 studies reported in 333 articles were located. Consistent with previous systematic reviews, trends over time indicate increasing output of published articles focusing on racism and (particularly adult) health, while a relative majority of research is still being conducted in the U.S. among African Americans [10, 14]. However, this meta-analysis indicates an increasing trend for articles to include European Americans (often for comparative purposes) with a growing focus on Latina/o and Asian Americans as well. The majority of participants were adults, and only about $16 \%$ of participants were younger than 18 years old. Most participants were female, and over a third of articles focused on student samples (predominately from secondary and tertiary, rather than elementary, education levels). This research demonstrates a primary focus on locally-born populations but with a third of articles also including migrant populations (see also [14]). Comparative studies on the impact of racism over time on both migrants and native-born populations of similar ethnic/racial backgrounds are currently lacking and should be examined in future research.

This meta-analysis indicates that racism is significantly related to poorer health, with the relationship being stronger for poor mental health and weaker for poor physical health. After adjusting for publication bias, the correlation with poor mental health remained twice as large as the correlation for poor physical health, with results for general health (unspecified as mental or physical health/mental and physical health combined) falling in-between. This contrasts with the findings reported by Pascoe and Richman [13], where the association between perceived discrimination and physical health compared to mental health did not differ significantly. One possible reason for the discrepancy is that Pascoe and Richman [13] examined multiple forms of perceived discrimination, whereas the present study focused on discrimination based explicitly on race and related classifiers like ethnicity and nationality. 
A more detailed examination of health outcomes indicates a two-fold range in the strength of association between racism and poor mental health (from $r=-0.16$ for suicidal ideation, planning, and attempts and $\mathrm{r}=-0.34$ for post-traumatic stress and post-traumatic stress disorder). After adjustment for publication bias, depression (the most commonly reported outcome) had the same magnitude of association as the broader category of negative mental health. With regard to physical health, only overweight-related outcomes and a range of miscellaneous physical health outcomes were significantly associated with racism, as found in recent longitudinal studies [399, 400]. A recent review [401] found only some significant associations between racism and obesity. Our different finding may be due to the more comprehensive nature of our examination of overweight-related outcomes (including BMI, WC, WHR, overweight and obesity), the inclusion of additional studies (some of which were conducted more recently), and the use of different designs (a meta-analysis versus a literature review).

Small sample sizes for cholesterol $(k=4)$ and heart conditions/illnesses $(k=8)$ may have limited power to detect associations for such outcomes, however this was not the case for the null finding between racism and blood pressure/hypertension $(k=24)$. In a recent meta-analysis Dolezsar et al. [34] also found that racism was not significantly related to either blood pressure or hypertension. Whereas previous meta-analyses in this field have tended to consider physical health outcomes as a group, our additional examination of disaggregated outcomes reveals mixed findings across distinct physical health outcomes. Although some research has suggested the relationship between racism and blood pressure may be curvilinear $[121,281$, 304, 402-403], this possibility was not explored in the current meta-analysis due to limitations in the statistical analysis program we utilized.

The stronger association between racism and mental health outcomes, compared with physical health, raises questions about the mechanisms by which racism affects health. Chronic exposure to racism may be implicated in hypothalamic-pituitary-adrenal (HPA) axis dysregulation that, in turn, can damage bodily systems and lead to physical outcomes such as CVD and obesity. The impacts of racism on the dysregulation of cognitive-affective regions such as the prefrontal cortex, anterior cingulate cortex, amygdala and thalamus share similarities with pathways leading to anxiety, depression and psychosis [404]. Neuroimaging studies have also identified activation of these regions in response to social rejection that are correlated with selfreport distress levels and are analogous to the activation of regions involved in physical pain [405]. Such neurobiological changes may also be precursors to racism-related vigilance and rumination which are emerging as health risk factors in their own right [406-411].

For negative mental health, the effect size for studies using cross-sectional data was larger than the effect size for studies using longitudinal data. We found that long-term longitudinal data (more than one year between exposure and outcome) showed weaker, although still significant, associations between racism and health compared to either cross-sectional or shorterterm longitudinal data (up to one year between exposure and outcome). Schmitt et al. [23] have found similar results with regards to discrimination more broadly. This finding suggests that the detrimental impact of racism may attenuate over time, perhaps because of the fading impact of brief exposure or due to individuals becoming 'hardened' to racism over time [412, 413]. The implications of such preliminary evidence for the etiological 'half-life' of racism warrant further investigation through a greater focus on longitudinal data in the field (comprising only $9 \%$ of articles to date).

Moderation by age, sex, education level and birthplace of study participants has been found in previous individual studies (e.g., [42, 414]) but has been inconclusive in previous systematic reviews and meta-analyses [e.g., [13]). Similarly, we found that these variables did not significantly moderate the association between racism and the health outcomes. Ethnicity, however, significantly moderated the association between racism and depression, negative mental health, 
and physical health, providing tentative evidence that the association between racism and negative mental health is stronger for Asian Americans and Latino/a Americans compared with African Americans, and that the association between racism and physical health was stronger for Latino/a Americans compared with African Americans. There were no significant differences between African Americans and either European or Native Americans. These findings could suggest that African (and possibly Native) Americans are more resilient to racism than other minority groups [415]. It is also possible that, as may be the case for European Americans [416], their experiences are qualitatively distinct from other minority groups. These results should be treated as preliminary given the number of studies reporting effects for some ethnic groups was rather small (for example, only 6 studies of Native Americans and 6 studies of European Americans were used in analyses of racism and mental health, and only 5 studies of Latino/a Americans were used in analyses of racism and physical health).

Other studies have found variations in correlation strength within Latino/a American groups (Cubans, Mexicans, Dominicans and Puerto Ricans) [29] and between Asian, African and Latino Americans in relation to chronic conditions [417]. The magnitude of associations in our meta-analysis was similar (or slightly higher) than findings from previous meta-analyses that focused on these specific ethnic/racial population groups [28-31].

In terms of study quality, there was some indication of publication bias whereby some associations between racism and health outcomes were stronger in published versus unpublished studies, consistent with the tendency for 'null' studies to remain unpublished (i.e., the 'file drawer' problem [418]). Similarly, studies using non-representative samples had larger effect sizes than those using representative samples, indicating that bias may be introduced through 'convenience' and other sampling strategies. This finding raises questions about the potential role of sampling bias. Convenience samples often employ strategies such as snowball sampling, whereby participants are connected to one another, which then leads to problems with autocorrelation, or recruitment via advertisements in community locations that could lead to recruitment of those participants for whom racism is more salient, thus inflating effect sizes. By contrast, larger and more representative studies often use more sophisticated sampling methods, as well as statistical corrections (e.g. sampling weights) that may lead to less biased estimates. We stress that the associations between racism and health are evident regardless of the study methodology, but note that studies using convenience may overestimate the association between racism and health outcomes.

It is not immediately clear why associations between racism and some negative mental health outcomes were stronger in studies published more recently (from 2006) or in non-U.S. studies. Further research, including meta-regression to control for potential methodological covariates, should investigate such trends more closely. Unlike Pieterse et al. [31] who found no moderation by sample, publication or instrument type in their meta-analysis of perceived racism and mental health for Black Americans, we found stronger associations for some health outcomes in studies utilizing direct rather than indirect exposure measures, exposure assessment with specified rather than unspecified timeframes, and instruments with more rather than less items. The latter resonates with previous findings that the association between racism and health is stronger in studies that employ multiple item or multiple domain measures of racism $[10,22,419]$.

One of the key challenges in the study of racism and health is the profusion of exposure measurements currently utilized by researchers [420, 421]. Combining the eight most popular scales accounts for only about a third of extant articles, with the Schedule of Racist Events (the most commonly utilized tool) being referenced in only around $10 \%$ of articles. As the field matures, it is likely that measurement will converge on validated best-practice instruments. Both the Everyday Discrimination Scale [422] and Experiences of Discrimination scale [221] 
are likely candidates given applicability to a range of ethnoracial groups and extensive psychometric validation [280, 423-428], although a focus on how these and other instruments can validly assess racism among children and youth is currently lacking [14]. We caution however, that our focus on explicit mentions of race will tend to understate the contribution of scales like the Everyday Discrimination Scale, for which attributions to race are volunteered by participants, rather than intrinsic to the question asked.

This study noted some differential findings by exposure measures, for example for PRS. Studies using PRS found stronger effects of racism on mental health when compared with studies using RaLES, whereas the effect of racism on physical health was weaker in studies using PRS compared with studies using EDS and EOD. These novel findings should be investigated in future studies that explicitly compare effects between various measures (e.g., [429]).

Internal reliability, however, did not moderate associations between racism and health. Alpha coefficients are the most commonly reported indicator of a study's reliability, but unfortunately, only measure a single dimension (internal consistency). More valid and reliable instruments should be better able to detect associations between racism and health. Accordingly, we encourage authors to provide more comprehensive description of their instrument's psychometric properties (e.g., test-retest). Finally, the relatively weaker association found in studies using indirect measures (e.g., group and vicarious exposures to racism) may stem from the relatively under-developed nature of measurement approaches to date (e.g., [295, 430, 431]), highlighting a need for further development.

Although required to estimate variations in exposure over time [432], explicit time frames were not always included in exposure instruments. Gee, Walsemann and Brondolo [413] have argued that explicit attention to the timing of racism is critical both for theoretical and empirical reasons, especially these dimensions of time: (1) the length of exposure to discriminatory events; (2) the timing of these events within the life course; and (3) the etiological period between exposure and the onset of illness. While in this study the effects of racism on health were not modified by age (categorized as 18 years and older vs. less than 18 years), it is highly plausible that children are more vulnerable to the harmful effects of racism, and that experiences of racism in the early years of life have more severe and persistent health consequences than racism experienced later in life [14]. This is likely through the biological embedding of early life stress as well as weathering effects resulting from chronic exposure to stress throughout life [433]. The few studies on racism and health conducted among pre-adolescent populations limit the extent to which moderation effects by age can be tested. More longitudinal studies commencing early in the lifespan, from pre-conception onwards, are required to further elucidate these causal pathways.

This study includes a number of limitations. First, it does not include articles in languages other than English and thus may under-represent studies from countries which publish in other languages. Second, it focuses only on unadjusted associations, mainly because of the challenges related to adjusting for different sets of covariates. A recent meta-analysis demonstrated that for mental health and discrimination more generally, differences between unadjusted associations and those adjusted for covariates were not significant [23]. Nonetheless, we concur with Pascoe and Richman [13] that a specific set of control covariates should be reported in future studies to allow more thorough meta-analytic investigation of partial correlations. A growing body of literature may also allow further elucidation of moderators using meta-regression. Although beyond the scope of this paper, a fine-grained examination of individual outcomes (e.g., psychological stress, depression) is also required given evidence of differential associations between racism and various health outcomes.

This study is the most comprehensive meta-analysis on racism and health to date, providing information on the state of play in this rapidly growing field. Our findings corroborate previous 
research findings as to the magnitude of associations between racism and mental health, adding novel meta-analyses of associations between racism and a diverse range of outcomes, including overweight, somatization, psychological stress, and post-traumatic stress (PTS) and stress disorder (PTSD). It also provides evidence that racism has long-term effects on health that remain significant despite attenuation over time. It is hoped that this meta-analysis can provide new directions for research in understanding, as well as addressing, racism as a determinant of illhealth.

\section{Supporting Information}

S1 Table. PRISMA 2009 Checklist.

(PDF)

S1 Appendix. Search Strategy.

(PDF)

\section{Acknowledgments}

We would like to thank Carla De Oliveira Bernardo, Joanna Burrow, Hannah Reich, Brigid Trenerry, Mandy Truong, and Mary Tumushime for their valuable assistance with various aspects of this research, especially reviewing and data extraction.

\section{Author Contributions}

Conceived and designed the experiments: YP JB NP AP AG MK GG. Performed the experiments: YP JB AE NP AP AG MK GG. Analyzed the data: YP JB ND. Wrote the paper: YP JB ND AE NP AP AG MK GG.

\section{References}

1. Berman G, Paradies Y. Racism, disadvantage and multiculturalism: towards effective anti-racist praxis. Ethnic \& Racial Studies. 2010; 33(2):214-32.

2. Paradies $Y$. Defining, Conceptualizing and Characterizing Racism in Health Research. Critical Public Health. 2006; 16(2):143-57.

3. Hamilton C, Carmichael S. Black Power. New York: Random House; 1967.

4. United Nations. World Conference against Racism, Racial Discrimination, Xenophobia and Related Intolerance: Declaration and Programme of Action. 2009.

5. Brika J, Lemaine G, Jackson J. Racism and xenophobia in Europe, Eurobarometer opinion poll no 47.1. Employment, Industrial Relations and Social Affairs Directorate (DGV), the European Commission., 1997.

6. Semyonov M, Raijman R, Gorodzeisky A. The rise of anti-foreigner sentiment in European societies, 1988-2000. American Sociological Review. 2006; 71(3):426-49.

7. Gallup Poll. Race relations. http://www.gallup.com/poll/1687/race-relations.aspx, 2014

8. The Guardian. Racism on the rise in Britain. 2014.

9. Markus A. Mapping Social Cohesion: The Scanlon Foundation surveys 2014. Caulfield East: Australian Centre for Jewish Civilization, 2014.

10. Paradies $Y$. A systematic review of empirical research on self-reported racism and health. Int J Epidemiol. 2006; 35(4):888-901. PMID: 16585055

11. Brondolo E, Brady N, Libby D, Pencille M. Racism as a Psychosocial Stressor. In: Baum A, Contrada R, editors. Handbook of Stress Science. New York: Springer; 2011. p. 167-84.

12. Harrell CP, Burford TI, Cage BN, McNair Nelson T, Shearon S, Thompson A, et al. Multiple Pathways Linking Racism to Health Outcomes. Du Bois Review. 2011; 8(1):143-57. PMID: 22518195

13. Pascoe EA, Richman LS. Perceived Discrimination and Health: A Meta-Analytic Review. Psychological Bulletin. 2009; 135(4):531-54. doi: 10.1037/a0016059 PMID: 19586161 
14. Priest N, Paradies Y, Trenerry B, Truong M, Karlsen S, Kelly Y. A systematic review of studies examining the relationship between reported racism and health and wellbeing for children and young people. Social Science and Medicine. 2013; 95:115-27. doi: 10.1016/j.socscimed.2012.11.031 PMID: 23312306

15. Gee GC, Ro A, Shriff-Marco S, Chae D. Racial Discrimination and Health Among Asian Americans: Evidence, Assessment, and Directions for Future Research. Epidemiologic Reviews. 2009;(ePub ahead of print):1-22.

16. Krieger N, Rowley D, Hermann AA, Avery B, Phillips MT. Racism, sexism and social class: implications for studies of health, disease, and well-being. Am J Prev Med. 1993; 9(6):82-122. PMID: 8123288

17. Williams DR, Lavizzo-Mourey $\mathrm{R}$, Warren $\mathrm{RC}$. The concept of race and health status in America. Public Health Rep. 1994; 109(1):26-41. PMID: 8303011

18. Williams DR, Williams-Morris R. Racism and mental health: the African American experience. EthnHealth. 2000; 5(3-4):243-68.

19. Brondolo E, Rieppi R, Kelly KP, Gerin W. Perceived racism and blood pressure: a review of the literature and conceptual and methodological critique. AnnBehavMed. 2003; 25(1):55-65.

20. Williams DR, Neighbors HW, Jackson JS. Racial/Ethnic discrimination and health: findings from community studies. Am J Public Health. 2003; 93(2):200-8. PMID: 12554570

21. Wyatt SB, William DR, Calvin R, Henderson FC, Walker ER, Winters K. Racism and Cardiovascular Disease in African Americans. Am J Med Sci. 2003; 325(6):315-31. PMID: 12811228

22. Williams DR, Mohammed SA. Discrimination and racial disparities in health: evidence and needed research. J Behav Med. 2009; 32(1):20-47. doi: 10.1007/s10865-008-9185-0 PMID: 19030981

23. Schmitt MT, Branscombe NR, Postmes T, Garcia A. The Consequences of Perceived Discrimination for Psychological Well-Being: A Meta-Analytic Review. Psychological Bulletin. 2014; 140(4):921-48. doi: 10.1037/a0035754 PMID: 24547896

24. Goto JB, Couto PFM, Bastos JL. Systematic review of epidemiological studies on interpersonal discrimination and mental health. Cadernos De Saude Publica. 2013; 29(3):445-59. PMID: 23532281

25. Conklin HD. Perceived Racism and Mental Health: A Meta-Analytic Review: Brigham Young University; 2011.

26. Sanders-Phillips K. Racial Discrimination: A Continuum of Violence Exposure for Children of Color. Clin Child Fam Psychol Rev. 2009; 12(2):174-95. doi: 10.1007/s10567-009-0053-4 PMID: 19466544

27. Pachter LM, Garcia Coll C. Racism and Child Health: A Review of the Literature and Future Directions. J Dev Behav Pediatr. 2009; 30(3):255-63. doi: 10.1097/DBP.0b013e3181a7ed5a PMID: 19525720

28. Lee DL, Ahn S. Racial Discrimination and Asian Mental Health: A Meta-Analysis. The Counseling Psychologist. 2011; 39(3):463-89.

29. Lee DL, Ahn S. Discrimination Against Latina/os: A Meta-Analysis of Individual-Level Resources and Outcomes. The Counseling Psychologist. 2012; 40(1):28-65.

30. Lee DL, Ahn S. The relation of racial identity, ethnic identity, and racial socialization to discriminationdistress: A meta-analysis of Black Americans. Journal of Counseling Psychology. 2013; 60(1):1-14 doi: 10.1037/a0031275 PMID: 23356464

31. Pieterse AL, Todd NR, Neville HA, Carter RT. Perceived Racism and Mental Health Among Black American Adults: A Meta-Analytic Review. Journal of Counseling Psychology. 2012; 59(1):1-9. doi: 10.1037/a0026208 PMID: 22059427

32. Lewis TT, Williams DR, Clark CR. Self-Reported Experiences of Discrimination and Cardiovascular Disease. Current Cardiovascular Risk Reports. 2014; 8:365. PMID: 24729825

33. Cuffee YL, Hargraves JL, Allison J. Exploring the association between reported discrimination and hypertension among African Americans: a systematic review. Ethnicity \& Disease. 2012; 22(4):42231. PMID: 23140072

34. Dolezsar CM, McGrath JJ, Herzig AJM, Miller SB. Perceived Racial Discrimination and Hypertension: A Comprehensive Systematic Review. Health Psychology. 2014; 33(1):20-34. doi: 10.1037/ a0033718 PMID: 24417692

35. Brondolo E., Love E. E., Pencille M., Schoenthaler A., \& Ogedegbe G. (2011). Racism and hypertension: a review of the empirical evidence and implications for clinical practice. American journal of hypertension, 24(5), 518-529. doi: 10.1038/ajh.2011.9 PMID: 21331054

36. Pavalko EK, Mossakowski KN, Hamilton VJ. Does perceived discrimination affect health? Longitudinal relationships between work discrimination and women's physical and emotional health. $J$ Health Soc Behav. 2003; 44(1):18-33. PMID: 12751308 
37. Gee G, Walsemann K. Does health predict the reporting of racial discrimination or do reports of discrimination predict health? Findings from the National Longitudinal Study of Youth. Soc Sci Med. 2009; 69(9):1676-84.

38. Lewis TT, Everson-Rose SA, Powell LH, Matthews KA, Brown C, Karzvolos K, et al. Chronic exposure to everyday discrimination and coronary artery calcification in African-American women: the SWAN Heart Study. PsychosomMed. 2006; 68(3):362-8.

39. Baron RM, Kenny DA. The moderator-mediator variable distinction in social psychological research: conceptual, strategic, and statistical considerations. J PersSoc Psychol. 1986; 51(6):1173-82.

40. Clark R, Anderson NB, Clark VR, Williams DR. Racism as a stressor for African Americans. A biopsychosocial model. Am Psychol. 1999; 54(10):805-16. PMID: 10540593

41. Williams DR, Mohammed SA. Racism and Health I: Pathways and Scientific Evidence American Behavioral Scientist. 2013; 57(8):1152-73.

42. English D, Lambert SF, lalongo NS. Longitudinal associations between experienced racial discrimination and depressive symptoms in African American adolescents. Developmental Psychology. 2014; 50(4):1190-6. doi: 10.1037/a0034703 PMID: 24188037

43. Gee GC, Ryan A, Laflamme DJ, Holt J. Self-Reported Discrimination and Mental Health Status Among African Descendants, Mexican Americans, and Other Latinos in the New Hampshire REACH 2010 Initiative: The Added Dimension of Immigration. Am J Public Health. 2006; 96(10):1821-8. PMID: 17008579

44. Mulia N, Zemore SE. Social Adversity, Stress, and Alcohol Problems: Are Racial/Ethnic Minorities and the Poor More Vulnerable? Journal of Studies on Alcohol \& Drugs. 2012; 73(4):570-80. PMID: 22630795

45. Moher D, Liberati A, Tetzlaff J, Altman DG. Preferred reporting items for systematic reviews and metaanalyses: the PRISMA statement. Annals of internal medicine. 2009; 151(4):264-9. PMID: 19622511

46. Paradies Y, Priest N, Ben J, Truong M, Gupta A, Pieterse A, et al. Racism as a determinant of health: A protocol for conducting a systematic review and meta-analysis. Systematic Reviews. 2013; 2(85).

47. Utsey SO. Development and validation of a short form of the Index of Race-Related Stress (IRRS)brief version. Measurement \& Evaluation in Counseling \& Development. 1999; 32(3):149-67.

48. Harrell SP. The Racism and Life Experience Scales (RaLES): Self-administration version. Unpublished Manuscript1997.

49. McNeilly MD, Anderson NB, Armstead CA, Clark R, Corbett M, Robinson EL, et al. The perceived racism scale: a multidimensional assessment of the experience of white racism among African Americans. Ethn Dis. 1996; 6(1-2):154-66. PMID: 8882844

50. Chakraborty A, King M, Leavey G, McKenzie K. Perceived racism, medication adherence, and hospital admission in African-Caribbean patients with psychosis in the United Kingdom. Social Psychiatry And Psychiatric Epidemiology. 2011; 46(9):915-23. doi: 10.1007/s00127-010-0261-8 PMID: 20607213

51. Clark R, Anderson NB. Efficacy of racism-specific coping styles as predictors of cardiovascular functioning. Ethn Dis. 2001; 11(2):286-95. PMID: 11456003

52. Clark VR, Hill OW Jr. Body mass and cardiovascular reactivity to racism in African American college students. Ethn Dis. 2009; 19(1):2-6. PMID: 19341155

53. McCracken MO. Endnote X7.1.2013.

54. Borenstein M, Hedges LV, Higgins JP, Rothstein HR: Comprehensive Meta-analysisVersion 2.2.057. Biostat: Englewood, NJ; 2010.

55. Bowman NA. Effect sizes and statistical methods for meta-analysis in higher education. Research in Higher Education. 2012; 53:475-382.

56. Practical meta-analysis effect size calculator [Internet]. 2015.

57. Cohen J, Cohen P, West SG, Aiken LS. Applied multiple regression/correlation analysis for the behavioral sciences. 3rd ed. Mahwah, MJ: Lawrence Earlbaum Associates; 2003.

58. Cooper HM. Synthesizing research: A guide for literature reviews. 3rd ed. Thousand Oaks, CA.: Sage; 1998.

59. Hedges L, Vevea J. Fixed- and random-effects models in meta-analysis. Psychological Methods. 1998; 3:486-504.

60. Fu R, Gartlehner G, Grant M, Shamliyan T, Sedrakyan A, Wilt T, et al. Conducting quantitative synthesis when comparing medical interventions: $A H R Q$ and the effective health care program. Journal of Clinical Epidemiology. 2011; 64:1187-97. doi: 10.1016/j.jclinepi.2010.08.010 PMID: 21477993

61. Higgins J, Green S, editors. Cochrane Handbook for Systematic Reviews of Interventions 5.1.0 [updated March 2011)2011. 
62. Helms JE, Henze KT, Sass TL, Mifsud VA. Treating Cronbach's Alpha reliability coefficients as data in counseling research. The Counseling Psychologist. 2006; 34(5):630-60.

63. Schnittker J, McLeod JD. The Social Psychology of Health Disparities. Annual Review of Sociology. 2005; 31:75-103.

64. Egger M, Smith GD, Schneider M, Minder C. Bias in meta-analysis detected by a simple, graphical test. British Medical Journal. 1997; 315 (629-634).

65. Quintana SM, Minami T. Guidelines for meta-analysis of counseling psychology research. Counseling Psychologist. 2006; 34:839-77.

66. Duval S, Tweedie R. Trim and fill: a simple funnel plot-based method of testing and adjusting for publication bias in meta-analysis. Biometrics. 2000; 56:455-63. PMID: 10877304

67. Duval S, Tweedie R. A nonparametric "trim and fill" method of accounting for publication bias in metaanalysis. J AmStat Assoc. 2000; 96:89-98.

68. Abbassi-Zoabi MJ. Discrimination, ethnic identity, and social support as predictors of self-efficacy in Arab American adolescents [Ph.D.]. Ann Arbor: Fordham University; 2012.

69. Abdulrahim S, James SA, Yamout R, Baker W. Discrimination and psychological distress: does Whiteness matter for Arab Americans? Social science \& medicine 2012; 75(12):2116-23. doi: 10. 1016/j.socscimed.2012.07.030 PMID: 22901668

70. Agaskar VR. Mediating and moderating factors in the Asian American's psychological distress: An analysis of National Latino and Asian American study (NLAAS) data [Ph.D.]. Ann Arbor: Oakland University; 2011.

71. Agudelo-Suarez AA, Ronda-Perez E, Gil-Gonzalez D, Vives-Cases C, Garcia AM, Ruiz-Frutos C, et al. The effect of perceived discrimination on the health of immigrant workers in Spain. BMC public health. 2011; 11:652. doi: 10.1186/1471-2458-11-652 PMID: 21849020

72. Ahmed SR, Kia-Keating $\mathrm{M}$, Tsai KH. A structural model of racial discrimination, acculturative stress, and cultural resources among Arab American adolescents. Am J Community Psychol. 2011; 48(34):181-92. doi: 10.1007/s10464-011-9424-3 PMID: 21287262

73. Alamilla SG, Kim BSK, Lam NA. Acculturation, enculturation, perceived racism, minority status stressors, and psychological symptomatology among Latino/as. Hispanic Journal of Behavioral Sciences. 2010; 32(1):55-76.

74. Albert MA, Cozier Y, Ridker PM, Palmer JR, Glynn RJ, Rose L, et al. Perceptions of race/ethnic discrimination in relation to mortality among Black women: results from the Black Women's Health Study. Archives of internal medicine. 2010; 170(10):896-904. doi: 10.1001/archinternmed.2010.116 PMID: 20498418

75. Anderson ME. Perceived discrimination and worldview: The relationship to health status among patients with diabetes [Ph.D.]. Ann Arbor: The Ohio State University; 2007.

76. Appel RE. Perceived ethnic discrimination and its association to ecological momentary assessment of daily interactions [Ph.D.]. Ann Arbor: St. John's University (New York); 2003.

77. Armenta BE, Hunt JS. Responding to Societal Devaluation: Effects of Perceived Personal and Group Discrimination on the Ethnic Group Identification and Personal Self-Esteem of Latino/Latina Adolescents. Group Processes \& Intergroup Relations. 2009; 12(1):23-39.

78. Asamen JK. The effects of perceived prejudice, alientation, and acculturation on the self concept of Japanese and Chinese Americanns. Ann Arbor: University of California, Los Angeles; 1983.

79. Ashburn-Nardo L, Monteith MJ, Arthur SA, Bain A. Race and the Psychological Health of African Americans. Group Processes Intergroup Relations. 2007; 10(4):471-91.

80. Ayalon L, Gum AM. The relationships between major lifetime discrimination, everyday discrimination, and mental health in three racial and ethnic groups of older adults. Aging \& Mental Health. 2011; 15 (5):587-94. doi: 10.1080/13607863.2010.543664 PMID: 21815851

81. Bailey T-KM. Construct validation of the Internalized Racial Oppression Scale [Ph.D.]. Ann Arbor: Georgia State University; 2008.

82. Banks $\mathrm{KH}$, Kohn-Wood $\mathrm{L}$. The influence of racial identity profiles on the relationship between racial discrimination and depressive symptoms. Journal of Black Psychology. 2007; 33(3):331-54.

83. Barksdale DJ, Farrug ER, Harkness K. Racial discrimination and blood pressure: perceptions, emotions, and behaviors of black American adults. Issues MentHealth Nurs. 2009; 30(2):104-11.

84. Barnes PW, Lightsey OR. Perceived Racist Discrimination, Coping, Stress, and Life Satisfaction. Journal of Multicultural Counseling and Development. 2005; 33(1):48-61.

85. Barrett ME, Joe GW, Simpson DD. Acculturation Influences on Inhalant Use. Hispanic Journal of Behavioral Sciences. 1991; 13(3):296. 
86. Barry DT, Grilo CM. Cultural, Self-Esteem, and Demographic Correlates of Perception of Personal and Group Discrimination Among East Asian Immigrants. Am J Orthopsychiatry. 2003; 73(2):223-9. PMID: 12769243

87. Basurto Jr R. The relationship of ethnic identity to self-esteem and stress as a function of perceived discrimination among Mexican-Americans [Ph.D.]. Ann Arbor: California School of Professional Psychology—Los Angeles; 1996.

88. Becares $L$, Nazroo J, Stafford M. The buffering effects of ethnic density on experienced racism and health. Health Place. 2009; 5(3):670-8.

89. Behnke AO, Plunkett SW, Sands T, Bamaca-Colbert MY. The Relationship Between Latino Adolescents' Perceptions of Discrimination, Neighborhood Risk, and Parenting on Self-Esteem and Depressive Symptoms. Journal of Cross Cultural Psychology. 2011; 42(7):1179-97.

90. Benjamins MR. Race/Ethnic discrimination and preventive service utilization in a sample of whites, blacks, mexicans, and puerto ricans. Medical Care. 2012; 50(10):870-6. doi: 10.1097/MLR. Ob013e31825a8c63 PMID: 22643195

91. Benjamins MR, Whitman S. Relationships between discrimination in health care and health care outcomes among four race/ethnic groups. Journal of Behavioral Medicine. 2014; 37(3):402-13. doi: 10. 1007/s10865-013-9496-7 PMID: 23456249

92. Berg AO, Melle I, Rossberg JI, Romm KL, Larsson S, Lagerberg TV, et al. Perceived discrimination is associated with severity of positive and depression/anxiety symptoms in immigrants with psychosis: a cross-sectional study. BMC Psychiatry. 2011; 11(1):77-85.

93. Berkel C, Knight GP, Zeiders KH, Tein JY, Roosa MW, Gonzales NA, et al. Discrimination and Adjustment for Mexican American Adolescents: A Prospective Examination of the Benefits of Culturally Related Values. Journal of Research on Adolescence. 2010; 20(4):893-915. PMID: 21359093

94. Best JL. An integrative analysis of racism and quality of life: A comparison of multidimensional moderators in an ethnically diverse sample [Ph.D.]. Ann Arbor: University of Southern California; 2005.

95. Bird ST, Bogart LM, Delhanty DL. Health-related correlates of perceived discrimination in HIV care. AIDS Patient Care STDS. 2004; 18:19-26. PMID: 15006191

96. Blankenau J, Boye-Beaman J, Mueller K. Health-care utilization and the status of Latinos in rural meat-processing communities. Great Plains Research. 2000; 10(2):275-94.

97. Bodkin-Andrews GH, Seaton M, Nelson GF, Craven RG, Yeung AS. Questioning the general selfesteem vaccine: General self-esteem, racial discrimination, and standardised achieve- ment across Indigenous and non-Indigenous students. Australian Journal of Guidance and Counselling. 2010; 20 (1):1-21.

98. Bogart LM, Wagner GJ, Galvan FH, Landrine H, Klein DJ, Sticklor LA. Perceived discrimination and mental health symptoms among Black men with HIV. Cultural diversity \& ethnic minority psychology. 2011; 17(3):295-302. doi: 10.1037/a0024056 PMID: 21787061

99. Borges G, Azrael D, Almeida J, Johnson RM, Molnar BE, Hemenway D, et al. Immigration, suicidal ideation and deliberate self-injury in the Boston youth survey 2006. Suicide \& life-threatening behavior. 2011; 41(2):193-202. doi: 10.1111/j.1943-278X.2010.00016.x PMID: 21470295

100. Borrell LN, Jacobs DR, Williams DR, Pletcher MJ, Houston TK, Kiefe Cl. Self-reported Racial Discrimination and Substance Use in the Coronary Artery Risk Development in Adults Study. Am J Epidemiol. 2007; 166(9):1068-79. PMID: 17698506

101. Borrell LN, Kiefe Cl, Williams DR, Diez-Roux AV, Gordon-Larsen P. Self-reported health, perceived racial discrimination, and skin color in African Americans in the CARDIA study. SocSciMed. 2006; 63 (6):1415-27.

102. Bowen-Reid TL, Harrell JP. Racist Experiences and Health Outcomes: An Examination of Spirituality as a Buffer. Journal of Black Psychology. 2002; 28 (1):18-36

103. Bowman T. An exploration of the relationship between racism-related stress and emotional well-being for African American college students [Ph.D.]. Ann Arbor: Oklahoma State University; 2008.

104. Branscombe NR, Schmitt MT, Harvey RD. Perceiving Pervasive Discrimination Among African Americans: Implications for Group Identification and Well-Being. Journal of Personality \& Social Psychology. 1999; 77(1):135-49.

105. Brody GH, Chen Y-F, Murry VM, Ge X, Simons RL, Gibbons FX, et al. Perceived Discrimination and the Adjustment of African American Youths: A Five-Year Longitudinal Analysis with Contextual Moderation Effects. Child Development. 2006; 77(5):1170-89. PMID: 16999791

106. Broman CL. Race-related factors and life satisfaction among African Americans. Journal of Black Psychology. 1997; 23(1):36-49. 
107. Brondolo E, Hausmann LR, Jhalani J, Pencille M, Atencio-Bacayon J, Kumar A, et al. Dimensions of Perceived Racism and Self-Reported Health: Examination of Racial/Ethnic Differences and Potential Mediators. Annals of Behavioural medicine. 2011 42(1):14-28.

108. Broudy R, Brondolo E, Coakley V, Brady N, Cassells A, Tobin JN, et al. Perceived Ethnic Discrimination in Relation to Daily Moods and Negative Social Interactions. J BehavMed. 2007; 30(1):31-43.

109. Brown JF. The relationships between racial and gender discrimination, childhood socialization messages, and the self-esteems of professional Black women. Ann Arbor: University of Maryland College Park; 1991.

110. Brown TN, Sellers SL, Gomez JP. The relationship between internalization and self-esteem among black adults. Sociological Focus. 2002; 35(1):55-71.

111. Buchanan NT. Examining the impact of racial harassment on sexually harassed African American women [Ph.D.]. Ann Arbor: University of Illinois at Urbana-Champaign; 2002.

112. Buchanan NT, Fitzgerald LF. Effects of racial and sexual harassment on work and the psychological well-being of African American women. J Occup Health Psychol. 2008; 13(2):137-51. doi: 10.1037/ 1076-8998.13.2.137 PMID: 18393583

113. Burgess DJ, Grill J, Noorbaloochi S, Griffin JM, Ricards J, van Ryn M, et al. The Effect of Perceived Racial Discrimination on Bodily Pain among Older African American Men. Pain Medicine. 2009; 10 (8):1341-52. doi: 10.1111/j.1526-4637.2009.00742.x PMID: 20021596

114. Burrow AL, Ong AD. Racial Identity as a Moderator of Daily Exposure and Reactivity to Racial Discrimination. Self and Identity. 2010; 9(4):383-402.

115. Byrd DR. Race/Ethnicity and self-reported levels of discrimination and psychological distress, California, 2005. Preventing chronic disease. 2012; 9:E156. doi: 10.5888/pcd9.120042 PMID: 23078667

116. Cakir SG, Yerin Guneri O. Exploring the factors contributing to empowerment of Turkish migrant women in the UK. International journal of psychology: Journal international de psychologie. 2011; 46 (3):223-33. doi: 10.1080/00207594.2010.532800 PMID: 22044235

117. Camacho-Gonsalves T. Depressive symptomatology among Dominicans: Links to acculturative and economic stressors, skin tone, and perceived discrimination [Ph.D.]. Ann Arbor: University of New Hampshire; 2002.

118. Cardarelli R, Cardarelli KM, Fulda KG, Espinoza A, Cage C, Vishwanatha J, et al. Self-reported racial discrimination, response to unfair treatment, and coronary calcification in asymptomatic adults- the North Texas Healthy Heart study. BMC public health. 2010; 10:285. doi: 10.1186/1471-2458-10-285 PMID: 20507602

119. Cassidy C, O'Conner RC, Howe C, Warden D. Perceived Discrimination and Psychological Distress: The Role of Personal and Ethnic Self-Esteem. Journal of Counseling Psychology. 2004; 51(3):32939.

120. Cassidy $C, O^{\prime}$ Connor RC, Howe $C$, Warden D. Perceived discrimination among ethnic minority young people: The role of psychological variables. Journal of Applied Social Psychology. 2005; 35(6):124665.

121. Chae D, Lincoln K, Adler N, Syme S. Do experiences of racial discrimination predict cardiovascular disease among African American men? The moderating role of internalized negative racial group attitudes. Soc Sci Med. 2010; 71(6):1182-8. doi: 10.1016/j.socscimed.2010.05.045 PMID: 20659782

122. Chae $\mathrm{DH}$, Lincoln KD, Jackson JS. Discrimination, attribution, and racial group identification: Implications for psychological distress among Black Americans in the National Survey of American Life (2001-2003). American Journal of Orthopsychiatry. 2011; 81(4):498-506. doi: 10.1111/j.1939-0025. 2011.01122.x PMID: 21977935

123. Chakraborty AT, McKenzie KJ, Hajat S, Stansfeld SA. Racism, mental illness and social support in the UK. Social Psychiatry \& Psychiatric Epidemiology. 2010; 45(12):1115-24. doi: 10.1007/s00127009-0156-8 PMID: 19847373

124. Chambers EC, Tull ES, Fraser HS, Mutunhu NR, Sobers N, Niles E. The relationship of internalized racism to body fat distribution and insulin resistance among African adolescent youth. J NatlMed Assoc. 2004; 96(12):1594-8.

125. Chen H-J, Mallinckrodt B, Mobley M. Attachment Patters of East Asian International Students and Sources of Perceived Social Supoort as Moderators of the Impact of US Racism and Cultural Distress. Asian Journal of Counseling. 2002; 9(1 \& 2):27-48.

126. Cho-Chang $Y-Y$. The moderating role of religious coping in the relationship between perceived racial discrimination and depression in Korean American Christians [Ph.D.]. Ann Arbor: Boston University; 2013.

127. Choi K-H, Paul J, Ayala G, Boylan R, Gregorich SE. Experiences of Discrimination and Their Impact on the Mental Health Among African American, Asian and Pacific Islander, and Latino Men Who Have 
Sex With Men. American Journal of Public Health. 2013; 103(5):868-74. doi: 10.2105/AJPH.2012. 301052 PMID: 23488483

128. Chrobot-Mason D, Ragins BR, Linnehan F. Second hand smoke: ambient racial harassment at work. Journal of Managerial Psychology. 2013; 28(5):470-91.

129. Cislo AM. Psychological distress among Cuban and Colombian immigrants in Miami: Considering the roles of acculturation and ethnic discrimination. Tallahassee: Florida State University; 2008.

130. Clark R. Perceptions of interethnic group racism predict increased vascular reactivity to a laboratory challenge in college women. Annals of Behavioral Medicine. 2000; 22(3):214-22. PMID: 11126466

131. Clark R. Self-reported racism and social support predict blood pressure reactivity in blacks. Annals of Behavioral Medicine. 2003; 25(2):127-36. PMID: 12704015

132. Clark R, Coleman AP, Novak JD. Brief report: Initial psychometric properties of the everyday discrimination scale in black adolescents. Journal of Adolescence. 2004; 27(3):363-8. PMID: 15159094

133. Clark R, Gochett P. Interactive effects of perceived racism and coping responses predict a schoolbased assessment of blood pressure in black youth. Annals of behavioral medicine: a publication of the Society of Behavioral Medicine. 2006; 32(1):1-9.

134. Clement R, Noels KA, Deneault $B$. Interethnic contact, identity and psychological adjustment: The mediating and moderating roles of communication. Journal of Social Issues. 2001; 57(3):559-77.

135. Cogburn CD. Racial Cognition and School-Based Racial Discrimination: The Role of Racial Identity, Racial Identity Exploration and Critical Race Consciousness in Adaptive Academic and Psychological Functioning among African American Adolescents [Ph.D.]. Ann Arbor: University of Michigan; 2010.

136. Cogburn CD, Chavous TM, Griffin TM. School-based racial and gender discrimination among African American adolescents: Exploring gender variation in frequency and implications for adjustment. Race and Social Problems. 2011; 3(1): 25-37. PMID: 22837794

137. Coker TR, Elliott MN, Kanouse DE, Grunbaum JA, Schwebel DC, Gilliland MJ, et al. Perceived racial/ ethnic discrimination among fifth-grade students and its association with mental health. American Journal of Public Health. 2009; 99(5):878-84. doi: 10.2105/AJPH.2008.144329 PMID: 19299673

138. Combs DR, Penn DL, Cassisi J, Michael C, Wood T, Wanner J, et al. Perceived racism as a predictor of paranoia among African Americans. Journal of Black Psychology. 2006; 32(1):87-104.

139. Contrada RJ, Ashmore RD, Gary ML, Coups E, Egeth JD, Sewell A, et al. Measures of ethnicityrelated stress: Psychometric properties, ethnic group differences, and associations with well-being. Journal of Applied Social Psychology. 2001; 31(9):1775-820.

140. Cooke DY. Racial discrimination and well-being among African American university students [Ph.D.]. Ann Arbor: University of Michigan; 2002.

141. Cooper DC, Mills PJ, Bardwell WA, Ziegler MG, Dimsdale JE. The Effects of Ethnic Discrimination and Socioeconomic Status on Endothelin-1 Among Blacks and Whites. Am J Hypertens. 2009; 22 (7):698-704. doi: 10.1038/ajh.2009.72 PMID: 19390511

142. Copeland-Linder N, Lambert SF, Chen YF, lalongo NS. Contextual Stress and Health Risk Behaviors Among African American Adolescents. Journal of Youth and Adolescence. 2011; 40(2):158-73. doi: 10.1007/s10964-010-9520-y PMID: 20213481

143. Crengle S, Robinson E, Ameratunga S, Clark T, Raphael D. Ethnic discrimination prevalence and associations with health outcomes: data from a nationally representative cross-sectional survey of secondary school students in New Zealand. BMC public health. 2012; 12:45. doi: 10.1186/14712458-12-45 PMID: 22257643

144. Cronin TJ, Levin S, Branscombe NR, van Laar C, Tropp LR. Ethnic identification in response to perceived discrimination protects well-being and promotes activism: A longitudinal study of Latino college students. Group Processes \& Intergroup Relations. 2012; 15(3):393-407.

145. Crouter AC, Davis KD, Updegraff KA, Delgado M, Fortner M. Mexican American Fathers' occupational conditions: Links to family members' psychological adjustment. Journal of Marriage and the Family. 2006; 68(4):843-58. PMID: 18414596

146. Currie CL, Wild TC, Schopflocher DP, Laing L, Veugelers $P$, Parlee B. Racial Discrimination, Post Traumatic Stress, and Gambling Problems among Urban Aboriginal Adults in Canada. Journal of gambling studies / co-sponsored by the National Council on Problem Gambling and Institute for the Study of Gambling and Commercial Gaming. 2013; 29(3):393-415.

147. Dailey $A B$. The influence of neighborhood-level socioeconomic status and perceived racial discrimination on non-adherence to mammography screening guidelines [Ph.D.]. Ann Arbor: Yale University; 2006.

148. Dang TA. Effects of perceived discrimination on Asian Americans: A daily process study [Ph.D.]. Ann Arbor: Washington State University; 2012. 
149. Dawson BA, Panchanadeswaran S. Discrimination and Acculturative Stress among First-Generation Dominicans. Hispanic Journal of Behavioral Sciences. 2010; 32(2):216-31.

150. de Castro AB, Gee GC, Takeuchi DT. Workplace Discrimination and Health Among Filipinos in the United States. Am J Public Health. 2008; 98(3):520-6. doi: 10.2105/AJPH.2007.110163 PMID: 18235069

151. De Maio FG, Kemp E. The deterioration of health status among immigrants to Canada. Global Public Health. 2010; 5(5):462-78. doi: 10.1080/17441690902942480 PMID: 19513909

152. Deblaere C. Perceived discrimination experiences and mental health of Asian American women. Dissertation Abstracts International: Section B Sciences and Engineering 2009; 73(1):612.

153. Delgado MY, Updegraff KA, Roosa MW, Umaña-Taylor AJ. Discrimination and Mexican-Origin Adolescents' Adjustment: The Moderating Roles of Adolescents', Mothers', and Fathers' Cultural Orientations and Values. Journal of Youth and Adolescence. 2011; 40(2):125-39. doi: 10.1007/s10964-0099467-z PMID: 19882238

154. Diaz RM, Ayala G, Bein E, Henne J, Marin BV. The impact of Homophobia, Poverty, and Racism on the Mental Health of Gay and Bisexual Latino Men; Findings from 3 US Cities. Am J Public Health. 2001; 91(6):927-32. PMID: 11392936

155. Dixon B, Rifas-Shiman SL, James-Todd T, Ertel K, Krieger N, Kleinman KP, et al. Maternal experiences of racial discrimination and child weight status in the first 3 years of life. Journal of Developmental Origins of Health and Disease. 2012; 3(6):433-41. doi: 10.1017/S2040174412000384 PMID: 25084296

156. Dominguez TP, Dunkel-Schetter C, Glynn LM, Hobel C, Sandman CA. Racial differences in birth outcomes: The role of general, pregnancy, and racism stress. Health Psychology. 2008; 27(2):194-203. doi: 10.1037/0278-6133.27.2.194 PMID: 18377138

157. Donovan RA, Huynh Q-L, Park IJK, Kim SY, Lee RM, Robertson E. Relationships Among Identity, Perceived Discrimination, and Depressive Symptoms in Eight Ethnic-Generational Groups. Journal of Clinical Psychology. 2013; 69(4):397-414. doi: 10.1002/jclp.21936 PMID: 23124607

158. Downie MS. The impact of racism and sexism on the well-being of African-American female college students. Dissertation Abstracts International: Section B Sciences and Engineering. 1998; 59(5B):2483.

159. DuBois DL, Burk-Braxton C, Swenson LP, Tevendale HD, Hardesty JL. Race and Gender Influences on Adjustment in Early Adolescence: Investigation of an Integrative Model. Child Development. 2002; 73(5):1573-92. PMID: 12361320

160. Enchautegui de Jesus N. Relationships between normative and race/ethnic-related job stressors and marital and individual well-being among Black and Latino/a workers [Ph.D.]. Ann Arbor: New York University; 2001.

161. Epel OB, Kaplan G, Moran M. Perceived discrimination and health-related quality of life among Arabs and Jews in Israel: A population-based survey. BMC Public Health. 2010; 10:282-91. doi: 10.1186/ 1471-2458-10-282 PMID: 20507564

162. Everage NJ, Gjelsvik A, McGarvey ST, Linkletter CD, Loucks EB. Inverse associations between perceived racism and coronary artery calcification. Annals of Epidemiology. 2012; 22(3):183-90. doi: 10. 1016/j.annepidem.2012.01.005 PMID: 22365645

163. Finch BK, Vega WA. Acculturation Stress, Social Support, and Self-Rated Health Among Latinos in California. J Immigr Health. 2003; 5(3):109-17. PMID: 14512765

164. Fischer AR, Shaw CM. African Americans' mental health and perceptions of racist discrimination: The moderating effects of racial socialization experiences and self-esteem. Journal of Counseling Psychology. 1999; 46(3):395-407.

165. Flores E, Tschann JM, Dimas JM, Bachen EA, Pasch LA, de Groat CL. Perceived discrimination, perceived stress, and mental and physical health among Mexican-origin adults. Hispanic Journal of Behavioral Sciences. 2008; 30(4):401-24.

166. Flores E, Tschann JM, Dimas JM, Pasch LA, de Groat CL. Perceived Racial/Ethnic Discrimination, Posttraumatic Stress Symptoms, and Health Risk Behaviors among Mexican American Adolescents. Journal of Counseling Psychology. 2010; 57(3):264-73. doi: 10.1037/a0020026 PMID: 21133578

167. Ford KR, Hurd NM, Jagers RJ, Sellers RM. Caregiver Experiences of Discrimination and African American Adolescents' Psychological Health Over Time. Child Development. 2013; 84(2):485-99. doi: 10.1111/j.1467-8624.2012.01864.x PMID: 23020184

168. Freedenthal S, Stiffman AR. Suicidal Behavior in Urban American Indian Adolescents: A Comparison with Reservation Youth in a Southwestern State. Suicide and Life ThreateninG Behavior. 2004; 34 (2):160-71. PMID: 15191272 
169. French SE, Tran N, Chávez NR. Exploring the effect of in-group and out-group race-related stressors on anxiety among Asian Pacific Islander American students. Journal of Applied Social Psychology. 2013; 43(Suppl 2):E339-E50.

170. Galvan N. Experiences of ethnic-related discrimination and their influence on the health of Mexican immigrants [Ph.D.]. Ann Arbor: University of Illinois at Urbana-Champaign; 2010.

171. Gee GC, Ro A, Gavin A, Takeuchi DT. Disentangling the Effects of Racial and Weight Discrimination on Body Mass Index and Obesity Among Asian Americans. Am J Public Health. 2008; 98(3):493500. doi: 10.2105/AJPH.2007.114025 PMID: 18235065

172. Gerrard M, Stock ML, Roberts ME, Gibbons FX, O'Hara RE, Weng CY, et al. Coping With Racial Discrimination: The Role of Substance Use. Psychology of Addictive Behaviors. 2012; 26(3):550-60. doi: 10.1037/a0027711 PMID: 22545585

173. Giamo LS, Schmitt MT, Outten HR. Perceived discrimination, group identification, and life satisfaction among multiracial people: a test of the rejection-identification model. Cultural diversity \& ethnic minority psychology. 2012; 18(4):319-28. doi: 10.1037/a0029729 PMID: 23066642

174. Gibbons FX, Etcheverry PE, Stock ML, Gerrard M, Weng C-Y, Kiviniemi M, et al. Exploring the link between racial discrimination and substance use: what mediates? What buffers? Journal of personality and social psychology. 2010; 99(5):785-801. doi: 10.1037/a0019880 PMID: 20677890

175. Gibbons FX, Gerrard M, Cleveland MJ, Wills TA, Brody G. Perceived discrimination and substance use in African American parents and their children: a panel study. Journal of personality and social psychology. 2004; 86(4):517-29. PMID: 15053703

176. Gibbons FX, Yeh HC, Gerrard M, Cleveland MJ, Cutrona C, Simons RL, et al. Early experience with racial discrimination and conduct disorder as predictors of subsequent drug use: A critical period hypothesis. Drug and Alcohol Dependence. 2007; 88(Suppl 1):S27-S37. PMID: 17275213

177. Giurgescu C, Zenk SN, Dancy BL, Park CG, Dieber W, Block R. Relationships among neighborhood environment, racial discrimination, psychological distress, and preterm birth in African American women. Journal of obstetric, gynecologic, and neonatal nursing: JOGNN / NAACOG. 2012; 41(6): E51-61.

178. Gonzales KL. Perceived medical discrimination in American Indian women: Effect on health care decisions, cancer screening, diabetes services and diabetes management [Ph.D.]. Ann Arbor: Oregon State University; 2010.

179. Green NL. Stress, self-esteem and racism as factors associated with low birth weight and preterm delivery in African-American childbearing women [PH.D.]. San Francisco: University of California; 1991.

180. Greene ML, Way N, Pahl K. Trajectories of perceived adult and peer discrimination among Black, Latino, and Asian American adolescents: Patterns and psychological correlates. Dev Psychol. 2006; 42(2):218-38. PMID: 16569162

181. Grekin ER. Perceived Racism and Alcohol Consequences Among African American and Caucasian College Students. Psychology of Addictive Behaviors. 2012; 26(4):924-30. doi: 10.1037/a0029593 PMID: 23046273

182. Gutierres SE, Saenz DS, Green BL. Job stress and health outcomes among White and Hispanic employees: A test of the person-environment fit model. In: Keita GP, Hurrell JJ Jr, editors. Job stress in a changing workforce: Investigating gender, diversity, and family issues. Washington, DC: American Psychological Association; 1994. p. 107-25.

183. Hammond WP. Psychosocial Correlates of Medical Mistrust Among African American Men. Am J Community Psychol. 2010; 45(1-2):87-106. doi: 10.1007/s10464-009-9280-6 PMID: 20077134

184. Han M, Lee M. Risk and Protective Factors Contributing to Depressive Symptoms in Vietnamese American College Students. Journal of College Student Development. 2011; 52(2):154-66.

185. Hansen KL, Sørlie T. Ethnic discrimination and psychological distress: A study of Sami and non-Sami populations in Norway. Transcultural Psychiatry. 2012; 49(1):26-50. doi: 10.1177/ 1363461511433944 PMID: 22334242

186. Harris-Britt A, Valrie CR, Kurtz-Costes B, Rowley SJ. Perceived racial discrimination and self-esteem in African American youth: Racial socialization as a protective factor. Journal of Research on Adolescents. 2007; 17(4):669-82.

187. Hausmann LRM, Jeong K, Bost JE, Kressin NR, Ibrahim SA. Perceived Racial Discrimination in Health Care: A Comparison of Veterans Affairs and Other Patients American Journal of Public Health. 2009; 99(Suppl 3):S718-S24. doi: 10.2105/AJPH.2008.150730 PMID: 19443818

188. Heim D, Hunter SC, Jones R. Perceived Discrimination, Identification, Social Capital, and Well-Being: Relationships With Physical Health and Psychological Distress in a UK Minority Ethnic Community Sample. Journal of Cross-Cultural Psychology. 2011; 42(7):1145-64. 
189. Hickman NJ. Does cigarette smoking mediate the relationship between racial discrimination and depression for African Americans participating in the National Survey of American Life? [Ph.D.]. Ann Arbor: University of California, San Diego and San Diego State University; 2008.

190. Hightow-Weidman LB, Phillips Gn, Jones KC, Outlaw AY, Fields SD, Smith JC, et al. Racial and sexual identity-related maltreatment among minority YMSM: prevalence, perceptions, and the association with emotional distress. AIDS patient care and STDs. 2011; 25 (Suppl 1):S39-45. doi: 10.1089/ apc.2011.9877 PMID: 21688988

191. Hill LK, Kobayashi I, Hughes JW. Perceived racism and ambulatory blood pressure in African American college students. Journal of Black Psychology. 2007; 33(4):404-21.

192. Hirschel MJ. The relationship between discrimination, acculturation, and general psychological functioning in international students [Ph.D.]. Ann Arbor: The University of Mississippi; 2011.

193. Hocoy D. Apartheid, racism, and Black mental health in South Africa, and the role of racial identity [Ph.D.]. Ann Arbor: Queen's University at Kingston (Canada); 1997.

194. Howarter AD, Bennett KK. Perceived discrimination and health-related quality of life: testing the Reserve Capacity Model in Hispanic Americans. The Journal of social psychology. 2013; 153(1):6279. PMID: 23421006

195. Huynh Q-L, Devos T, Dunbar CM. The psychological costs of painless but recurring experiences of racial discrimination. Cultural diversity \& ethnic minority psychology. 2012; 18(1):26-34. doi: 10.1037/ a0026601 PMID: 22250896

196. Huynh VW. Ethnic Microaggressions and the Health and Well-being of Latino and Asian American Adolescents [Ph.D.]. Ann Arbor: University of California, Los Angeles; 2011.

197. Huynh VW, Fuligni AJ. Discrimination Hurts: The Academic, Psychological, and Physical Well-Being of Adolescents. Journal of Research on Adolescence. 2010; 20(4):916-41.

198. Jackson FM, Hogue CR, Phillips MT. The development of a race and gender-specific stress measure for African-American women: Jackson, Hogue, Phillips contextualized stress measure. Ethn Dis. 2005; 15(4):594-600. PMID: 16259481

199. Jackson JS, Brown TN, Williams DR, Torres M, Sellers SL, Brown K. Racism and the physical and mental health status of African Americans: a thirteen year national panel study. EthnDis. 1996; 6(12):132-47.

200. Jackson KF, Yoo HC, Guevarra R Jnr, Harrington BA. Role of Identity Integration on the Relationship Between Perceived Racial Discrimination and Psychological Adjustment of Multiracial People. Journal of Counseling Psychology. 2012; 59(2):240-50. doi: 10.1037/a0027639 PMID: 22506908

201. Jagusztyn NE. Internalized Racism as a Moderator for Stereotype Threat: Effects on Self-Handicapping, Performance, and Cardiovascular Responses in Black Individuals [Master of Arts]: University of South Florida; 2007.

202. Jamieson LM, Paradies YC, Gunthorpe W, Cairney SJ, Sayers SM. Oral health and social and emotional well-being in a birth cohort of Aboriginal Australian young adults. BMC public health. 2011; 11:656. doi: 10.1186/1471-2458-11-656 PMID: 21851641

203. Jasinskaja-Lahti I, Liebkind K. Perceived discrimination and psychological adjustment among Russian-speaking immigrant adolescents in Finland. International Journal of Psychology. 2001; 36 (3):174-85.

204. Jasinskaja-Lahti I, Liebkind K, Perhoniemi R. Perceived ethnic discrimination at work and well-being of immigrants in Finland: The moderating role of employment status and work-specific group-level control beliefs. International Journal of Intercultural Relations. 2007; 31(2):223-42.

205. Jasinskaja-Lahti I, Liebkind K, Solheim E. To Identify or Not To Identify? National Disidentification as an Alternative Reaction to Perceived Ethnic Discrimination. Applied Psychology: An International Review. 2009; 58(1):105-28.

206. Jasperse $M$, Ward $C$, Jose $P E$. Identity, perceived religious discrimination, and psychological wellbeing in Muslim immigrant women. Applied Psychology. 2012; 61(2):250-71.

207. Jenifer ES. Anger, racism, caste discrimination and posttraumatic stress disorder in African-American and Indian college students. Washington, DC: Howard University; 2009.

208. Jones HL, Cross WE Jr., DeFour DC. Race-related stress, racial identity attitudes and mental health among black women. Journal of Black Psychology. 2007; 33(2):208-31.

209. Jones MD. Longitudinal and reciprocal effects of ethnic identity and experiences of discrimination on psychosocial adjustment of Navajo (Dine) adolescents [Ph.D.]. Ann Arbor: Utah State University; 2008.

210. Juang LP, Alvarez AA. Discrimination and Adjustment Among Chinese American Adolescents: Family Conflict and Family Cohesion as Vulnerability and Protective Factors. American Journal of Public Health. 2010; 100(12):2403-9. doi: 10.2105/AJPH.2009.185959 PMID: 20966371 
211. Juang LP, Cookston JT. Acculturation, discrimination, and depressive symptoms among Chinese American adolescents: a longitudinal study. Journal of Primary Prevention. 2009; 30(3):475-96.

212. Kaduvettoor-Davidson A, Inman AG. South Asian Americans: Perceived Discrimination, Stress, and Well-Being. Asian American Journal of Psychology. 2013; 4(3):155-65.

213. Kaholokula J, Grandinetti A, Keller S, Nacapoy A, Kingi T, Mau M. Association between perceived racism and physiological stress indices in Native Hawaiians. Journal of Behavioral Medicine. 2012; 35(1):27-37. doi: 10.1007/s10865-011-9330-z PMID: 21360284

214. Kemp-Blackmon V. Perceived discrimination of African-American military personnel based in Hawaii: Life experiences and the implications for self esteem [Ph.D.]. Ann Arbor: Saybrook Graduate School and Research Center; 2000.

215. Kim JGS. Racial perceptions and psychological well being in Asian and Hispanic Americans [Ph.D.]. Ann Arbor: Loma Linda University; 2002.

216. Klonoff EA, Landrine $H$. Cross-validation of the Schedule of Racist Events. Journal of Black Psychology. 1999; 25(2):231-54.

217. Krieger N, Carney D, Lancaster K, Waterman PD, Kosheleva A, Banaji M. Combining explicit and implicit measures of racial discrimination in health research. American journal of public health. 2010; 100(8):1485-92. doi: 10.2105/AJPH.2009.159517 PMID: 19965567

218. Krieger N, Chen JT, Waterman PD, Hartman C, Stoddard AM, Quinn MM, et al. The inverse hazard law: Blood pressure, sexual harassment, racial discrimination, workplace abuse and occupational exposures in US low-income black, white and Latino workers. Social Science \& Medicine. 2008; 67 (12):1970-81. doi: 10.1016/j.socscimed.2008.09.039 PMID: 18950922

219. Krieger N, Kaddour A, Koenen K, Kosheleva A, Chen JT, Waterman PD, et al. Occupational, social, and relationship hazards and psychological distress among low-income workers: implications of the 'inverse hazard law'. Journal of Epidemiology and Community Health. 2011; 65(3):260-72. doi: 10. 1136/jech.2009.087387 PMID: 20713372

220. Krieger N, Kosheleva A, Waterman PD, Chen JT, Koenen K. Racial Discrimination, Psychological Distress, and Self-Rated Health Among US-Born and Foreign-Born Black Americans. American Journal of Public Health. 2011; 101(9):1704-13. doi: 10.2105/AJPH.2011.300168 PMID: 21778504

221. Krieger N, Smith K, Naishadham D, Hartman C, Barbeau EM. Experiences of discrimination: Validity and reliability of a self-report measure for population health research on racism and health. Soc Sci Med. 2005; 61(7):1576-96. PMID: 16005789

222. Kulis S, Marsiglia FF, Nieri T. Perceived Ethnic Discrimination versus Acculturation Stress: Influences on Substance Use among Latino Youth in the Southwest. Journal of Health and Social Behavior. 2009; 50(4):443-59. PMID: 20099450

223. Lam AMC, Tsoi KW, Chan TS. Adolescent Chinese immigrants in Hong Kong: a comparison with locally born students and factors associated with their psychological well-being. International Journal of Adolescent Medical Health 2005 17(2):157-68.

224. Lambert SF, Herman KC, Bynum MS, lalongo NS. Perceptions of racism and depressive symptoms in African American adolescents: the role of perceived academic and social control. Journal of youth and adolescence. 2009; 38(4):519-31. doi: 10.1007/s10964-009-9393-0 PMID: 19636725

225. LaMonica J. Occupational stressors and the psychological well-being of women in a welfare work program [Ph.D.]. Ann Arbor: Fordham University; 2000.

226. Landrine $\mathrm{H}$, Klonoff EA. The Schedule of Racist Events: A Measure of Racial Discrimination and a Study of Its Negative Physical and Mental Health Consequences. The Journal of Black Psychology. 1996; 22(2):144-68.

227. Larson C, Belue R, Schulandt DG, McClellan L. Relationship Between Symptoms of Depression, Functional Health Status, and Chronic Disease Among a Residential Sample of African Americans. J Ambulatory Care Manage. 2008; 29(2):133-40.

228. Lay C, Nguyen T. The role of acculturation-related and acculturation non-specific daily hassles: Vietnamese Canadian students and psychological distress. Canadian Journal of Behavioural Science. 1998; 30(3):172-81.

229. LeBel TP. "If one doesn't get you another one will": Formerly incarcerated persons' perceptions of discrimination. Prison Journal. 2012; 92(1):63-87.

230. Lee RM. Do ethnic identity and other group orientation protect against discrimination for Asian Americans? Journal of Counseling Psychology. 2003; 50(2):133-41.

231. Lee RM. Resilience Against Discrimination: Ethnic Identity and Other-Group Orientation as Protective Factors for Korean Americans. Journal of Counseling Psychology. 2005; 52(1):36-44.

232. Lee S. Impact of ethnic identity on psychological well-being among Korean Americans in the United States [Ph.D.]. Ann Arbor: State University of New York at Albany; 2001. 
233. LeFevre AL. Sociocultural Mechanisms Associated with Posttraumatic Stress Disorder: An Analysis of Latino Veterans [Ph.D.]. Ann Arbor: University of Maryland, Baltimore; 2011.

234. Lewin A, Mitchell SJ, Rasmussen A, Sanders-Phillips K, Joseph JG. Do human and social capital protect young African American mothers from depression associated with ethnic discrimination and violence exposure?. Journal of Black Psychology. 2011; 37(3):286-310.

235. Liddell AL. Length of incarceration, perceived discrimination and social support as predictors of psychological distress in African-American spouses of inmates [Ph.D.]. Ann Arbor: California School of Professional Psychology—Los Angeles; 1998.

236. Liebkind K, Jasinskaja-Lahti I. Acculturation and Psychological Well-Being among Immigrant Adolescents in Finland: A Comparative Study of Adolescents From Different Cultural Backgrounds. Journal of Adolescent Research. 2000; 15(4):446-69.

237. Llacer A, Amo JD, Garcia-Fulgueiras A, Ibanez-Rojo V, Garcia-Pino R, Jarrin I, et al. Discrimination and mental health in Ecuadorian immigrants in Spain. Journal of epidemiology and community health. 2009; 63(9):766-72. doi: 10.1136/jech.2008.085530 PMID: 19416929

238. Logie C, James L, Tharao W, Loutfy M. Associations Between HIV-Related Stigma, Racial Discrimination, Gender Discrimination, and Depression Among HIV-Positive African, Caribbean, and Black Women in Ontario, Canada. AIDS Patient Care \& STDs. 2013; 27(2):114-22. doi: 10.1089/apc.2012. 0296 PMID: 23373665

239. Loo CM, Fairbank JA, Scurfield RM, Ruch LO, King DW, Adams LJ, et al. Measuring exposure to racism: development and validation of a Race- Related Stressor Scale (RRSS) for Asian American Vietnam veterans. Psychol Assess. 2001; 13(4):503-20. PMID: 11793894

240. Lorenzo-Blanco El, Unger JB, Ritt-Olson A, Soto D, Baezconde-Garbanati L. Acculturation, Gender, Depression, and Cigarette Smoking among U.S. Hispanic Youth: The Mediating Role of Perceived Discrimination. Journal of Youth and Adolescence. 2011; 40(11):1519-33. doi: 10.1007/s10964-0119633-y PMID: 21293915

241. Low D, Radhakrishnan P, Schneider K, Rounds J. The Experiences of Bystanders of Workplace Ethnic Harassment. Journal of Applied Social Psychology. 2007; 37:2261-97.

242. Lyles CR, Karter AJ, Young BA, Spigner C, Grembowski D, Schillinger D, et al. Correlates of patientreported racial/ethnic health care discrimination in the Diabetes Study of Northern California (DISTANCE). Journal of Health Care for the Poor \& Underserved. 2011; 22(1):211-25. doi: 10.1353/hpu. 2011.0033 PMID: 21317516

243. Lyles CR, Karter AJ, Young BA, Spigner C, Grembowski D, Schillinger D, et al. Patient-reported racial/ethnic healthcare provider discrimination and medication intensification in the Diabetes Study of Northern California (DISTANCE). Journal of general internal medicine. 2011; 26(10):1138-44. doi: 10.1007/s11606-011-1729-2 PMID: 21547610

244. Mahonen TA, Jasinskaja-Lahti I. Acculturation Expectations and Experiences as Predictors of Ethnic Migrants' Psychological Well-Being. Journal of Cross-Cultural Psychology. 2013; 44(5):786-806.

245. Majied KF. The impact of racism and homophobia on depression [Ph.D.]. Ann Arbor: State University of New York at Albany; 2003.

246. Major B, Kaiser CR, O'Brien LT, McCoy SK. Perceived discrimination as worldview threat or worldview confirmation: Implications for self-esteem. J PersSocPsychol. 2007; 92(6):1068-86.

247. Mak AS, Nesdale D. Migrant distress: the role of perceived racial discrimination and coping resources. Journal of Applied Social Psychology. 2001; 31(1):2632-47.

248. Mansouri F, Jenkins L, Morgan L, Taouk M. The Impact of Racism upon the Health and Wellbeing of Young Australians Melbourne: Foundation for Young Australians and the Institute for Citizenship and Globalisation, Deakin University 2009.

249. Martin MJ. Racial discrimination and delinquency: Economic hardship, communities, discrimination, and conduct disorder among African American youth. Davis: University of California; 2005.

250. Matthews CJ. Generational status, racial, and ethnic identity, and psychological well-being among Afro-Caribbean college students [Ph.D.]. Ann Arbor: Fordham University; 2012.

251. Matthews DD, Hammond WP, Nuru-Jeter A, Cole-Lewis Y, Melvin T. Racial discrimination and depressive symptoms among African-American men: The mediating and moderating roles of masculine self-reliance and John Henryism. Psychology of Men \& Masculinity. 2013; 14(1):35-46.

252. McNeil S, Harris-McKoy D, Brantley C, Fincham F, Beach SRH. Middle class african american mothers' depressive symptoms mediate perceived discrimination and reported child externalizing behaviors. Journal of Child and Family Studies. 2013; 23(2):381-8.

253. Medley-Proctor KN. Racial discrimination in the job search: Psychological implications for African Americans [Ph.D.]. Ann Arbor: The George Washington University; 2005. 
254. Mesche GS, Turgeman H, Fishman G. Perceived Discrimination and the Well-being of Immigrant Adolescents. Journal of Youth and Adolescence. 2008; 37(5):592-604.

255. Moghaddam FM, Taylor DM, Ditto B, Jacobs K, Bianchi E. Psychological distress and perceived discrimination: a study of women from India. International Journal of Intercultural Relations. 2002; 26 (4):381-90.

256. Moore KM. The mental health implications of experiencing racial/ethnic microaggressions among Latina/os: Cognitive, affective, and behavioral components [Ph.D.]. Ann Arbor: Marquette University; 2012.

257. Moore-Greene GM, Gross SM, Silver KD, Perrino CS. Chronic stress and decreased physical exercise: impact on weight for African American women. Ethnicity \& disease. 2012; 22(2):185-91. PMID: 22764641

258. Moradi B, Hasan NT. Arab American Persons' Reported Experiences of Discrimination and Mental Health: The Mediating Role of Personal Control. Journal of Counseling Psychology. 2004; 51(4):41828.

259. Moradi B, Risco C. Perceived discrimination experiences and mental health of Latina/o American persons. Journal of Counseling Psychology. 2006; 53(4):411-21.

260. Moradi B, Subich LM. A concomitant examination of the relations of perceived racism and the sexist events to psychological distress for African American women. Counseling Psychologist. 2003; 31 (4):451-69.

261. Morris JK. Latina college students: The impact of stress, acculturation, and social support on psychological well-being and distress [Ph.D.]. Ann Arbor: California School of Professional Psychology—Los Angeles; 1997.

262. Murry VM, Brown PA, Brody GH, Cutrona CE, Simons RL. Racial discrimination as a moderator of the links among stress, maternal psychological functioning, and family relationships. J Marriage Fam. 2001; 63(4):915-26.

263. Murry VM, Harrell AW, Brody GH, Chen Y-F, Simons RL, Black AR, et al. Long-Term Effects of Stressors on Relationship Well-Being and Parenting among Rural African American Women. Family Relations. 2008; 57(2):117-27. PMID: 20657726

264. Nair RL. Cultural stressors, supportiveness, and psychopathology among Mexican American adolescents: A test of three competing models [Ph.D.]. Ann Arbor: Arizona State University; 2008.

265. Neblett EW Jr., Carter SE. The protective role of racial identity and Africentric worldview in the association between racial discrimination and blood pressure. Psychosomatic medicine. 2012; 74(5):50916. doi: 10.1097/PSY.0b013e3182583a50 PMID: 22685241

266. Neblett EWJ, White RL, Ford KR, Philip CL, Nguyên HX, Sellers RM. Patterns of racial socialization and psychological adjustment: Can parental communications about race reduce the impact of racial discrimination?. Journal of Research on Adolescence. 2008; 18(3):477-515.

267. Neto F. Satisfaction with life among adolescents from immigrant families in Portugal. Journal of Youth and Adolescence. 2001; 30(1):53-67.

268. Neto F. Psycho-Social Predictors of Perceived Discrimination Among Adolescents of Immigrant Background: A Portuguese Study. Journal of Ethnic \& Migration Studies. 2006; 32(1):89-109.

269. Neto F, Barros J. Predictors of Loneliness Among Adolescents from Portuguese Immigrant Families in Switzerland. Social Behavior \& Personality: An International Journal. 2000; 28(2):193-206.

270. Nyborg VM, Curry JF. The impact of perceived racism: psychological symptoms among African American boys. Journal of clinical child and adolescent psychology: the official journal for the Society of Clinical Child and Adolescent Psychology, American Psychological Association, Division 53. 2003; 32 (2):258-66.

271. Odom EC, Vernon-Feagans L. Buffers of Racial Discrimination: Links with Depression among Rural African American Mothers. Journal of Marriage and Family. 2010; 72(2):346-59. PMID: 20672013

272. Oh MY. Contingencies of self-esteem: The psychological well-being and impact of perceived experiences of discrimination among Korean Americans (Doctoral dissertation, California School of Professional Psychology, 2001) Dissertation Abstracts International. 2001;2B(1093).

273. Omma L, Jacobsson LH, Petersen S. The health of young Swedish Sami with special reference to mental health. International journal of circumpolar health. 2012; 71:18381. doi: 10.3402/ijch.v71i0. 18381 PMID: 22765937

274. Ong AD, Fuller-Rowell T, Burrow AL. Racial discrimination and the stress process. Journal of personality and social psychology. 2009; 96(6):1259-71. doi: 10.1037/a0015335 PMID: 19469600

275. Oppedal B. The role of social support in the association between perceived discrimination and mental health among youth immigrants in Norway. International Journal of Developmental Science. 2011; 5 $(1-2): 85-99$. 
276. Oppedal B, Roysamb E, Heyerdahl S. Ethnic group, acculturation, and psychiatric problems in young immigrants. Journal of Child Psychology \& Psychiatry \& Allied Disciplines. 2007; 46(6):646-60.

277. Ornelas IJ, Perreira KM. The role of migration in the development of depressive symptoms among Latino immigrant parents in the USA. Social science \& medicine (1982). 2011; 73(8):1169-77. doi: 10.1016/j.socscimed.2011.07.002 PMID: 21908089

278. Padela Al, Heisler M. The Association of Perceived Abuse and Discrimination After September 11, 2001, With Psychological Distress, Level of Happiness, and Health Status Among Arab Americans. American Journal of Public Health. 2010; 100(2):284-91. doi: 10.2105/AJPH.2009.164954 PMID: 20019301

279. Pan SW, Spittal PM. Health effects of perceived racial and religious bullying among urban adolescents in China: A cross-sectional national study. Global Public Health. 2013; 8(6):685-97. doi: 10. 1080/17441692.2013.799218 PMID: 23713464

280. Peek ME, Nunez-Smith M, Drum M, Lewis TT. Adapting the everyday discrimination scale to medical settings: reliability and validity testing in a sample of African American patients. Ethnicity and Disease. 2011; 21(4):502-9. PMID: 22428358

281. Peters RM. Racism and hypertension among African Americans. Western Journal of Nursing Research. 2004; 26(6):612-31. PMID: 15359074

282. Peters RM. The Relationship of Racism, Chronic Stress Emotions, and Blood Pressure. Journal of Nursing Scholarship. 2006; 38(3):234-40. PMID: 17044340

283. Phinney JS, Madden T, Santos LJ. Psychological variables as predictors of perceived ethnic discrimination among minority and immigrant adolescents. Journal of Applied Social Psychology. 1998; 28 (11):937-53

284. Piedrahita Palacio SP. Examining social support as a moderator of the link between perceived discrimination and psychological health among Latinos/ as in the United States. Carbondale: Southern Illinois University; 2007.

285. Pieterse AL, Carter RT. An examination of the relationship between general life stress, racism-related stress, and psychological health among black men. Journal of Counseling Psychology. 2007; 54 (1):101-9.

286. Pieterse AL, Carter RT. An Exploratory Investigation of the Relationship between Racism, Racial Identity, Perceptions of Health, and Health Locus of Control among Black American Women. Journal of Health Care for the Poor and Underserved. 2010; 21(1):334-48. doi: 10.1353/hpu.0.0244 PMID: 20173273

287. Pieterse AL, Carter RT. The Role of Racial Identity in Perceived Racism and Psychological Stress Among Black American Adults: Exploring Traditional and Alternative Approaches. Journal of Applied Social Psychology. 2010; 40(5):1028-53.

288. Pointer MA, Livingston JN, Yancey S, McClelland MK, Bukoski RD. Psychosocial factors contribute to resting blood pressures in African Americans. Ethn Dis. 2008; 18(3):289-93. PMID: 18785441

289. Pole N, Best SR, Metzler T, Marmar CR. Why Are Hispanics at Greater Risk for PTSD? Cultural Diversity and Ethnic Minority Psychology. 2009; 11(2):144-61.

290. Polek E, hrle J, van Oudenhoven JP. The role of attachment styles, perceived discrimination, and cultural distance in adjustment of German and Eastern European immigrants in the Netherlands. CrossCultural Research. 2010; 44(1):60-88.

291. Postmes T, Branscombe NR. Influence of long-term racial environmental composition on subjective well-being in African Americans. Journal of Personality and Social Psychology. 2002; 83(3):735-51. PMID: 12219866

292. Poston WS, Pavlik VN, Hyman DJ, Ogbonnaya K, Hanis CL, Haddock CK, et al. Genetic bottlenecks, perceived racism, and hypertension risk among African Americans and first-generation African immigrants. Journal of human hypertension. 2001; 15(5):341-51. PMID: 11378837

293. Prelow HM, Danoff-Burg S, Swenson RR, Pugiano D. The impact of ecological risk and perceived discrimination on the psychological adjustment of African American and European American youth. Journal of CommunityPsychology. 2004; 32(4):375-89.

294. Prelow HM, Mosher CE, Bowman MA. Perceived racial discrimination, social support, and psychological adjustment among African American college students. Journal of Black Psychology. 2006; 32 (4):442-54.

295. Priest N, Paradies Y, Stevens M, Bailie R. Exploring relationships between racism, housing and child illness in remote Aboriginal communities. Journal of Epidemiology and Community Health. 2012; 66 (5):440-7. doi: 10.1136/jech.2010.117366 PMID: 21118951

296. Priest N, Paradies $Y$, Stewart $P$, Luke J. Racism and health among urban Aboriginal young people. BMC Public Health. 2011; 11(568):1-9. 
297. Priest NC, Paradies YC, Gunthorpe W, Cairney SJ, Sayers SM. Racism as a determinant of social and emotional wellbeing for Aboriginal Australian youth. The Medical journal of Australia. 2011; 194 (10):546-50. PMID: 21644910

298. Raver JL, Nishii LH. Once, twice, or three times as harmful? Ethnic harassment, gender harassment, and generalized workplace harassment. Journal of Applied Psychology. 2010; 95(2):236-54. doi: 10. 1037/a0018377 PMID: 20230066

299. Rees CA. Patient and provider factors, patient-reported racial/ethnic discrimination in the healthcare setting, and quality of care in the diabetes study of Northern California (distance). Seattle: University of Washington; 2010.

300. Reisen CA, Brooks KD, Zea MC, Poppen PJ, Bianchi FT. Can additive measures add to an intersectional understanding? Experiences of gay and ethnic discrimination among HIV-positive Latino gay men. Cultural diversity \& ethnic minority psychology. 2013; 19(2):208-17. doi: 10.1037/a0031906 PMID: 23647331

301. Revollo H-W, Qureshi A, Collazos F, Valero S, Casas M. Acculturative stress as a risk factor of depression and anxiety in the Latin American immigrant population. International Review of Psychiatry. 2011; 23(1):84-92. doi: 10.3109/09540261.2010.545988 PMID: 21338303

302. Rich Rice KL. The effects of perceived racial discrimination on interparental conflict and child emotional adjustment in White, Hispanic, and Black families [Ph.D.]. Ann Arbor: The University of Texas at Arlington; 2008.

303. Rivas-Drake D, Hughes D, Way N. A closer look at peer discrimination, ethnic identity, and psychological well-being among urban Chinese American sixth graders. Journal of Youth and Adolescence. $200837(1): 12-21$.

304. Roberts CB, Vines AI, Kaufman JS, James SA. Cross-sectional association between perceived discrimination and hypertension in African-American men and women: the Pitt County Study. American Journal of Epidemiology. 2008; 167(5):624-32. PMID: 18083714

305. Roberts ME, Gibbons FX, Gerrard M, Weng CY, Murry VM, Simons LG, et al. From Racial Discrimination to Risky Sex: Prospective Relations Involving Peers and Parents. Developmental Psychology. 2012; 48(1):89-102. doi: 10.1037/a0025430 PMID: 21942666

306. Rodriguez MG. Job stress and perceptions among Hispanic professionals of prejudice and discrimination in the workplace [Ph.D.]. Ann Arbor: The University of Tennessee; 2002.

307. Rosas MC. The impact of affirmative action legislation and racism experiences on the collective selfesteem and psychological well-being of college students of color. Los Angeles: California School of Professional Psychology; 1999.

308. Rospenda KM, Richman JA, Shannon CA. Prevalence and Mental Health Correlates of Harassment and Discrimination in the Workplace. Journal of Interpersonal Violence. 2009; 24(5):819-43. doi: 10. 1177/0886260508317182 PMID: 18463311

309. Rousseau C, Hassan G, Measham T, Moreau N, Lashley M, Castro T, et al. From the family universe to the outside world: Family relations, school attitude, and perception of racismin Caribbean and Filipino adolescents. Health \& Place. 2009; 15(3):751-60. doi: 10.1016/j.healthplace.2008.12.004 PMID: 19217820

310. Rucker LS. Correlates of worry and generalized anxiety disorder in Black/African Americans. Dissertation Abstracts International, Section B: Sciences and Engineering. 2005; 66(4-B).

311. Rucker LS, West LM, Roemer L. Relationships among perceived racial stress, intolerance of uncertainty, and worry in a black sample. Behavior therapy. 2010; 41(2):245-53. doi: 10.1016/j.beth.2009. 04.001 PMID: 20412889

312. Salgado de Synder VN. Factors associated with acculturative stress and depressive symptomatology. Psychology of Women Quarterly. 1987; 11(4):475-88.

313. Santana V, Almeida-Filho N, Roberts R, Cooper SP. Skin Colour, Perception of Racism and Depression among Adolescents in Urban Brazil. Child \& Adolescent Mental Health. 2007; 12(3):125-31.

314. Schaafsma J. Discrimination and subjective well-being: The moderating roles of identification with the heritage group and the host majority group. European Journal of Social Psychology. 2011; 41(6):78695.

315. Schmitt MT, Spears R, Branscombe NR. Constructing a minority group identity out of shared rejection: The case of international students. European Journal of Social Psychology. 2003; 33(1):1-12.

316. Schneider KT, Hitlan RT, Radhakrishnan P. An examination of the nature and correlates of ethnic harassment experiences in multiple contexts. Journal of Applied Psychology. 2000; 85(1):3-12. PMID: 10740951

317. Seaton EK, Neblett EW, Upton RD, Hammond WP, Sellers RM. The Moderating Capacity of Racial Identity between Perceived Discrimination and Psychological Well-Being over Time among African 
American Youth. Child Development. 2011; 82(6):1850-67. doi: 10.1111/j.1467-8624.2011.01651.x PMID: 21954919

318. Sellers RM, Caldwell $\mathrm{CH}$, Schmeelk-Cone KH, Zimmerman MA. Racial Identity, Racial Discrimination, Perceived Stress, and Psychological Distress among African American Young Adults. Journal of Health \& Social Behavior. 2003; 44(3):302-17. PMID: 14582310

319. Sellers RM, Shelton JN. The role of racial identity in perceived racial discrimination. Journal of personality and social psychology. 2003; 84(5):1079-92. PMID: 12757150

320. Sellers RM, Copeland-Linder N, Martin PP, L'Heureux Lewis R. Racial Identity Matters: The Relationship between Racial Discrimination and Psychological Functioning in African American Adolescents. Journal of Research on Adolescence. 2006; 16(2):187-216.

321. Sellers SL, Bonham V, Neighbors HW, Amell JW. Effects of racial discrimination and health behaviors on mental and physical health of middle-class African American men. Health education \& behavior: the official publication of the Society for Public Health Education. 2009; 36(1):31-44. PMID: 17130248

322. Sharif $\mathrm{H}$. Obesity-related behaviors, perceived racism, and health status among African American and black immigrant students [Ed.D.]. Ann Arbor: Teachers College, Columbia University; 2007.

323. Shariff-Marco S. Racism and Cancer Prevention: The Role of Perceived Racism and Race-based Residential Segregation on Behavioural Cancer Risk Profiles. Baltimore: John Hopkins University; 2006.

324. Shariff-Marco S, Klassen AC, Bowie JV. Racial/Ethnic Differences in Self-Reported Racism and Its Association With Cancer-Related Health Behaviors. American Journal of Public Health. 2010; 100 (2):364-74. doi: 10.2105/AJPH.2009.163899 PMID: 20019302

325. Sharma A. Acculturation and psychological adjustment: The case of second-generation Asian Indians. Ann Arbor: State Unviersity of New York at Bufallo; 1995.

326. Sheridan LP. Islamophobia pre- and post-September 11th, 2001. Journal of Interpersonal Violence. 2006; 21(3):317-36. PMID: 16443594

327. Shorey HS, Cowan G, Sullivan MP. Predicting perceptions of discrimination among Hispanics and Anglos. Hispanic Journal of Behavioral Sciences. 2002; 24(1):3-22.

328. Shrake EK, Rhee S. Ethnic identity as a predictor of problem behaviors among Korean American Adolescents. Adolescence. 2004; 39(155):601-22. PMID: 15673233

329. Siefert K, Bowman PJ, Helfin CM, Danzinger S, Williams DR. Social and environmental predictors of maternal depression in current and recent welfare recipients. Am J Orthopsychiatry. 2000; 70(4):51022. PMID: 11086529

330. Silove D, Sinnerbrink I, Field A, Manicavasagar V, Steel Z. Anxiety, depression and PTSD in asylumseekers: assocations with pre-migration trauma and post-migration stressors. The British journal of psychiatry: the journal of mental science. 1997; 170:351-7.

331. Simons RL, Chen Y-F, Stewart EA, Brody GH. Incidents of Discrimination and Risk for Delinquency: A Longitudinal Test of Strain Theory with an African American Sample. Justice Quarterly. 2003; 20 (4):827-54.

332. Simons RL, Murry V, McLoyd V, Lin KH, Cutrona C, Conger RD. Discrimination, crime, ethnic identity, and parenting as correlates of depressive symptoms among African American children: A multilevel analysis. Development and Psychopathology. 2002; 14(2):371-93. PMID: 12030697

333. Sinkule JA. The psychological functioning of Bosnian refugees residing in the United States: An examination of the impact of trauma, acculturation, community connectedness, perceived discrimination and ethnic identity [Ph.D.]. Ann Arbor: George Mason University; 2008.

334. Smith J. A study of stress and perceived health status among international college students [M.S.]. Ann Arbor: Utah State University; 2003.

335. Smokowski PR, Bacallao ML. Acculturation, internalizing mental health symptoms, and self-esteem: cultural experiences of Latino adolescents in North Carolina. Child psychiatry and human development. 2007; 37(3):273-92. PMID: 17103301

336. Smokowski PR, Bacallao ML, Lee Buchana R. Interpersonal mediators linking acculturation stressors to subsequent internalizing symptoms and self-esteem in latino adolescents. Journal of Community Psychology. 2009; 37(8):1024-45.

337. Smokowski PR, Rose RA, Bacallao M. Influence of Risk Factors and Cultural Assets on Latino Adolescents' Trajectories of Self-Esteem and Internalizing Symptoms. Child Psychiatry \& Human Development. 2010; 41(2):133-55. doi: 10.1007/s10578-009-0157-6 PMID: 19672704

338. Soriano FI, Ramirez A. Unequal employment status and ethnicity: Further analyses of the USPI-ESPI model. Hispanic Journal of Behavioral Sciences. 1991; 13(4):391-400. 
339. Soylu A. Causes and consequences of work stress: A comparison of foreign and American workers in the United States. Dissertation Abstracts International: Section A Humanities and Social Sciences. 2008; 69(1):290.

340. Staggers-Hakim R. The moderating effect of discrimination and the intersection of race, class, and gender on obesity [Ph.D.]. Ann Arbor: Howard University; 2009.

341. Steffen PR, Bowden M. Sleep disturbance mediates the relationship between perceived racism and depressive symptoms. EthnDis. 2006; 16(1):16-21.

342. Steffen PR, McNeilly M, Anderson N, Sherwood A. Effects of perceived racism and anger inhibition on ambulatory blood pressure in African Americans. Psychosomatic medicine. 2003; 65(5):746-50. PMID: 14508015

343. Stein GL, Gonzalez LM, Huq N. Cultural stressors and the hopelessness model of depressive symptoms in Latino adolescents. Journal of youth and adolescence. 2012; 41(10):1339-49. doi: 10.1007/ s10964-012-9765-8 PMID: 22528371

344. Stevens GWJM, Vollebergh WAM, Pels TVM, Crijnen AAM. Predicting internalizing problems in Moroccan immigrant adolescents in the Netherlands. Social Psychiatry and Psychiatric Epidemiology. 2005; 40(12):1003-11. PMID: 16341615

345. Stevens-Watkins D, Perry B, Harp KL, Oser CB. Racism and Illicit Drug Use Among African American Women: The Protective Effects of Ethnic Identity, Affirmation, and Behavior. Journal of Black Psychology. 2012; 38(4):471-96. PMID: 24482547

346. Suleiman Gonzalez LP. Stress, sociocultural mediators and mental health in Mexican Americans [Ph. D.]. Ann Arbor: Loyola University of Chicago; 1999.

347. Swami V, Arteche A, Chamorro-Premuzic T, Furnham A. Sociocultural adjustment among sojourning Malaysian students in Britain: a replication and path analytic extension. Social Psychiatry \& Psychiatric Epidemiology. 2010; 45(1):57-65. doi: 10.1007/s00127-009-0042-4 PMID: 19337675

348. Szalacha LA, Erkut S, Garcia Coll C, Alarcon O, Fields JP, Ceder I. Discrimination and Puerto Rican children's and adolescents' mental health. Cultur Divers Ethnic Minor Psychol. 2003; 9(2):141-55. PMID: 12760326

349. Szanton S, Rifkind J, Mohanty J, Miller E, Thorpe R, Nagababu E, et al. Racial Discrimination Is Associated with a Measure of Red Blood Cell Oxidative Stress: A Potential Pathway for Racial Health Disparities. International Journal of Behavioral Medicine. 2012; 19(4):489-95. doi: 10.1007/s12529-0119188-z PMID: 21913047

350. Szymanski DM, Obiri O. Do Religious Coping Styles Moderate or Mediate the External and Internalized Racism-Distress Links? Counseling Psychologist. 2011; 39(3):438-62.

351. Tartakovsky E. A longitudinal study of acculturative stress and homesickness: high-school adolescents immigrating from Russia and Ukraine to Israel without parents. Social psychiatry and psychiatric epidemiology. 2007; 42(6):485-94. PMID: 17502976

352. Tartakovsky E. The Psychological Well-Being of Unaccompanied Minors: A Longitudinal Study of Adolescents Immigrating from Russia and Ukraine to Israel without Parents. Journal of Research on Adolescence. 2009; 19(2):177-204.

353. Tawa J, Suyemoto KL, Roemer L. Implications of Perceived Interpersonal and Structural Racism for Asian Americans' Self-Esteem. Basic and Applied Social Psychology. 2012; 34(4):349-58.

354. Taylor J, Jackson B. Factors affecting alcohol consumption in black women. Part I. Int J Addictions. 1990; 25(11):1287-300.

355. Taylor J, Turner RJ. Perceived discrimination, social stress, and depression in the transition to adulthood: Racial contrasts. Social Psychology Quarterly. 2002; 65(3):213-25.

356. Terrell BP. Impact of ethnic socialization, ethnic identity, and discrimination on self-esteem and parenting attitudes of middle-class African-American men [Ph.D.]. Ann Arbor: Institute for Clinical Social Work (Chicago); 2003.

357. Thoma BC, Huebner DM. Health Consequences of Racist and Antigay Discrimination for Multiple Minority Adolescents. Cultural Diversity and Ethnic Minority Psychology. 2013; 19(4):404-13. doi: 10. 1037/a0031739 PMID: 23731232

358. Thomas A, Cairney S, Gunthorpe W, Paradies Y, Sayers S. Strong Souls: The Development and validation of a culturally appropriate tool for assessment of social and emotional well being in Indigenous youth. Aust NZ J Psychiatry. 2010; 44(1):40-8.

359. Thomas D-M. The influence of perceptions and experiences of racial discrimination on body mass index among the Black Women's Health Study cohort [Ph.D.]. Ann Arbor: Virginia Commonwealth University; 2006. 
360. Thompson HS. The relationship between chronic acculturative/ racial stressors and cardiovascular outcomes in African American adults: Is cardiovascular reactivity a mediating variable?: University of Pittsburgh; 1999.

361. Todorova ILG, Falcon LM, Lincoln AK, Price LL. Perceived discrimination, psychological distress and health. Sociology of health \& illness. 2010; 32(6):843-61. doi: 10.1111/j.1467-9566.2010.01257.x PMID: 20649891

362. Torres L, Driscoll MW, Burrow AL. Racial Microaggressions and Psychological Functioning among Highly Achieving African-Americans: A Mixed-Methods Approach. Journal of Social and Clinical Psychology. 2010; 29(10):1074-99.

363. Torres L, Driscoll MW, Voell M. Discrimination, acculturation, acculturative stress, and Latino psychological distress: A moderated mediational model. Cultural Diversity and Ethnic Minority Psychology. 2012; 18(1):17-25. doi: 10.1037/a0026710 PMID: 22250895

364. Torres L, Ong AD. A Daily Diary Investigation of Latino Ethnic Identity, Discrimination, and Depression. Cultural Diversity and Ethnic Minority Psychology. 2010; 16(4):561-8. doi: 10.1037/a0020652 PMID: 21058819

365. Torres L, Yznaga SD, Moore KM. Discrimination and Latino psychological distress: The moderating role of ethnic identity exploration and commitment. American Journal of Orthopsychiatry. 2011; 81 (4):526-34. doi: 10.1111/j.1939-0025.2011.01117.x PMID: 21977938

366. Tran N. Using color-blindness to understand the effects of discrimination on the well-being of Asian Americans [Ph.D.]. Ann Arbor: University of Illinois at Chicago; 2010.

367. Trevino B, Ernst FA. Skin tone, racism, locus of control, hostility, and blood pressure in Hispanic college students. Hispanic Journal of Behavioral Sciences. 2012; 34(2):340-8.

368. Tull ES, Chambers EC. Internalized racism is associated with glucose intolerance among black Americans in the US Virgin Islands. Diabetes Care. 2001; 24(8):1498. PMID: 11473095

369. Tull ES, Cort MA, Gwebu ET, Gwebu K. Internalized racism is associated with elevated fasting glucose in a sample of adult women but not men in Zimbabwe. EthnDis. 2007; 17(4):731-5.

370. Tull ES, Wickramasuriya T, Taylor J, Smith-Burns V, Brown M, Champagnie G, et al. Relationship of internalized racism to abdominal obesity and blood pressure in Afro-Caribbean women. Journal of the National Medical Association. 1999; 91(8):447-52. PMID: 12656433

371. Tummala-Narra $P$, Claudius $M$. Perceived discrimination and depressive symptoms among immigrant-origin adolescents. Cultural diversity \& ethnic minority psychology. 2013; 19(3):257-69. doi: 10. 1037/a0032960 PMID: 23875851

372. Tynes BM, Umaña-Taylor AJ, Rose CA, Lin J, Anderson CJ. Online racial discrimination and the protective function of ethnic identity and self-esteem for African American adolescents. Developmental Psychology. 2012; 48(2):343-55. doi: 10.1037/a0027032 PMID: 22369340

373. Ullah J. An examination of the role of social constraint in the relationship of perceived racism to depression and anxiety [Ph.D.]. Ann Arbor: St. John's University (New York); 2011.

374. Umaña-Taylor AJ, Updegraff KA. Latino adolescents' mental health: Exploring the interrelations among discrimination, ethnic identity, cultural orientation, self-esteem, and depressive symptoms. Journal of Adolescence. 2007; 30(4):549-67. PMID: 17056105

375. Vasquez $\mathrm{J}$. The relationship between ethnic identity and ethnic- racial socialization in predicting perceived discrimination and subjective well-being among Latino college students in the southwest. Dissertation Abstracts International: Section B Sciences and Engineering. 2010; 70(10):6610.

376. Verkuyten M. Perceived Discrimination and Self-Esteem among Ethnic Minority Adolescents. Journal of Social Psychology. 1998; 138(4):479-93. PMID: 9664864

377. Verkuyten M. The puzzle of high self-esteem among ethnic minorities: Comparing explicit and implicit self-esteem. Self and Identity. 2005; 4(2):177-92.

378. Verkuyten M, Nekuee S. Self-Esteem, Discrimination, and Coping Among Refugees: The Moderating Role of Self-Categorization. Journal of Applied Social Psychology. 2001; 31(5):1058-75.

379. Vrem roiu A-M, Fodoreanu L. Perceived discrimination, a risk factor for developing psychoses in Romanian emigrants? Clujul Medical. 2013; 86(1):53-6.

380. Wadsworth E, Dhillon K, Shaw C, Bhui K, Stansfeld S, Smith A. Racial discrimination, ethnicity and work stress. Occup Med (Lond). 2007; 57(1):18-24.

381. Wagner GJ, Bogart LM, Galvan FH, Banks D, Klein DJ. Discrimination as a key mediator of the relationship between posttraumatic stress and HIV treatment adherence among African American men. Journal of Behavioral Medicine. 2012; 35(1): 8-18. doi: 10.1007/s10865-011-9320-1 PMID: 21318411 
382. Wagner J, Abbott G. Depression and depression care in diabetes: Relationship to perceived discrimination in African Americans. Diabetes Care. 2007; 30(2):364-6. PMID: 17259510

383. Walls ML. A mixed methods examination of Indigenous youth suicide [Ph.D.]. Ann Arbor: The University of Nebraska-Lincoln; 2007.

384. Walters JM. Testing a biopsychosocial model of perceived racism among Latinos [Ph.D.]. Ann Arbor: University of Illinois at Urbana-Champaign; 2004

385. Wei M, CJ. Y, RC. C, S. C, JC. S. Family Support, Self-Esteem, and Perceived Racial Discrimination Among Asian American Male College Students. Journal of Counseling Psychology. 2013; 60(3):45361. doi: 10.1037/a0032344 PMID: 23544839

386. Wei M, Ku T-Y, Russell DW, Mallinckrodt B, Liao KY-H. Moderating effects of three coping strategies and self-esteem on perceived discrimination and depressive symptoms: A minority stress model for Asian international students. Journal of Counseling Psychology. 2008; 55(4):451-62. doi: 10.1037/ a0012511 PMID: 22017552

387. Wei M, Wang KT, Heppner PP, Du Y. Ethnic and mainstream social connectedness, perceived racial discrimination, and posttraumatic stress symptoms. Journal of Counseling Psychology. 2012; 59 (3):486-93. doi: 10.1037/a0028000 PMID: 22774871

388. Wei M, Wang KT, Ku T-Y. A development and validation of the Perceived Language Discrimination Scale. Cultural diversity \& ethnic minority psychology. 2012; 18(4):340-51. doi: 10.1037/a0029453 PMID: 22866690

389. Whitbeck LB, Hoyt DR, McMorris BJ, Chen XJ, Stubben JD. Perceived discrimination and early substance abuse among American Indian children. Journal of Health and Social Behavior. 2001; 42 (4):405-24. PMID: 11831140

390. Wickrama TKA. The association between racial discrimination and depressive symptoms: An examination of African American couples. Dissertation Abstracts International: Section A Humanities and Social Sciences. 2010; 71(2):601.

391. Williams DR, Spencer MS, Jackson JS. Race, stress, and physical health: The role of group identity. In: Contrada RJ, Ashmore RD, editors. Self, social identity, and physical health: Interdisciplinary explorations. New York, NY: Oxford University Press; 1999. p. 71-100.

392. Wong CA. The risks and protective factors of the content of racial stigma on African-American and White early adolescents' development [Ph.D.]. Ann Arbor: University of Michigan; 1997.

393. Yap SCY. Understanding the association between perceived discrimination, racial identity and wellbeing [M.A.]. Ann Arbor: Michigan State University; 2011.

394. Yap SCY, Settles IH, Pratt-Hyatt JS. Mediators of the relationship between racial identity and life satisfaction in a community sample of African American women and men. Cultural Diversity and Ethnic Minority Psychology. 2011; 17(1):89-97. doi: 10.1037/a0022535 PMID: 21341901

395. Yoder KA, Whitbeck LB, Hoyt DR, LaFromboise T. Suicidal Ideation Among American Indian Youths. Archives of Suicide Research. 2006; 10(2):177-90. PMID: 16574615

396. Yoo HC, Lee RM. Ethnic Identity and Approach-Type Coping as Moderators of the Racial Discrimination/Well-Being Relation in Asian Americans. Journal of Counseling Psychology. 2005; 52(4):497506.

397. Yoon E, Hacker J, Hewitt A, Abrams M, Cleary S. Social Connectedness, Discrimination, and Social Status as Mediators of Acculturation/Enculturation and Well-Being. Journal of Counseling Psychology. 2012; 59(1):86-96. doi: 10.1037/a0025366 PMID: 21895356

398. Zeiders KH, Umaña-Taylor AJ, Derlan CL. Trajectories of depressive symptoms and self-esteem in Latino youths: Examining the role of gender and perceived discrimination. Developmental Psychology. 2013; 49(5):951-63. doi: 10.1037/a0028866 PMID: 22686175

399. Cunningham TJ, Berkman LF, Kawachi I, Jacobs DR, Seeman TE, Kiefe Cl, et al. Changes in Waist Circumference and Body Mass Index in the US Cardia Cohort: fixed-effects associations with selfreported experiences of racial/ethnic discrimination. Journal of Biosocial Science. 2013; 45(02):26778.

400. Hunte HER. Association Between Perceived Interpersonal Everyday Discrimination and Waist Circumference Over a 9-Year Period in the Midlife Development in the United States Cohort Study. American Journal of Epidemiology. 2011; 173(11):1232-9. doi: 10.1093/aje/kwq463 PMID: 21354988

401. Brondolo E, Lackey S, Love E. Race, Racism \& Health: Evaluating racial disparities in hypertension to understand the links between racism and health status. In: Baum A, Revenson TA, Singer JE, editors. Handbook of health psychology. 2nd ed: New York: Psychology Press; 2011. p. 569-94.

402. Chae DH, Nuru-Jeter AM, Adler NE. Implicit racial bias as a moderator of the association between racial discrimination and hypertension: a study of Midlife African American men. Psychosomatic Medicine. 2012; 74(9):961-4. doi: 10.1097/PSY.0b013e3182733665 PMID: 23107842 
403. Krieger N, Sidney S. Racial discrimination and blood pressure: the CARDIA Study of young black and white adults. Am J Public Health. 1996; 86(10):1370-8. PMID: 8876504

404. Berger M, Sarnyai Z. More than skin deep: Stress neurobiology and mental health consequences of racial discrimination. Stress. 2015; 18(1):1-10. doi: 10.3109/10253890.2014.989204 PMID: 25407297

405. Eisenberger N, Lieberman M, Williams K. Does Rejection Hurt? An fMRI study of social exclusion. Science. 2003; 302:290-2. PMID: 14551436

406. LaVeist TA, Thorpe RJ Jr, Pierre G. The Relationships among Vigilant Coping Style, Race, and Depression. Journal of Social Issues. 2014; 70(2):241-55. PMID: 24954953

407. Hicken MT, Lee H, Ailshire J, Burgard SA, Williams DR. "Every Shut Eye, Ain't Sleep": The Role of Racism-Related Vigilance in Racial/Ethnic Disparities in Sleep Difficulty Race and Social Problems. 2013; 5(2):100-12. PMID: 23894254

408. Hicken MT, Lee H, Morenoff J, House JS, Williams DR. Racial/ethnic disparities in hypertension prevalence: reconsidering the role of chronic stress. American Journal of Public Health. 2014; 104:11723. doi: 10.2105/AJPH.2013.301395 PMID: 24228644

409. Utsey SO, Belvet B, Hubbard RR, Fischer NL, Opare-Henaku A, Gladney LL. Development and Validation of the Prolonged Activation and Anticipatory Race-Related Stress Scale. Journal of Black Psychology. 2013; 39(6):532-59.

410. Borders A, Liang CTH. Rumination partially mediates the associations between perceived ethnic discrimination, emotional distress, and aggression. Cultural Diversity \& Ethnic Minority Psychology. 2011; 17(2):125-33. doi: 10.1037/a0023357 PMID: 21604836

411. Himmelstein MS, Young DM, Sanchez DT, Jackson JS. Vigilance in the discrimination-stress model for Black Americans. Psychology and Health. 2015; 30(3):253-67. doi: 10.1080/08870446.2014. 966104 PMID: 25247925

412. Clark R, Anderson NB, Bulatao RA, Cohen B. Significance of perceived racism: Toward understanding ethnic-group disparities in health, the later years. Critical Perspectives on Racial and Ethnic Differences in Health in Late Life. Washington, DC.: National Academy Press; 2004. p. 540-66.

413. Gee GC, Walsemann KM, Brondolo E. A Life Course Perspective on How Racism May Be Related to Health Inequities. American Journal of Public Health. 2012; 102(5):967-74. doi: 10.2105/AJPH.2012. 300666 PMID: 22420802

414. Kim IH, Noh S. Ethnic and gender differences in the association between discrimination and depressive symptoms among five immigrant groups. Journal of immigrant and minority health / Center for Minority Public Health. 2014; 16(6):1167-75. doi: 10.1007/s10903-013-9969-3 PMID: 24375383

415. Shigemoto $Y$, Thoen MA, Robitschek C, Ashton MW. Assessing Measurement Invariance of the Personal Growth Initiative Scale-II Among Hispanics, African Americans, and European Americans. J Couns Psychol. 2015:In press.

416. Mayrl D, Saperstein A. When white people report racial discrimination: The role of region, religion, and politics. Social Science Research. 2013; 42(3):742-54. doi: 10.1016/j.ssresearch.2012.12.007 PMID: 23521992

417. Carlisle SK. Perceived discrimination and chronic health in adults from nine ethnic subgroups in the USA. Ethnicity and Health. 2014; 20(3):309-26. doi: 10.1080/13557858.2014.921891 PMID: 24920185

418. Rosenthal $R$. The file drawer problem and tolerance for null results. Psychological Bulletin. 1979; 86 (3):638-41.

419. Hausmann LRM, Kressin NR, Hanusa BH, Ibrahim SA. Perceived racial discrimination in health care and its association with patients' healthcare experiences: does the measure matter? Ethnicity \& Disease. 2010; 20:40-7. PMID: 20178181

420. Bastos JL, Celeste RK, Faerstein E, Barros AJD. Racial discrimination and health: A systematic review of scales with a focus on their psychometric properties. Social Science \& Medicine. 2010; 70 (7):1091-9. doi: 10.1016/j.socscimed.2009.12.020 PMID: 20122772

421. Yoo HC, Pituc ST. Assessments of perceived racial stereotypes, discrimination, and racism. APA handbooks in psychology: American Psychological Association, Washington, DC; 2013. p. 605-451.

422. Williams DR, Yu Y, Jackson JS, Anderson NB. Racial differences in physical and mental health: socioeconomic status, stress, and discrimination. Journal of Health Psychology. 1997; 2(3):335-51. doi: 10.1177/135910539700200305 PMID: 22013026

423. Lewis TT, Yang FM, Jacobs EA, Fitchett G. Racial/Ethnic Differences in Responses to the Everyday Discrimination Scale: A Differential Item Functioning Analysis. American Journal of Epidemiology. 2012; 175(5):391-401. doi: 10.1093/aje/kwr287 PMID: 22306556 
424. Stucky BD, et al. An Item Factor Analysis and Item Response Theory-Based Revision of the Everyday Discrimination Scale. Cultural Diversity and Ethnic Minority Psychology. 2011; 17(2):175-85. doi: 10. 1037/a0023356 PMID: 21604841

425. Reeve BB, Willis G, Shariff-Marco S, et al. Comparing Cognitive Interviewing and Psychometric Methods to Evaluate a Racial Ethnic Discrimination Scale. Field Methods. 2011; 23(4):397-419.

426. Chana KT, Trana TV, Nguyen TN. Cross-Cultural Equivalence of a Measure of Perceived Discrimination Between Chinese-Americans and Vietnamese-Americans. Journal of Ethnic And Cultural Diversity in Social Work. 2012; 21(1):20-36.

427. Kim G, Sellbom M, Ford KL. Race/ethnicity and measurement equivalence of the Everyday Discrimination Scale. Psychological Assessment. 2014; 26(3):892-900. doi: 10.1037/a0036431 PMID: 24708076

428. Cunningham TJ, Berkman LF, Gortmaker SL, Kiefe Cl, Jacobs DR, Seeman TE, et al. Assessment of differential item functioning in the experiences of discrimination index: the Coronary Artery Risk Development in Young Adults (CARDIA) Study. American Journal of Epidemiology. 2011; 174:1266-74. doi: 10.1093/aje/kwr253 PMID: 22038104

429. Benjamins MR. Comparing measures of racial/ethnic discrimination, coping, and associations with health-related outcomes in a diverse sample. Journal Of Urban Health. 2013; 90(5):832-48. doi: 10. 1007/s11524-013-9787-x PMID: 23430374

430. Tran AGTT. Family Contexts: Parental Experiences of Discrimination and Child Mental Health. Am J Community Psychol. 2014; 53(1-2):37-46. doi: 10.1007/s10464-013-9607-1 PMID: 24146093

431. Halim ML, Yoshikawa H, Amodio DM. Cross-Generational Effects of Discrimination Among Immigrant Mothers: Perceived Discrimination Predicts Child's Healthcare Visits for Illness. Health Psychology. 2013; 32(2):203-11. doi: 10.1037/a0027279 PMID: 22390736

432. Blank RM, Dabady M, Citro CF. Measuring Racial Discrimination. Washington, DC: The National Academies Press; 2004.

433. Shonkoff JP, Boyce W, McEwen B. Neuroscience, molecular biology, and the childhood roots of health disparities: building a new framework for health promotion and disease prevention. JAMA 2009; 301:2252-9. doi: 10.1001/jama.2009.754 PMID: 19491187 